OPEN ACCESS

Edited by:

Jianmin Cui,

Washington University in St. Louis,

United States

Reviewed by:

Yoko Hirata,

Gifu University, Japan

Satoru Yamagishi,

Hamamatsu University School

of Medicine, Japan

*Correspondence:

Arne lttner

arne.ittner@mq.edu.au

Received: 08 June 2020

Accepted: 18 August 2020 Published: 08 September 2020

Citation:

Asih PR, Prikas E, Stefanoska K, Tan ARP, Ahel Hl and Ittner A (2020)

Functions of p38 MAP Kinases

in the Central Nervous System.

Front. Mol. Neurosci. 13:570586. do: 10.3389/fnmol.2020.570586

\section{Functions of p38 MAP Kinases in the Central Nervous System}

\author{
Prita R. Asih, Emmanuel Prikas, Kristie Stefanoska, Amanda R. P. Tan, Holly I. Ahel and \\ Arne Ittner*
}

Dementia Research Centre, Faculty of Medicine, Health and Human Sciences, Macquarie University, Sydney, NSW, Australia

Mitogen-activated protein (MAP) kinases are a central component in signaling networks in a multitude of mammalian cell types. This review covers recent advances on specific functions of p38 MAP kinases in cells of the central nervous system. Unique and specific functions of the four mammalian p38 kinases are found in all major cell types in the brain. Mechanisms of p38 activation and downstream phosphorylation substrates in these different contexts are outlined and how they contribute to functions of p38 in physiological and under disease conditions. Results in different model organisms demonstrated that p38 kinases are involved in cognitive functions, including functions related to anxiety, addiction behavior, neurotoxicity, neurodegeneration, and decision making. Finally, the role of p38 kinases in psychiatric and neurological conditions and the current progress on therapeutic inhibitors targeting p38 kinases are covered and implicate p38 kinases in a multitude of CNS-related physiological and disease states.

Keywords: signal transduction, central nervous system, neuron, astrocyte, microglia, oligodendrocyte, mitogen activated protein (MAP) kinase p38

\section{INTRODUCTION}

Extracellular and environmental stimuli need to be integrated for adequate cellular and organismal responses. Signal transduction is a key mechanism to translate stimuli into intracellular responses that converge in alterations in gene expression, of cellular shape and motility, and of metabolic activity (Hynes et al., 2013). Mitogen-activated protein (MAP) kinases are central to multiple signal transduction pathways across a variety of cell types, including cells of the central and peripheral nervous systems (Morrison, 2012), and are evolutionarily conserved across phyla (Widmann et al., 1999). Among the three canonical MAP kinase classes are extracellular signal-regulated kinases (ERKs), c-Jun N-terminal kinases (JNK), and p38 MAP kinases (Avruch, 2007; Morrison, 2012). This review will focus on the functions of p38 MAP kinases in cells of the nervous system.

\section{The p38 MAP Kinase Gene Family}

p38 MAP kinases are encoded in four separate genes in mammalian genomes: p38 $\alpha$ by the MAPK14

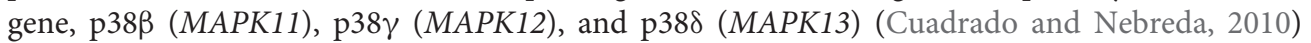
(Figure 1A). The structure of $\mathrm{p} 38$ kinases consists of $\mathrm{N}$ - and $\mathrm{C}$-lobes of the kinase domain with the active site in between ATP binding site and TGY dual phosphorylation site. The active site is covered by the activation loop, which undergoes dual phosphorylation resulting in conformation change, permitting access of substrates to the active site and full kinase activation (Figure 1B). 
A

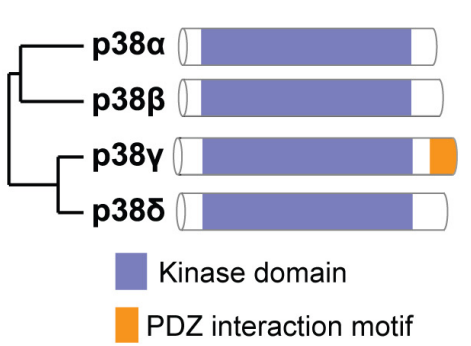

B

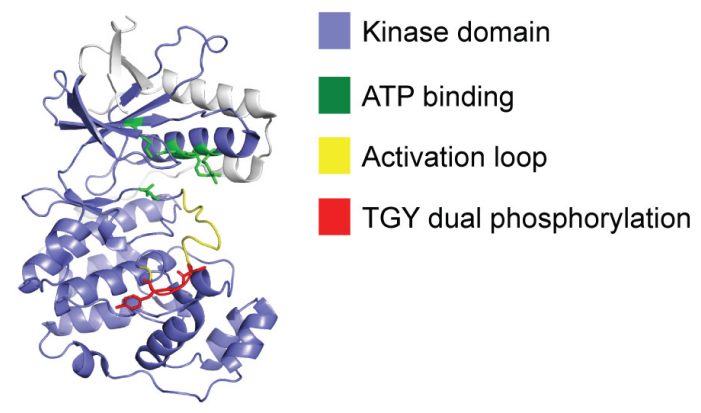

C

MAPK cascade

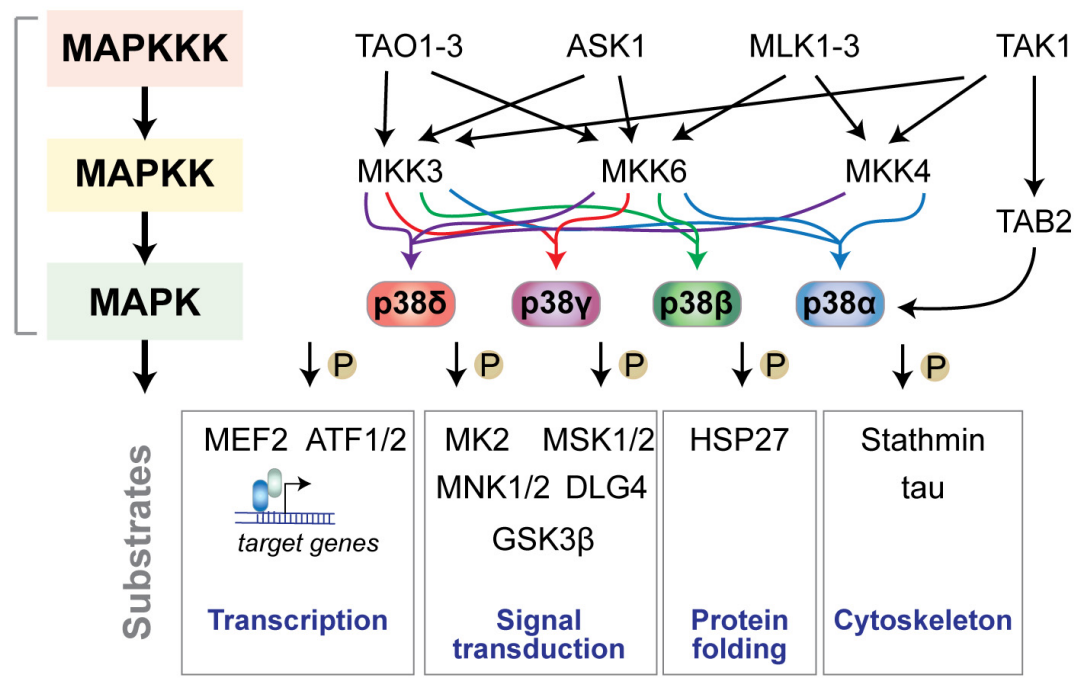

FIGURE 1 | The p38 MAP kinase signaling pathway. (A) Dendrogram of the four mammalian p38 MAP kinases p38 $\alpha$, p38 $\beta$, p38 $\gamma$, and p388. Kinase domain and unique PDZ interaction motif in p38 $\gamma$ are highlighted. (B) Structure of $p 38 \alpha$ showing $\mathrm{N}$ - and C-lobes of the kinase domain with the active site in between. ATP binding site, activation loop and TGY dual phosphorylation are highlighted. The active site is covered by the activation loop, which undergoes dual phosphorylation resulting in conformation change, access of substrates to the active site and full kinase activation. Structure was reproduced from PDB 3HVC using Pymol. (C) Mammalian p38 kinases comprise of 4 proline-directed serine/threonine kinases - p38 $\alpha$, p38 $\beta$, p38 $\gamma$, and p38 - encoded in 4 individual genes. p38 MAP kinases are activated by a plethora of extrinsic (extracellular) or intrinsic (intracellular) factors. The classic activation of p38 follows a three-tiered mechanism. Stimuli of p38 activation are cellular stressors such as oxidative stress, inflammatory stimuli/cytokines, UV radiation, and osmotic pressure at cell membranes. Upstream stimuli activate a MAP kinase kinase kinase (MAPKKK) such as ASK1, TAK1, MLK or TAO kinases, which in turn phosphorylate and activate a MAPKK, such as MKK3, MKK4 or MKK6, which in turn phosphorylates p38 kinases on Threonine and Tyrosine residues in the activation loop. Dual phosphorylation of p38 can be detected by phospho-specific antibodies as a marker of activated p38. Dual-phosphorylated p38 is fully active and targets downstream phosphorylation substrates to alter their structure, activity, function, localization or interaction with other biomolecules. An alternative activation mechanism of p38 $\alpha$ downstream of TAK1 involves direct interaction with TAB2 followed by auto-phosphorylation of p38 $\alpha$. Classic downstream targets of p38 kinases include transcription factors (e.g., ATF-1/2 and MEF2), chaperones (e.g., HSP27), cytoskeletal regulators (stathmin, tau), and other signaling factors (e.g., MAPKAP kinase 2/3, MSK1/2, MNK1/2, DLG4, and GSK3ß). Feedback inhibition of p38 kinases occurs through dephosphorylation by MAP kinase phosphatases (e.g., MKP1), limiting activity of upstream kinases, or transcriptional feedback.

Mammalian p38 genes arose from a common ancestor related to the single, orthologous HOG1 gene in yeast (Han et al., 1994), and p38-encoding genes occur in organisms of different taxa in increasing number (Table 1). The four mammalian p38 genes emerged from tandem and segmental gene duplications (Li M. et al., 2011), and genes MAPK14-MAPK11 and MAPK12$M A P K 13$, are co-located on chromosomes 22 and 6, respectively (Li S. et al., 2011). Mammalian p38 proteins exhibit a high degree of similarity with 60 percent sequence identity between the four kinases (Jiang et al., 1997) and are expressed as one single gene product per gene (Kyriakis and Avruch, 2001), with the exception of p38 $\alpha$ (Lee et al., 1994; Yagasaki et al., 2004; Casar et al., 2007).

\section{Expression of p38 MAP Kinases}

Expression of $\mathrm{p} 38 \alpha$ in different tissues is ubiquitous compared with that of p38 $\beta$, p38 $\gamma$, or p38 (Cuenda and Rousseau, 2007; Cuadrado and Nebreda, 2010; Consortium, 2015; Uhlen et al., 2015). The four p38 isoforms were detected in whole mouse brain and cerebellum, while mainly $\mathrm{p} 38 \alpha$ and $\mathrm{p} 38 \beta$ localize to cells in the murine neocortex and hippocampus, with lower levels of p38 $\gamma$ or p38 (Kato et al., 2000; Beardmore et al., 2005). p38 $\alpha$ and 
TABLE 1 | p38 homologs in different model organisms and their sequence identity to human $\mathrm{p} 38 \alpha$.

\begin{tabular}{|c|c|c|c|}
\hline Organism & Kinase & Identity to Hs p38 $\alpha(\%)$ & Gene name \\
\hline \multirow[t]{4}{*}{ Human (Homo sapiens) } & p38 $\alpha$ & 100 & MAPK14 \\
\hline & p38 $\beta$ & 72.8 & MAPK11 \\
\hline & p38 $\gamma$ & 60.2 & MAPK12 \\
\hline & p38 & 58.5 & MAPK13 \\
\hline \multirow[t]{4}{*}{ Mouse (Mus musculus) } & $\mathrm{p} 38 \alpha$ & 99.4 & Mapk14 \\
\hline & p38 $\beta$ & 73.3 & Mapk11 \\
\hline & p38 $\gamma$ & 59.7 & Mapk12 \\
\hline & p38 & 59.7 & Mapk13 \\
\hline Fruitfly (Drosophila & p38a & 67.2 & p38a \\
\hline \multirow[t]{2}{*}{ melanogaster) } & p38b & 68.2 & p38b \\
\hline & p38c & 44.1 (hERK1/2 37.1/36) & p38c \\
\hline \multirow[t]{3}{*}{$\begin{array}{l}\text { Nematode } \\
\text { (Caenorhabditis elegans) }\end{array}$} & PMK-1 & $\begin{array}{l}61.8 \text { (hERK1/2 41.7/41.4; } \\
\text { hJNK1 36.9) }\end{array}$ & pmk-1 \\
\hline & PMK-2 & 48.2 (hERK1/2 37.1/36) & pmk-2 \\
\hline & PMK-3 & 32.8 (hERK1/2 27.8/27.6) & pmk-3 \\
\hline $\begin{array}{l}\text { Yeast (Saccharomyces } \\
\text { cerevisiae) }\end{array}$ & HOG1 & 40.4 (hERK1/2 34.5/36.7) & $\operatorname{hog} 1$ \\
\hline
\end{tabular}

p38 $\beta$ are found in most cell types of the central nervous system, including in neurons, astrocytes, microglia, endothelial cells, and spinal cord (Da Silva et al., 1997; Lee S.H. et al., 2000; Nito et al., 2008; Fitzsimmons et al., 2010; Lawson et al., 2013; Haines et al., 2015). p38 $\gamma$ is expressed at relatively higher levels in muscle and liver, yet is found in most tissues (Cuenda and Rousseau, 2007). p38 $\gamma$ expression in brain is lower compared with other organs and it is found mainly in large pyramidal neurons of the cortex and hippocampus (Ittner et al., 2016) (A Ittner, unpublished results). Expression of $\mathrm{p} 38 \delta$ is more restricted compared with other p38 kinases and is found in exocrine and endocrine pancreas, brain, lung, heart, and myeloid granulocytes (Sumara et al., 2009; Ittner et al., 2012; Gonzalez-Teran et al., 2016). Thus, all four p38 kinases are present in the CNS, however, they serve non-redundant functions depending on cell type and context.

\section{p38 MAP Kinase Signaling}

p38 MAP kinases are engaged by a multitude of stimuli in a context- and cell type-dependent manner (Figure 1C). p38 was originally discovered as protein kinase activated in response to lipopolysaccharide (LPS) and osmotic stress (Han et al., 1994) and in regulation of cytokine biosynthesis (Lee et al., 1994). Work over the last 25 years established that p38 regulates various cellular functions such as metabolism, secretion, migration, differentiation, apoptosis, and senescence (Boulton et al., 1991; Herlaar and Brown, 1999; Wada and Penninger, 2004). p38 is activated by cellular stressors such as inflammatory cytokines (e.g., IL-1 and TNF- $\alpha$ ), UV irradiation, osmotic pressure, and oxidative stress (Freshney et al., 1994; Han et al., 1994; Lee et al., 1994; Rouse et al., 1994; Raingeaud et al., 1995; Borisova et al., 2018). Upstream stimuli engage a three-tiered hierarchical phosphorylation cascade to activate p38, involving sequential activation of a MAP kinase kinase kinase (MAP3K), a MAP2K, and finally the p38 MAP kinase (Zarubin and Han, 2005). The p38-specific MAP2Ks MKK3 and MKK6 are dual-specificity kinases that phosphorylate Threonine (T) and Tyrosine (Y) residues within the Thr-Gly-Tyr motif of the activation loop of p38 (Zarubin and Han, 2005). Dual phosphorylation results in structural changes within the kinase domain and increased activity of p38 (Enslen et al., 1998; Alonso et al., 2000; Brancho et al., 2003). Scaffolding proteins (e.g., JIP4) recruit upstream MAP2Ks and MAP3Ks to potentiate activation of p38 kinases (Kelkar et al., 2005). Alternative modes of activation have been described, which are mediated by protein interaction, small molecules, and both tyrosine- and autophosphorylation of p38 (Ge et al., 2002; Mittelstadt et al., 2005; Salvador et al., 2005; Gills et al., 2007). Downstream targets of p38 include cytoskeletal and scaffold proteins, transcription factors, molecular chaperones, metabolic enzymes, and signaling factors (Tannenbaum et al., 1988; Goedert et al., 1997; Parker et al., 1998; Kuma et al., 2004; Sabio et al., 2005). p38 is regulated by localization, e.g., between the cytoplasm and nuclear compartment (Kotlyarov et al., 2002; Cheung et al., 2004; Gong et al., 2010) and inactivated by transcriptional feedback, termination of stimuli, inhibition of upstream kinases or direct dephosphorylation by MAP kinase dual-specificity phosphatases (DUSPs) (Jeffrey et al., 2007; Patterson et al., 2009). DUSPs specifically dephosphorylate threonine and tyrosine residues within the MAPK activation loop, including in $\mathrm{p} 38$, thus negatively regulating their activation (Caunt and Keyse, 2013). Several DUSPs have been found to target p38, including DUSP12, which regulates macrophage responses (Cho et al., 2017), DUSP1, DUSP8, DUSP10, and DUSP16, which are specific for p38 and JNK (Muda et al., 1996; Theodosiou and Ashworth, 2002).

\section{CENTRAL METHODS TO STUDY p38 KINASES}

\section{Small Molecule Inhibitors}

Development of new kinase inhibitors is critical to studying protein kinase function (Fabian et al., 2005). Small molecule inhibitors are key tools to study p38 function in many cell types including within the CNS (Table 2). The 1st generation of p38 inhibitors are based on imidazole-pyrimidine scaffolds (Scior et al., 2011) and include SB239063 (Underwood et al., 2000), SB202190 (Nemoto et al., 1998), and SB203580 (Cuenda et al., 1995), which all target $\mathrm{p} 38 \alpha$ and $\mathrm{p} 38 \beta$ at concentrations used in most experimental conditions, yet show no activity toward

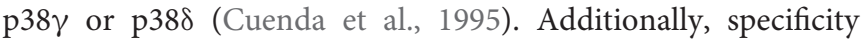
limitations of 1st generation p38 inhibitors led to off-target effects in autophagy, metabolism, and glucose uptake (Borsch-Haubold et al., 1998; Bazuine et al., 2004; Fabian et al., 2005; Menon et al., 2015). This prompted development of inhibitors that target all forms of p38, such as BIRB-796 (Regan et al., 2003), or compounds that are selective toward one specific p38 kinase, such as VX-745, a selective p38 $\alpha$ inhibitor (Alam et al., 2017). The number of isoform-specific p38 inhibitors has since increased, including VX-702 (Damjanov et al., 2009), MW-108, MW-181 (Watterson et al., 2013), SCIO 469 (Hideshima et al., 2004), and BMS 582949 targeting p38 $\alpha$ (Emami et al., 2015) (see Table 2). 
TABLE 2 | Examples of p38 MAP kinase inhibitors used in research.

\begin{tabular}{|c|c|c|c|c|c|c|}
\hline Inhibitor & $\begin{array}{l}\text { p38 } \\
\text { specificity }\end{array}$ & Chemical class & IC50 & Reference & $\begin{array}{l}\text { Off-target effects } \\
\text { (including ref.) }\end{array}$ & Target disease models \\
\hline SB203580 & $\mathrm{p} 38 \alpha / \beta$ & Imidazolidine & $\begin{array}{l}\text { For } \mathrm{p} 38 \alpha=50 \mathrm{nM}, \text { for } \\
\mathrm{p} 38 \beta=500 \mathrm{nM}\end{array}$ & $\begin{array}{l}\text { Lee et al., 1994; } \\
\text { Cuenda et al., } \\
1995\end{array}$ & $\begin{array}{l}\text { GLUT1/4 (Antonescu } \\
\text { et al., 2005), autophagy } \\
\text { (Menon et al., 2015), } \\
\text { CK1 (Shanware et al., } \\
\text { 2009) }\end{array}$ & Endometriosis, inflammation, AD \\
\hline MW069 & p38 $\alpha$ & Pyridazine & For $\mathrm{p} 38 \alpha=21 \mathrm{nM}$ & Song et al., 2013 & & ALS \\
\hline BIRB796 & $\mathrm{p} 38 \alpha / \beta / \gamma / \delta$ & Pyrazoles & $\begin{array}{l}\text { For } \mathrm{p} 38 \alpha=38 \mathrm{nM}, \text { for } \\
\text { p38 } \beta=65 \mathrm{nM}, \text { for } \\
\text { p38 }=200 \mathrm{nM} \text {, and for } \\
\text { p38 }=520 \mathrm{nM}\end{array}$ & Regan et al., 2003 & & $\begin{array}{l}\text { Crohn's disease (Schreiber et al., 2006) } \\
\text { Psoriasis } \\
\text { Rheumatoid arthritis } \\
\text { Hypertension }\end{array}$ \\
\hline VX-745 & p38 $\alpha$ & Pyrimidopyridazines & $\begin{array}{l}\text { For } \mathrm{p} 38 \alpha=10 \mathrm{nM}, \text { for } \\
\mathrm{p} 38 \beta=220 \mathrm{nM}\end{array}$ & Alam et al., 2017 & & $\begin{array}{l}\text { AD, Inflammation (Xu et al., 2010), } \\
\text { Rheumatoid or osteoarthritis (Gibson } \\
\text { et al., 2008), Werner syndrome }\end{array}$ \\
\hline SD-282 & $\mathrm{p} 38 \alpha$ & Indolecarboxamide & For $\mathrm{p} 38 \alpha=1.61 \mathrm{nM}$ & $\begin{array}{l}\text { Sweitzer et al., } \\
2004\end{array}$ & & $\begin{array}{l}\text { Nociception, neuropathic pain, } \\
\text { Diabetes, } \\
\text { Arthritis, } \\
\text { Myocardial injury, } \\
\text { Sepsis, } \\
\text { Asthma }\end{array}$ \\
\hline SB220025 & $\mathrm{p} 38 \alpha$ & Imidazolidine & For $p 38 \alpha=60 \mathrm{nM}$ & $\begin{array}{l}\text { Jackson et al., } \\
1998\end{array}$ & & $\begin{array}{l}\text { AD, } \\
\text { Angiogenesis, } \\
\text { Chronic Inflammation, } \\
\text { Arthritis }\end{array}$ \\
\hline MW151 & $\mathrm{p} 38 \alpha$ & Pyridazine & For $p 38 \alpha=50 \mathrm{nM}$ & $\begin{array}{l}\text { Amantini et al., } \\
2007\end{array}$ & & $\begin{array}{l}\text { AD, } \\
\text { Inflammation, } \\
\text { Multiple Sclerosis }\end{array}$ \\
\hline Ro3206145 & $\mathrm{p} 38 \alpha / \beta$ & 4-Azaindoles & For $p 38 \alpha=10 \mu \mathrm{M}$ & $\begin{array}{l}\text { Dapper et al., } \\
2013\end{array}$ & & Optic neuropathy (Dapper et al., 2013) \\
\hline VX-702 & $\mathrm{p} 38 \alpha$ & Pyridinecarboxamide & For $p 38 \alpha=20 \mathrm{nM}$ & $\begin{array}{l}\text { Damjanov et al., } \\
2009\end{array}$ & & $\begin{array}{l}\text { Rheumatoid arthritis (Damjanov et al., } \\
\text { 2009) }\end{array}$ \\
\hline $\begin{array}{l}\text { MW-108, } \\
M W-181\end{array}$ & $\mathrm{p} 38 \alpha$ & Pyridazine-3-amine & For $\mathrm{p} 38 \alpha=30 \mathrm{nM}$ & $\begin{array}{l}\text { Watterson et al., } \\
2013\end{array}$ & & $\begin{array}{l}\text { Neuroprotection against neurotoxic insult } \\
\text { (Xing et al., 2015) }\end{array}$ \\
\hline SCIO 469 & $\mathrm{p} 38 \alpha$ & $\begin{array}{l}\text { Indole-3-acetamide- } \\
\text { hydrochloride }\end{array}$ & For $\mathrm{p} 38 \alpha=9 \mathrm{nM}$ & $\begin{array}{l}\text { Hideshima et al., } \\
2004\end{array}$ & & $\begin{array}{l}\text { Monoclonal gammopathies (Roccaro } \\
\text { et al., 2008), multiple myeloma } \\
\text { (Hideshima et al., 2004) }\end{array}$ \\
\hline $\begin{array}{l}\text { BMS } \\
582949\end{array}$ & $\mathrm{p} 38 \alpha$ & $\begin{array}{l}\text { Triazine-6- } \\
\text { carboxamide }\end{array}$ & For $p 38 \alpha=13 n M$ & Emami et al., 2015 & & Arterial inflammation (Emami et al., 2015) \\
\hline
\end{tabular}

Development of isoform-specific compounds was based on more targeted inhibitor design strategies (Lee and Kim, 2017; Rohm et al., 2019). Nevertheless, non-specific effects of pharmacological p38 kinase inhibitors on other kinases or off-target effects, demand more specific targeting of individual p38 kinases.

\section{Gene Targeting Approaches}

Genetic modification of individual p38 genes has been instrumental in uncovering non-redundant functions of individual p38 kinases (Table 3). Two main strategies have been employed: (1) conventional gene targeting in mice to generate complete or conditional knockout alleles for $p 38 \alpha$ (Hui et al., 2007; Ventura et al., 2007), p38 $\beta$ (Beardmore et al.,

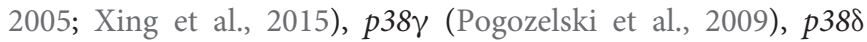
(Sumara et al., 2009; Risco et al., 2012). Global deletion of $p 38$ genes in mice results in viable offspring, with the exception of complete $p 38 \alpha$ knockout, which results in embryonic lethality due to placentation defects (Adams et al., 2000). (2) Gene editing approaches using the CRISPR-Cas system to target p38 genes in cells or mice (Goginashvili et al., 2015; Stefanoska et al., 2018).

\section{RNA Interference}

Expression of siRNA or shRNA targeting p38 transcripts offers a feasible solution for reducing p38 levels when neither kinase inhibitors nor genetic alteration on the DNA levels is possible or desired. RNA interference has been used for all $p 38$ transcripts in the past (Sumara et al., 2009; Yang et al., 2013; Stefanoska et al., 2018) and offers gene-specific reduction in p38 transcript and protein levels. Cell type-specific or brain region-specific isoformselective RNA interference likely will see increased use to explore functions of p38-regulated pathways in vivo in future studies.

\section{Protein Variants of p38}

Constitutively active (CA) variants of all human p38 kinases have been engineered by targeted codon exchanges in the coding sequences (Avitzour et al., 2007). For example, exchange of 
TABLE 3 | Mouse models of p38 gene targeting in and affecting functions of CNS cells.

\begin{tabular}{|c|c|c|c|c|c|}
\hline p38 gene & Mouse strain & Cell type targeted & Phenotype(s) & Potential disease relevance & References \\
\hline \multirow[t]{7}{*}{ p38a (Mapk14) } & Thy-cre $p 38 \alpha^{\operatorname{loxP} / \text { loxp }}$ & CNS neurons & $\begin{array}{l}\text { Increased anxiety-related } \\
\text { behavior }\end{array}$ & Depression, anxiety & Stefanoska et al., 2018 \\
\hline & $\begin{array}{l}\text { CamK2a-cre } \\
\text { p38 } \alpha^{\text {loxP/loxP }}\end{array}$ & Neurons & $\begin{array}{l}\text { Reduced } A \beta \text { accumulation, } \\
\text { Reduced tau pathology }\end{array}$ & $\begin{array}{l}\text { Tauopathies, Alzheimer's } \\
\text { disease }\end{array}$ & $\begin{array}{l}\text { Schnoder et al., 2016; } \\
\text { Colie et al., } 2017\end{array}$ \\
\hline & ePet1-cre p38 $\alpha^{\operatorname{loxP} / \text { loxP }}$ & $\begin{array}{l}\text { Serotonergic neurons, } \\
\text { Raphe nucleus neurons }\end{array}$ & $\begin{array}{l}\text { Increased stress resilience, } \\
\text { altered } 5 \mathrm{HT} \text { reuptake }\end{array}$ & $\begin{array}{l}\text { Depression, anxiety, addiction, } \\
\text { schizophrenia and autism }\end{array}$ & $\begin{array}{l}\text { Bruchas et al., 2011; } \\
\text { Lemos et al., 2012; } \\
\text { Schindler et al., } 2012\end{array}$ \\
\hline & $\begin{array}{l}\text { Nes-creERT2 } \\
\text { p38 } \alpha^{\text {loxP/loxP }}\end{array}$ & Neural progenitor cells & $\begin{array}{l}\text { Reduced neural progenitor } \\
\text { proliferation }\end{array}$ & Age-related neurodegeneration & Kase et al., 2019 \\
\hline & Gfap2-cre p38 $\alpha^{\text {loxP/loxP }}$ & Astrocytes & $\begin{array}{l}\text { Reduced cytokine release } \\
\text { from astrocytes, altered } \\
\text { serotonin uptake }\end{array}$ & Neuroinflammation & $\begin{array}{l}\text { Bruchas et al., 2011; Lo } \\
\text { et al., } 2014\end{array}$ \\
\hline & $\begin{array}{l}\text { Lys-cre } p 38 \alpha^{\text {loxP/loxP; }} \\
\text { Cx3cr1-cre } \\
\text { p38 } \alpha^{\text {loxP/loxp }}\end{array}$ & Microglia & $\begin{array}{l}\text { Reduced cytokine release } \\
\text { from microglia }\end{array}$ & $\begin{array}{l}\text { Neuroinflammation, traumatic } \\
\text { brain injury, Alzheimer's disease }\end{array}$ & $\begin{array}{l}\text { Bachstetter et al., 2011, } \\
\text { 2013; Morganti et al., } 2019\end{array}$ \\
\hline & $\begin{array}{l}\text { Ng2-cre } p 38 \alpha^{\text {loxP/loxP; }} \\
m P_{0} \text { TOTA-cre } \\
\text { p38 } \alpha^{\text {loxP/loxP }}\end{array}$ & Myelinating cells & $\begin{array}{l}\text { Inhibition of myelination } \\
\text { during development and } \\
\text { remyelination }\end{array}$ & Nerve injury, multiple sclerosis & $\begin{array}{l}\text { Chung et al., 2015, 2018; } \\
\text { Roberts et al., 2017; Chung } \\
\text { et al., } 2018\end{array}$ \\
\hline p38ß (Mapk11) & $p 38 \beta^{-/-}$ & Global & $\begin{array}{l}\text { No CNS phenotypes } \\
\text { reported }\end{array}$ & & Xing et al., 2015 \\
\hline \multirow[t]{2}{*}{ 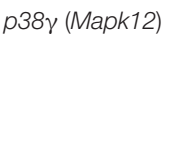 } & $p 38 \gamma^{-1-}$ & Global & $\begin{array}{l}\text { Increased susceptibility to } \\
\text { excitotoxicity }\end{array}$ & Alzheimer's disease & Ittner et al., 2016 \\
\hline & $p 38 \gamma^{-1-}$ & Global & $\begin{array}{l}\text { decreased peripheral nerve } \\
\text { myelin caliber }\end{array}$ & Multiple sclerosis & Noseda et al., 2016 \\
\hline p388 (Mapk13) & $p 38 \delta^{-/-}$ & Global & $\begin{array}{l}\text { No CNS phenotypes } \\
\text { reported }\end{array}$ & & $\begin{array}{l}\text { Sumara et al., 2009; Ittner } \\
\text { et al., } 2012\end{array}$ \\
\hline
\end{tabular}

the Asp-179 to Alanine residue in the activation loop in $\mathrm{p} 38 \gamma$ results in increased kinase activity, likely due to enhanced engagement with upstream activating kinases (Avitzour et al., 2007). In addition to codon exchanges near the activation loop, CA variants for $\mathrm{p} 38 \alpha$ and $\mathrm{p} 38 \delta$ have been generated by single residue exchange at Tyr-323 (Diskin et al., 2004), a region that is associated with tyrosine kinase-mediated $\mathrm{p} 38 \alpha$ activation by ZAP-70 (Salvador et al., 2005). CA variants have been used in cell culture to study effects of downstream target phosphorylation or of increased kinase activity itself (Sumara et al., 2009; Ittner et al., 2016). p38 $8^{\mathrm{CA}}$ expression by viral vectors or through transgenesis can be employed to address functions of p38 kinases and their activity in primary cells, organ culture or in vivo (Ittner et al., 2016). Dominant negative (DN) variants of p38 can be generated by mutations in the activation loop changing the dual phosphorylation motif into Ala-Gly-Phe, which cannot be phosphorylated and activated by upstream kinases. This approach has been used to study function of $\mathrm{p} 38 \alpha$ in mice using a transgenic or knock-in approach (Ren et al., 2005; Cortez et al., 2017).

New biochemical methods to label protein interactions and substrate engagement facilitate mapping of entire MAP kinase signaling cascades (Prikas et al., 2020). In summary, the molecular and genetic toolbox outlined above, including inhibitor molecules, gene knockout, CRISPR, RNAi, constitutively active (CA) p38 variants, and proximity labeling, facilitated the discovery of functions of p38 kinases and will be essential for future advances toward a better understanding of p38 kinases in CNS cell types and diseases.

\section{NEURONAL FUNCTIONS OF p38 KINASES}

Of the four p38 kinases, p38 $\alpha$ has most extensively been studied in the context of the central nervous system (Figure 2). Neuronspecific functions of $\mathrm{p} 38 \alpha$ are mediated through a multitude of neuronal molecules, some of them central to the roles of this cell type such as ion channels, neurotransmitter receptors, cytoskeletal and adhesion molecules. p38 $\alpha$ is expressed in CNS neurons (Stefanoska et al., 2018), where it localizes to soma, neurites and synapses (Ittner et al., 2016). p38 $\alpha$ is found at lower levels than other p38 kinases in neurons (i.e., p38 $\beta$ and p38 $\gamma$ (Lawson et al., 2013; Ittner et al., 2016). Similar to its function in other cell types, p38 $\alpha$ regulates the translation machinery in neurons through downstream regulation of MAP kinase-activated protein (MAPKAP) kinases and mRNA stability (Farooq et al., 2009; Lawson et al., 2013). MAPKAP kinases, including MAPKAPK2, phosphorylate Tristetraproline to regulate mRNA stability through adenine/uridine-rich elements (Clement et al., 2011). However, the identity and extent of target mRNAs downstream of $\mathrm{p} 38 \alpha$ and MAPKAP kinases in neurons remains to be determined.

\section{Long-Term Potentiation and Depression}

Central mechanisms of synaptic plasticity are long-term potentiation (LTP) or long-term depression (LTD), i.e., the activity-dependent up- or downregulation, respectively, of AMPA-type glutamate receptors (AMPARs) at the post-synapse. 


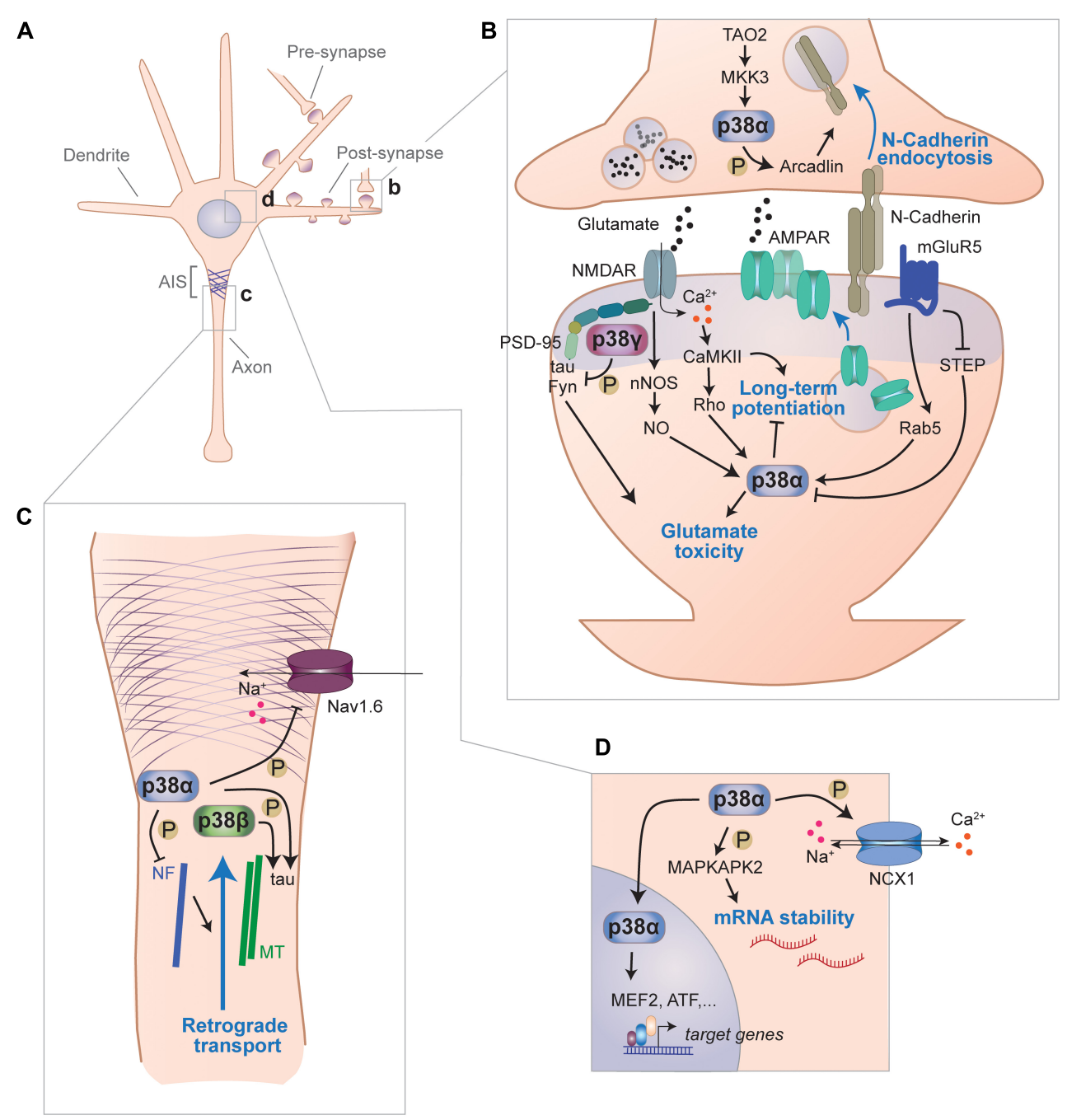

FIGURE 2 | Signaling functions of p38 kinases in neurons. (A) Functions of p38 kinases in neurons have been described for different subcellular locales, including pre- and postsynapse, axon and cell body. (B) p38 kinases are involved in signal transduction at synapses. Within the pre-synaptic moiety of synapses, p38 $\alpha$ phosphorylates arcadlin to promote $\mathrm{N}$-Cadherin endocytosis from the active zone when activated downstream of TAO2 and MKK3. p38 $\alpha$ is engaged downstream of multiple post-synaptic pathways and impairs LTP, which involves increasing surface expression of AMPA-type glutamate receptors (AMPAR) and promotes toxicity from excess glutamate. In this context, p38 $\alpha$ is activated downstream of NMDA receptors through neuronal nitric oxide synthase (nNOS)-mediate nitric oxide (NO) production or through CaMKII) activity. Alternatively, p38 $\alpha$ is activated downstream of metabotropic glutamate receptor 5 (mGluR5) through small G-protein Rab5 and/or inhibition of striatal enriched phosphatase (STEP). p38 $\gamma$, which binds to PSD-95 within the post-synaptic density, phosphorylates tau and inhibits glutamate excitotoxicity mediated by tau and Fyn kinase. (C) p38 kinases are involved in axonal signaling. p38 $\alpha$ phosphorylate voltage-gated sodium Nav1.6 channels, which localize to the axon initial segment, and reduce their sodium currents. p38 $\alpha$ phosphorylates neurofilaments and thereby impair retrograde axonal transport processes. Both, p38 $\alpha$ and p38 $\beta$ were shown to phosphorylate the cytoskeletal protein tau that associates with axonal microtubules (MT). (D) p38 kinases regulate neuronal processes with the soma and nucleus. p38 $\alpha$ regulates sodium/calcium exchange channel NCX1 by phosphorylation. p38 $\alpha$ targets MAP kinase-activated protein kinase-2 (MK2) that promotes stability of AUC-rich element containing neuronal messenger RNAs. Furthermore, p38 $\alpha$ regulates gene expression through nuclear targets such as MEF2 or ATF transcription factors.

This receptor reorganization is followed by increased or reduced excitatory currents and consequently an enhancement or reduction in synaptic strength (Huganir and Nicoll, 2013; Henley and Wilkinson, 2016). p38 is involved in regulation of glutamate neurotransmission at post-synaptic neurons (Figure 2B). Activity of $\mathrm{p} 38 \alpha$ is modulated downstream of NMDA-type glutamate receptors (NMDARs) (Krapivinsky et al., 2004), and activation of $\mathrm{p} 38 \alpha$ inversely correlates with the number of AMPA receptors (AMPARs) at synapses upon engagement of
NMDARs (Krapivinsky et al., 2004). These findings implicate p38 $\alpha$ in regulation of post-synaptic NMDAR signaling and AMPAR trafficking. Regulation of synaptic plasticity appears to be an evolutionary conserved function of $\mathrm{p} 38$. In the nematode Caenorhabditis elegans, trafficking of glutamate receptor GLR-1 is altered in pmk-1 (p38 MAPK) and sek-1 (MAPKK) mutants, which display greater GLR-1 internalization in neurons (Park and Rongo, 2016). In addition, increasing age of nematodes lowers p38 levels and reduces GLR-1 in membranes, which can 
be restored by increasing p38 levels (Park and Rongo, 2016). This is consistent with work in other model organisms suggesting that p38 promotes AMPAR downregulation and short- and long-term depression (Guan et al., 2003).

p38 $\alpha$ inhibits NMDAR-mediated LTP. Experimental stimulation of NMDARs results in inactivation of p38 and relieves inhibition of NMDAR-mediated synaptic AMPAR expression (Krapivinsky et al., 2004). NMDARs engage - at least in part - a pathway through calcium-activated/calmodulindependent protein kinase II (CamKII) that activates and SynGAP-MUPP1 that inhibits p38 $\alpha$, respectively (Krapivinsky et al., 2004). This inhibition of p38 $\alpha$ activity is concomitant with dephosphorylation of SynGAP, a negative regulator of Ras-RafMEK-ERK signaling (Krapivinsky et al., 2004). Interestingly, SynGAP knockout neurons show reduced AMPAR surface expression and yet lower p38 activation suggesting that p38 activity is either required for AMPAR surface presentation or other SynGAP-modulated pathways (deregulated in SynGAP knockout cells) have a dominant effect over lower p38 activity (Rumbaugh et al., 2006). Inhibition of LTP formation is mediated through p38 $\alpha$ in different models when LTP is inhibited by angiotensin-II (Dai et al., 2016), oligomerized amyloid-beta peptides (Li S. et al., 2011; Chen et al., 2013), or interleukin-1beta (Tong et al., 2012). Genetic ablation confirmed a specific involvement of $\mathrm{p} 38 \alpha$ in inhibition of LTP formation by amyloid- $\beta$ peptides (Colie et al., 2017). Thus, evidence from multiple experimental strategies corroborate $\mathrm{p} 38 \alpha$ as a negative regulator of LTP formation.

p38 $\alpha$ has been implicated in the induction of LTD in different model systems. p38 $\alpha$ enhances LTD in the rat hippocampus/dentate gyrus (Coogan et al., 1999; Rush et al., 2002; Murray and O'Connor, 2003; Stein et al., 2020). In this context, $\mathrm{p} 38 \alpha$ is activated downstream of group I metabolic glutamate receptors (mGluR1/5) through a mechanism dependent on small GTPase Rap1, leading to Rab5-mediated AMPAR internalization and LTD formation in hippocampal neurons (Rush et al., 2002; Huang et al., 2004; Hsieh et al., 2006). A key downstream target of p38 $\alpha$ in LTD is Rab5, a GTPase critical for the endocytic cycle of AMPARs (Brown et al., 2005). The protein tyrosine phosphatase STEP is inhibited downstream of mGluR1/5 (Moult et al., 2008). STEP can directly dephosphorylate and hence deactivate p38 $\alpha$ (Pulido et al., 1998; Munoz et al., 2003). STEP deactivation can also be mediated by extrasynaptic NMDA receptors through calcium entry (Xu et al., 2009), which confers inhibition of LTP and induction of LTD (Hardingham and Bading, 2003). STEP is itself of therapeutic interest. Regulation of STEP is involved in LTP deficits in a mouse model of fragile X syndrome (Goebel-Goody et al., 2012) and mouse models of $\mathrm{AD}$ ( $\mathrm{Xu}$ et al., 2014). The effects of modulated STEP activity though may be mediated through a multitude of pathways other than p38a (Deb et al., 2013; Xu et al., 2015). STEP is required for calcium homeostasis due to increased calcium levels and CamKII activation in hippocampal neurons from STEP-deficient mice (Bosco et al., 2018), suggesting STEP is an inhibitor of calcium-mediated signaling and neurotransmitter release.
Whether ionotropic properties of NMDA receptors or calcium-independent downstream signals are important for $\mathrm{p} 38$ mediated LTD is, however, unclear. Experiments with alterations in extracellular calcium suggest ionotropic NMDAR function is critical to activate $\mathrm{p} 38 \alpha$ downstream of NMDA receptors (Kawasaki et al., 1997; Ahn et al., 2000; Li et al., 2006; Babiec et al., 2014). However, LTD and dendritic spine shrinkage within a short timeframe could be induced through p38 activation downstream of NMDA receptors despite a complete blockage of NMDA receptor channel properties (Stein et al., 2015, 2020), suggesting that there are additional mechanisms to activate p38 during LTD enhancement that are independent of NMDARmediated calcium currents (Nabavi et al., 2013, 2014). The calcium-dependent activation of $\mathrm{p} 38$ through NMDARs requires neuron-specific factors such as PSD-95 and neuronal nitric oxide synthase (nNOS) (Soriano et al., 2008). The interaction of nNOS with the NMDAR promotes $\mathrm{p} 38$ activation and neuronal excitotoxicity, a mode of toxicity driven by excessive glutamate release/stimulation (Cao et al., 2005).

Synaptic plasticity is considered a neuronal proxy of memory consolidation or extinction (Bailey et al., 2015). Although experiments using cultured brain tissue slices or isolated primary neurons supported a critical role of $\mathrm{p} 38 \alpha$ in LTP inhibition and LTD induction, mice with neuron-specific deletion of $p 38 \alpha$ did not show altered or impaired memory function (Stefanoska et al., 2018).

\section{Regulation of Ion Channels}

p38 $\alpha$ has been implicated in modulating neuronal excitability through direct action on sodium channels (Figures 2C,D). p38 $\alpha$ phosphorylates Ser-553 in L1 region of voltage-gated sodium channel Nav1.6 (Wittmack et al., 2005). This phosphorylation event reduces sodium current amplitude through Nav1.6 channels (Wittmack et al., 2005). p38 $\alpha$ regulates channel Nav1.8 modulation by phosphorylation, which increases current density in dorsal root ganglion neurons (Hudmon et al., 2008). Voltage-gated sodium channels Nav1.6 and Nav1.8 are widely expressed (Goldin, 1999). Therefore, p38 $\alpha$-mediated sodium current modulation may be applicable to a variety of neurons involved in different brain regions and cognitive functions. In fact, p38 a colocalizes with Nav1.6 in cerebellar Purkinje cells and is found in a complex with Nav channels in lysates from rat brain (Wittmack et al., 2005). This association of Nav channels with p38 $\alpha$ may serve as a fast-acting regulatory mechanism when Nav channel currents need to be moderated. Consistent with this concept, Nav channel blocker riluzole increases p38 activation in hippocampal neurons (Kato et al., 2000; Ittner et al., 2014). Whether genetic ablation of neuronal $p 38 \alpha$ sufficiently disrupts regulation of Nav channels, resulting in lower voltagegated currents and further downstream effects (e.g., on action potentials and neuronal network synchronicity) remains unclear. Multiple kinases have been reported in regulation of $\mathrm{Nav}$ channels (Stamboulian et al., 2010). Hence, redundancy among kinases in their action on Nav channels could mask phenotypes of individual genetic deletion of $p 38 \alpha$.

p38 $\alpha$ regulates excitability and ion currents in neurons through other channels. Based on results from neuronal PC12 
cell line, NCX1-3 sodium/calcium exchange channels, which are required for maintenance of baseline calcium levels in neurons after excitation is under partial transcriptional control of p38 pathway (Sirabella et al., 2012).

In primary sensory neurons, the transient receptor potential cation channel subfamily V member 1 (TRPV1) channel levels in the plasma membrane are increased by NGF in a p38-dependent manner (Ji et al., 2002). This function of p38 $\alpha$ may be present in other CNS neurons as TRPV1 is found in the hippocampus, where they impact synaptic plasticity and memory function (Gibson et al., 2008). TRPV1 channels were also reported to activate p38 once engaged by noxious stimuli (e.g., capsaicin) (Amantini et al., 2007). This may be a positive feedback loop that enhances TRPV1 levels and thus augments noxious signal transmission and nociception.

\section{Synaptic Development}

Evidence from nematode studies suggests that p38 signaling may have a function in development of the presynapse. Presynaptic development requires suppression of a pathway consecutively involving DLK1, MKK4 and p38 (pmk-3) downstream of the RING ligase rpm1 (Nakata et al., 2005). This may be accompanied by changes in synaptic mRNA stability and translation downstream of the DLK1-p38-MAPKAP kinase pathway (Yan et al., 2009). Interestingly, p38 targets Rab5 in the context of ciliogenesis in the nematode (van der Vaart et al., 2015). Rab5 mediates effects of $\mathrm{p} 38 \alpha$ in LTD formation in mammalian cells (Rush et al., 2002; Huang et al., 2004; Hsieh et al., 2006). Thus, this conserved function in nematode dendritic ciliogenesis may relate to mammalian synaptic plasticity. However, the identity of the MAP kinases activated downstream of DLK may differ between invertebrate and mammalian neurons. In mammalian neurons, the DLK pathway has been linked to post-synaptic neurotoxic, axonal injury stress signaling, where DLK engages JNK downstream rather than p38 (Pozniak et al., 2013), and to neuronal migration (Hirai et al., 2006).

\section{Synaptic Adhesion}

p38 kinases are involved in synaptic adhesion molecule expression in neurons (Figure 2B). N-cadherin - a key neuronal homotypic cell-cell adhesion molecule regulating hippocampal spine density (Benson and Tanaka, 1998) and vesicle turnover at neuronal synapses (van Stegen et al., 2017) - is downregulated upon induced neuronal activity through a pathway that involves activation of p38 downstream of TAO2 kinase (Yasuda et al., 2007). Here, p38 $\alpha$ is likely the key p38 MAPK involved, based on the use of isoform-specific inhibition in these experiments (Yasuda et al., 2007). Downstream factors of p38 in downregulation of $\mathrm{N}$-cadherin are unknown, yet may involve Rab5 similar to p38-mediated AMPA receptor endocytosis (Rush et al., 2002; Huang et al., 2004; Hsieh et al., 2006). NMDAR activity induces $\mathrm{N}$-cadherin downregulation through $\beta$-catenin (Tai et al., 2007). This pathway is (at least partially) reminiscent of the TAO2 kinase-p38 $\alpha$ pathway function that was shown to regulate $\mathrm{N}$-cadherin endocytosis upon neuronal activation (Yasuda et al., 2007). Whether p38 $\alpha$ regulates spine morphology through $\mathrm{N}$-cadherin surface levels in the hippocampus of living mice remains to be determined.

\section{Neuronal Cytoskeleton}

Regulation of cytoskeletal proteins and processes through p38 has been investigated in various cell types. Neuronal targets of p38 kinases associated with the cytoskeleton include proteins of the intermediate filaments, microtubule and actin network (Figure 2C). p38 $\alpha$ phosphorylates neurofilament (NF) in neuronal axons (Ackerley et al., 2004). Though the physiologic function of this NF phosphorylation is unknown, phosphorylated NF colocalizes with active p38 $\alpha$ in neurons from SOD1 mouse model of ALS and in ALS patient samples. p38 kinases can affect the neuronal microtubule network through several targets. A key target is the microtubule-associated protein tau. p38 $\alpha$, p38 $\beta$, p38 $\gamma$, and p38 phosphorylate recombinant tau simultaneously on multiple sites in vitro (Goedert et al., 1997; Cavallini et al., 2013). In vitro experiments suggest that the phosphorylation of tau by p38 alters microtubule assembly (Feijoo et al., 2005). p38 kinases may phosphorylate markedly different sites on substrate proteins in cells in vivo than on recombinant protein isolated in the lab. Neuronal expression of constitutively active p38 $\gamma$ results in site-specific phosphorylation at a few sites on tau (Ittner et al., 2016). p38 kinases may regulate the microtubular cytoskeleton through different pathways than tau. The tubulin glutamate ligase TTLL-4 was shown to be activated by p38 (pmk-1) in ciliated sensory neurons of the nematode C. elegans (Kimura et al., 2018). Whether p38 kinases regulate microtubule assembly and tubulin glutamylation in mammalian neurons in vivo remains to be determined.

Regulation of the actin cytoskeleton by p38 kinases underlies the functions of p38 identified in neuronal migration. Neuronal migration of gonadotropin-releasing hormone-expressing neurons is mediated through $\mathrm{p} 38 \alpha$ and downstream MAPKAP kinase-Hsp25-mediated regulation of actin dynamics (Allen et al., 2002). Despite this function identified in a specific neuronal precursor type, p38s have been implicated more broadly in a signaling network that controls cortical neuron migration (Segarra et al., 2006). Whether this involvement depends on developmental stage and cortical layer is unclear as is the relevance to gross cortical development or the identity of the p38 kinase(s) involved. Notably, deletion of $p 38 \alpha$ in forebrain neurons late in development and postnatally does not result in compromised cortical layer microanatomy (Stefanoska et al., 2018). Additional systematic studies will be required to address the role of p38 kinases in migration of neuronal precursors or specialized neurons within the CNS of model organisms at different stages of their development.

\section{Axonal Maintenance and Transport}

p38 kinases may serve localized roles in the axon of neurons (Figure 2C). Both p $38 \alpha$ and p $38 \beta$ have at least partial axonal localization in cultured neurons (Ittner et al., 2016). Axonal injury experiments in cultured neurons support a function of JNK and p38 activation during axon regeneration (Nix et al., 2011). Activation of both MAP kinase classes was regulated at different stages of axonal regeneration. This sequential engagement of 
JNK and p38 kinase may reflect to some extent the invertebrate JIP1/DLK pathway involved in axonal injury and in physiological functions at synapses (Klinedinst et al., 2013). This indicates mammalian diversification of MAP kinase signaling in the axon.

Increasing evidence suggests that p38 kinases are involved in regulation of axonal transport. Kinesin function is inhibited by $\mathrm{p} 38$-dependent activation of kinesin light chain kinases (De Vos et al., 2000). This role of p38 activity in the axon was confirmed in a squid neuron model, a classic experimental system to study axonal transport (Song et al., 2013). Activation of p38 downstream of ASK1 interfered with axonal transport of mutant SOD1 protein, likely worsening symptoms of ALS (Morfini et al., 2013; Song et al., 2013). These results were recently supported by inhibitor experiments in a mouse model of ALS, suggesting that the p38 kinases involved in axonal transport inhibition is p38 $\alpha$ (Gibbs et al., 2018). The p38 $\alpha$ inhibitor MW069 restored axonal transport and outgrowth in FUS-expressing motor neurons (Sama et al., 2017), supporting again that $\mathrm{p} 38 \alpha$ has an important role in regulation of axonal transport processes, at least under disease conditions. This function of $\mathrm{p} 38 \alpha$ may also contribute to axonal impairments in optic neuropathy (Dapper et al., 2013). Insights into the role of p38 kinases, and in particular p38 $\alpha$, in axonal transport from inhibitor studies should be further corroborated by future experiments with genetic ablation.

\section{Neurotoxicity and Survival}

A bulk of studies based on p38 inhibitor experiments support a central function of p38 kinases in neurotoxic signaling or neurotoxicity in general. Most of this work explored the role of p38 kinases in cultured neurons. Specific inhibition of p38 $\alpha$ is neuroprotective in multiple forms of neurotoxicity, while p38 $\beta$ does not mediate neurotoxic signals (Xing et al., 2015). This function of p $38 \alpha$ may apply across different neuronal cell types. p38 $\alpha$ inhibition, for example, protected motoneurons from hypoxia-induced cell death (Guo and Bhat, 2007) or 1-methyl-4-phenyl-1,2,3,6-tetrahydropyridine (MPTP)-induced dopaminergic neuron loss (Wu et al., 2016). Excitotoxicity, a complex form of toxicity initiated by excess glutamate levels (Hardingham and Bading, 2003), is at least in part mediated through calcium- and Rho GTPase-mediated activation of p38 $\alpha$, resulting in excitotoxic cell death of cultured neurons (Semenova et al., 2007). Prions $\left(\operatorname{Prp}^{\mathrm{Sc}}\right.$ ) and prion-like amyloidbeta oligomers mediate some of their neurotoxic effect in cultured hippocampal neurons through a mechanism that involves NMDA receptor, calcium and p38 activation (Fang et al., 2018). This is partially reminiscent of excitotoxic signaling and these modes of neurotoxicity show substantial overlap in signaling molecules involved, e.g., downstream of NMDA receptors (Hardingham and Bading, 2003). Hence, many pathways that mediate NMDA receptor-mediated synaptic plasticity are also involved in glutamate excitotoxicity (Hardingham and Bading, 2003; Mucke and Selkoe, 2012). Upstream factors of p38 in synaptic plasticity, such as nNOS, calcium, STEP, Rho, and Rab5 affect the role of p38 in glutamate toxicity (Figure 2B). Other experimental methods used to induce glutamate-dependent excitotoxicity have included blocking inhibitory neuron function [e.g., by blocking GABA receptors (Cremer et al., 2009) or engaging kainic acid (KA) receptors (Chittajallu et al., 1996)] with KA to induce seizures (Namiki et al., 2007). Our systematic study of different p38 knockout mice, including neuronspecific $p 38 \alpha$ knockout mice, using PTZ-induced glutamate toxicity as model, did not find involvement of p38 $\alpha$, however, found $\mathrm{p} 38 \gamma$ is important in suppression of glutamate toxicity (Ittner et al., 2016).

NMDA receptor-mediated glutamate toxicity involves taudependent recruitment of Fyn kinase into a complex of NMDA receptor with scaffolding factor PSD-95 (Ittner and Ittner, 2018). PSD-95 serves as a postsynaptic hub for protective and toxic signaling cascades (Cao et al., 2005; Ittner et al., 2010, 2016). Fyn kinase phosphorylates NMDAR subunit NR2B on Tyrosine1472, which aggravates excitotoxicity (Aarts et al., 2002). This pathway is inhibited by $\mathrm{p} 38 \gamma$, which localizes to post-synapses and binds to PSD-95 through a PDZ domain interaction (Sabio et al., 2005; Ittner et al., 2016). p38 $\gamma$ phosphorylates dendritic tau on Threonine-205, which abolishes a complex of PSD95, tau and Fyn kinase (Ittner et al., 2016). Therefore, p38 $\gamma$ has a neuroprotective function in excitotoxicity and in other related forms of neurotoxicity such as amyloid- $\beta$ exposure (Ittner and Ittner, 2018). Whether p38 $\gamma$ protects neurons from other noxious stimuli and whether these functions of $\mathrm{p} 38 \gamma$ are all mediated through tau phosphorylation remains to be determined. Thus, depending on context - p38 kinases can have roles that promote survival of neurons and are likely linked to physiologic mechanisms e.g., for $\mathrm{p} 38 \alpha$ or $\mathrm{p} 38 \gamma$ in NMDA receptor signaling. p38 $\alpha$ was shown to promote neuronal survival in culture as a downstream factor of Rit GTPase (Cai et al., 2012) and proliferation of cerebellar granule neuron precursor (Guldal et al., 2012). Overall however, neuronspecific $p 38 \alpha$ or global deletion of $p 38 \beta, p 38 \gamma, p 38 \delta$ did not result in different neuronal numbers under physiological conditions (Ittner et al., 2016; Colie et al., 2017; Stefanoska et al., 2018). Effects of p38 kinases in neurotoxicity or protection become apparent upon exposure to noxious stimuli. Thus, studies in cultured neurons should be systematically translated to $\mathrm{KO}$ models to confirm relevance of the findings. Consistently, a rigorous approach supports a central function of JNK in neuronal apoptosis following excitotoxic insult rather than $\mathrm{p} 38 \alpha$ (Cao et al., 2004). Deletion of neuronal $p 38 \alpha$ or global deletion of $p 38 \beta, p 38 \delta$ did not result in altered susceptibility to excitotoxicity in mice (Ittner et al., 2016). Deletion of $p 38 \gamma$ aggravates glutamate toxicity, and neuronspecific transgenesis of CA $p 38 \gamma$ protects mice and cells from excitotoxicity, reflecting the protective function of $\mathrm{p} 38 \gamma$ (Ittner et al., 2016). Notably, neuron-specific CA p38 $\gamma$ transgenic mice show no obvious cognitive or behavior phenotypes (Ittner et al., 2016). Thus, depending on context, neuronal p38 kinases serve signaling functions that contribute to resolution of stress through their activity.

\section{Functions in Neuronal Subtypes}

p38 kinases have specific functions in neuronal subtypes. Though the functions of individual p38 kinases have not been studied across many different neuron types, there are outstanding examples in specific neuron classes. 
Mice that express a dominant negative (DN) variant of $\mathrm{p} 38 \alpha$ in neuronal progenitors show slower age-dependent decline in neurogenesis and context-dependent fear conditioning (Cortez et al., 2017). p38 $\alpha$ was shown to regulate proliferation in peripheral cell types, including hepatocyte and hematopoietic precursor cells (Hui et al., 2007). Effects on proliferation are mediated through JNK, MAP kinase-activated protein kinase-2 (MK2), and p53 (Hui et al., 2007; Gupta and Nebreda, 2015), yet neuronal precursor mechanisms have not been explored.

A study employing targeted deletion of $p 38 \alpha$ in serotonergic neurons elegantly showed that $\mathrm{p} 38 \alpha$ is required for stress resilience, a protective mechanism in depression and addiction. p38 $\alpha$ controls serotonin (5HT) levels in 5HT neurons in the dorsal raphe nucleus (DRN) by phosphorylation and trafficking of the serotonin transporter (SERT) (Bruchas et al., 2011). Whether other p38 kinases expressed in 5HT neurons can phosphorylate SERT has not been addressed. This action of p38 $\alpha$ results in differential $5 \mathrm{HT}$ re-uptake and modulation of serotonin involved in behavior related to anxiety or depression (Bruchas et al., 2011; Baganz et al., 2015). This mechanism is present in $5 \mathrm{HT}$ neurons across different brain regions. In the ventral striatum, SERT serotonin uptake is modulated upon stress exposure, which was shown to activate p38 $\alpha$ downstream of $\kappa$-opioid receptors resulting in increased SERT cell surface expression (Schindler et al., 2012). 5HT cells in the dorsal raphe nucleus respond to exposure of rodents to stress with activation of $\kappa$-opioid receptors and $\mathrm{p} 38 \alpha$ (Lemos et al., 2012). Consistently, $5 \mathrm{HT}$ neuron specific deletion of $\mathrm{p} 38 \alpha$ or administration of p38 $\alpha$ inhibitor (MW150) restores phenotypes of a SERT mutant mouse model of social defeat stress (Robson et al., 2018), and pan-neuronal deletion of $\mathrm{p} 38 \alpha$ resulted in reduced resilience to novelty stress and an altered anxiety response (Stefanoska et al., 2018). Pan-neuronal p $38 \alpha$-deficient mice had increased activity of JNK in the forebrain and stress response in these mice was restored by inhibition of JNK (Stefanoska et al., 2018). These pan-neuronal effects are likely to occur in combination with effects of p38 $\alpha$ activity in serotonergic neurons to achieve tailored responses to aversive stimuli and stress.

Similarly, p38 $\alpha$ acts in dopaminergic neurons to regulate aspects of behavioral inhibition. $\kappa$-opioid receptor engage p38 activation in DA neurons of the ventral tegmental area (VTA) (Abraham et al., 2018) and this pathway is critical in VTA DA neurons for regulating aversive behavior (Ehrich et al., 2015). Given the similarities between DA and 5HT transporters, these effects are potentially regulated through targeting of DA transporter trafficking and function by p38 (Foster et al., 2006).

In addition, p38 controls DA neuron survival and resistance to oxidative stress. p38 activity downstream of ASK1 is inhibited by klotho (Brobey et al., 2015b), a factor that prevents premature aging and striatal DA neuron loss (Hsieh et al., 2010; Kosakai et al., 2011) and promotes remyelination (Kosakai et al., 2011; Zeldich et al., 2015). Thus, inhibition of p38 by klotho may underlie protection from striatal DA neuron loss (Kosakai et al., 2011). Activation of ASK1 is controlled by calcium through binding and inhibition by the calcium-binding protein CIB1 through direct interaction (Yoon et al., 2017). ASK1 is a key upstream activator of p38 kinases in oxidative stress signaling in multiple cell types (Watanabe et al., 2015). Therefore, toxicity mechanisms that engage the ASK1-p38 pathway in DA neurons may depend on generation of reactive oxygen intermediates. Specific functions of other $\mathrm{p} 38$ kinases present in DA neurons are unknown, yet at minimum p38 $\beta$ can be activated downstream of ASK1 (Mizumura et al., 2006). Systematic investigation of expression and function of $\mathrm{p} 38 \beta$ and $\mathrm{p} 38 \gamma$ in DA neurons may contribute to our understanding of p38-dependent mechanisms in this neuron type.

p38 kinases were shown to be involved in basic mechanisms within clock neurons that regulate diurnal rhythms in organisms across phyla. Fruit flies deficient in $p 38 b$ or overexpressing p38b in clock neurons showed opposite arrhythmic circadian behavior. p38b controls period gene expression programs in clock neurons through downstream transcription factor Mef2 - an established nuclear target of p38 (Zhao et al., 1999) - and kinase MNK (Dusik et al., 2014; Vrailas-Mortimer et al., 2014). In vertebrates, active p38 was detected in pineal gland neurons, suggesting p38 kinases are involved in circadian periodicity (Hayashi et al., 2003). It is unclear how p38 kinases are involved in neurons in controlling the circadian rhythm in the mammalian brain. Studies in p38 knockout mice may inform whether lack of p38 kinases affects gross circadian rhythms in terms of activity, sleep, and metabolism.

\section{Neuronal Differentiation}

Apart from functions in specific neuron types, p38 kinases contribute to the control of neuronal differentiation and transdifferentiation. Transdifferentiation of sympathetic neurons into cholinergic neurons was shown to be regulated by $\mathrm{p} 38 \alpha$ and p38 $\beta$ in vitro (Loy et al., 2011). Experiments with neurospheres derived from adult hippocampal neural stem cells suggest that $\mathrm{p} 38 \alpha$ controls neuronal differentiation and inhibition of $\mathrm{p} 38 \alpha$ maintains pluripotency of progenitor cells (Yoshioka et al., 2015). However, p38 kinases appear dispensable for initial differentiation into neuronal cell types in vivo. Neuronal knockout of $p 38 \alpha$ and global knockout of $p 38 \beta$ or $p 38 \gamma$ does not result in gross reduction of neuronal numbers (Xing et al., 2013; Ittner et al., 2016; Maphis et al., 2016; Schnoder et al., 2016; Colie et al., 2017). These results may, however, not be conclusive to p38 $\alpha$ function for early neuronal differentiation processes in embryogenesis due to timing and restriction of cre recombinase expression (Dewachter et al., 2002). However, experiments in cultured cells have produced conflicting results. $p 38 \alpha$-deficient multipotent embryonic stem cells can undergo induced differentiation into neurons (Guo et al., 2007), suggesting p38 $\alpha$ is dispensable for neuronal differentiation, potentially based on compensation by other p38 kinases. Other results support that differentiation from murine embryonic stem cells is partially dependent on $\mathrm{p} 38 \alpha$ and transcriptional control of $b c l 2$ (Aouadi et al., 2006; Trouillas et al., 2008). NGF promotes neuronal differentiation through Rin GTPase and p38 $\alpha$ (Shi et al., 2005). Inhibition of p38 $\alpha$ may indirectly contribute to efficient differentiation through supporting survival of differentiating neurons (Okamoto et al., 2000; Wu et al., 2010). Future studies should explore whether there are indeed non-redundant pathways dependent on p38 
kinases in neuronal differentiation processes that are not solely related to stress signaling or confounding factors in cultured system. More systematic single neuron analysis with early or global ablation of p38 genes may give a broad picture of roles of these kinases in differentiation in the developing brain.

\section{ASTROCYTIC FUNCTIONS OF p38 KINASES}

While much work has focussed on neurons, the p38 family of MAP kinase has important functions in astrocytes. Astrocytes contribute to synaptic transmission by clearance of neurotransmitters, neurotransmitter metabolism and provide structural components of the tripartite synapse architecture, which is made up of a pre-synaptic, a post-synaptic neuronal as well as an astrocytic component in the mammalian central nervous system (Halassa et al., 2007; Santello et al., 2012). Thus, functions of signaling pathways in astrocytes can be relevant to cognition, memory, behavior, development and disease states of the CNS. At least $\mathrm{p} 38 \alpha$ and $\mathrm{p} 38 \beta$ are present in astrocytes (Piao et al., 2002; Lo et al., 2014). However, systematic expression studies of all four p38 kinases in astrocytes during resting and stimulated conditions are missing.

p $38 \alpha$ regulates astrocytic neuroinflammatory responses during brain injury or neurotoxic insults (Figure 3A). Astrocytic expression of $\mathrm{p} 38 \alpha$ increases upon excitotoxic stress using kainic acid (Che et al., 2001b). Both inhibitor studies and genetic ablation of $p 38 \alpha$ suggest that $\mathrm{p} 38 \alpha$ promotes cytokine and chemokine production during CNS inflammation (Lee Y.B. et al., 2000; Lee et al., 2003; Lo et al., 2014). Deletion of $p 38 \alpha$ in astrocytes using a $G f a p 2$-driven cre deleter mouse strain resulted in an altered immune response in the brain and modulated the activation state of astrocytes (Lo et al., 2014). Interestingly, JNK activation in $p 38 \alpha$-deficient astrocytes was enhanced (Lo et al., 2014). This is consistent with reports of JNK inhibition by $\mathrm{p} 38 \alpha$ in other cell types including hepatocytes and neurons (Hui et al., 2007; Heinrichsdorff et al., 2008; Stefanoska et al., 2018). Furthermore, $\mathrm{p} 38 \alpha$ enhances NFKB and MK2 signaling as well as production of reactive oxygen species in astrocytes (Nahirnyj et al., 2013; Lo et al., 2014), which are required for cytokine production downstream of $\mathrm{p} 38 \alpha$ in astrocytes (Lo et al., 2014) and other cell types (Bachstetter et al., 2013). Interestingly, deletion of $p 38 \alpha$ in astrocytes resulted in fewer activated astrocytes, yet increased influx of activated microglia and peripheral immune cells into sites of CNS inflammation (Lo et al., 2014), suggesting that astrocytic p38 $\alpha$ regulates recruitment of glial and immune cells, likely through regulation of chemokine release. Consistent with differential roles of $\mathrm{p} 38 \alpha$ in astrocytes and microglia, p $38 \alpha$ can affect mounting and resolution of peripheral inflammatory processes differently through its action in different cell types (Kim et al., 2008).

p38 $\alpha$ was shown to regulate serotonin metabolism in serotonergic neurons, impacting on anxiety and addiction behavior (Bruchas et al., 2011; Ehrich et al., 2015). This function of p $38 \alpha$ in 5 HT neurons is enhanced by astrocytic p38 $\alpha$, which regulates serotonin uptake into astrocytes (Bruchas et al., 2011).
A

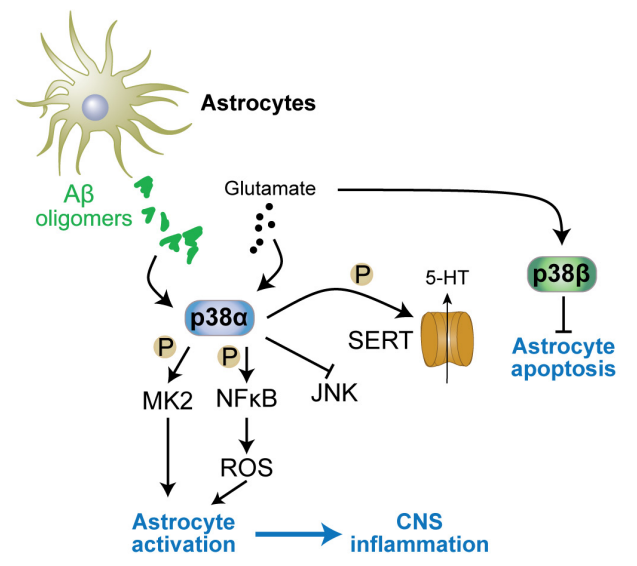

C

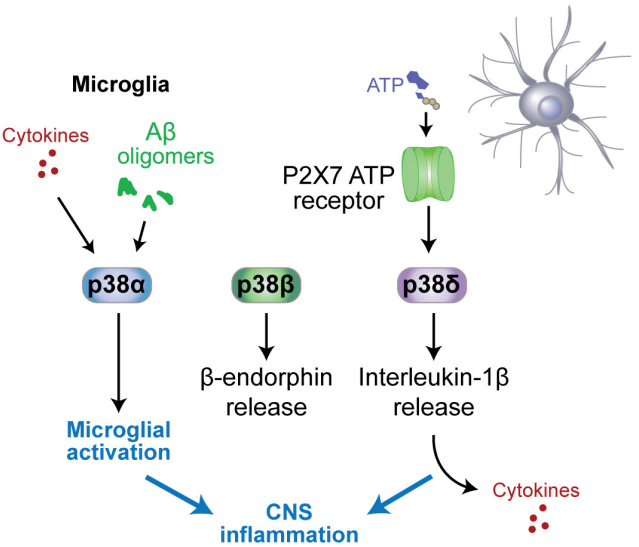

B

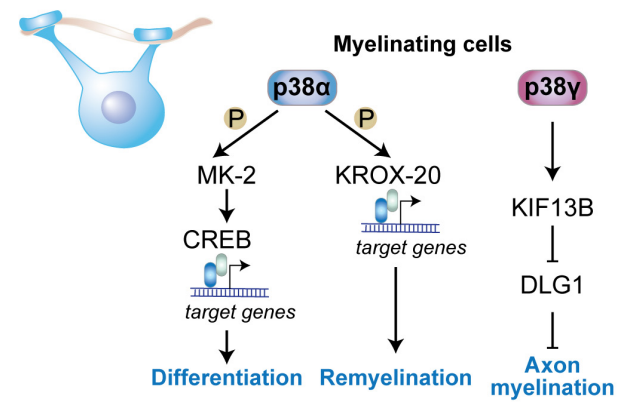

FIGURE 3 | Functions of p38 kinases in non-neuronal cells. (A) In astrocytes, p38 $\alpha$ is activated by stimuli including amyloid- $\beta$ oligomers or excess glutamate and contributes to astrocyte activation and neuroinflammation. MK2 is activated in astrocytes downstream of p38 $\alpha$. p38 $\alpha$ activates NFKB resulting in reactive oxygen species (ROS) production and astrocyte activation. Astrocyte p38 $\alpha$ inhibits c-jun N-terminal kinase (JNK) activity, and enhances serotonin (5-HT) uptake into astrocytes through phosphorylation of serotonin transporter (SERT). p38 $\beta$ is also activated by glutamate in astrocytes yet contributes to astrocyte survival by inhibiting apoptosis. (B) In myelinating cells, p38 $\alpha$ promotes remyelination through phosphorylation of key myelin transcription factor KROX-20 and downstream gene expression. p38 $\gamma$ contributes to diameters of myelin sheaths by reducing levels of disks large homolog 1 (DLG1), a inhibitor of myelination, through control of KIF13B levels. (C) In microglia, p38 $\alpha$ is activated by stimuli including cytokines and amyloid- $\beta$ oligomers, while microglial p38 is activated downstream of $\mathrm{P} 2 \times 7$ adenosine triphosphate (ATP) receptors. Both active p38 $\alpha$ and p38 contribute to neuroinflammation by promoting further cytokine release from microglia. p38 $\beta$ promotes release of microglial $\beta$-endorphin. 
Future studies may want to address whether $\mathrm{p} 38 \alpha$ regulates uptake and metabolism of other neurotransmitters in astrocytes.

p38 $\beta$ regulates cell survival of astrocytes by protecting them from apoptosis (Shin et al., 2011). Kainic acid induces different kinetics of expression of $\mathrm{p} 38 \beta$ compared with $\mathrm{p} 38 \alpha$ in astrocytes based on immunoreactivity (Che et al., 2001a). The protective function of $\mathrm{p} 38 \beta$ in astrocytes may be related to this difference in expression, yet detailed signaling events involved in this function of p38 $\beta$ are unknown.

\section{MICROGLIAL FUNCTIONS OF p38 KINASES}

Microglia express all four p38 kinases, and microglial p38 kinases have partially overlapping as well as redundant functions (Figure 3B). Inhibitor and gene knockout studies imply p38 and downstream pathways in mediating neuroinflammation in multiple contexts and models.

p38 kinases regulate microglial activation upon exposure to proinflammatory cytokines and amyloid- $\beta$ or during tissue injury (Bachstetter et al., 2013; Swaroop et al., 2016). Microglia-specific deletion of $p 38 \alpha$ (using $C \times 3 c r 1$-cre delete) reduces inflammatory reaction, cytokine levels, and microglial recruitment to damaged brain regions in a mouse model of traumatic brain injury (Morganti et al., 2019). Results from lysozyme promoter-driven p38 $\alpha$ deletion in myeloid cells that partially contribute to microglia populations resulted, however, in increased levels of cytokines during acute injury-related inflammation (Bachstetter et al., 2013). Cytokine production from microglia is regulated downstream of p38 $\alpha$ by MK2 (Culbert et al., 2006; Ghasemlou et al., 2010). Thus, p38 $\alpha$ and downstream pathways have an established role in microglial cytokine production. p38 $\alpha$ may indeed be a key p38 kinase in microglial activation. A study suggested p38 $\beta$ is not involved in microglia activation (Culbert et al., 2006; Xing et al., 2013).

p38 $\alpha$ regulates additional aspects of microglial biology. p38 $\alpha$ inhibits autophagy in microglia by phosphorylation of ULK1 (He et al., 2018). Autophagy in microglia was shown to inhibit inflammatory response ( $\mathrm{Su}$ et al., 2016; Bussi et al., 2017). In these experiments, microglia lacking p $38 \alpha$ were found to release more cytokines (He et al., 2018), similar to acute inflammatory response in p38 $\alpha$-deficient microglial cells (Bachstetter et al., 2013).

Microglia release exosomes (Potolicchio et al., 2005; Andaloussi et al., 2013), a mechanism that is important in brain physiology and for spreading of pathology in neurodegenerative diseases (Jan et al., 2017). Release of microparticles and IL-1 $\beta$ from microglia downstream of sphingomyelinase activity was shown to be p38-dependent based on an inhibitor that targets p38 $\alpha$ and p38 $\beta$ (Bianco et al., 2009). SB203580, the inhibitor used in this work, has been, however, shown to affect autophagy (Menon et al., 2015) and therefore may affect vesicle trafficking and release (Tian et al., 2019). Thus, studies in p38 knockout microglia are needed to clarify the role of p38 kinases.

p38 kinases can regulate neuroprotective pathways through their action in microglia. The neuroprotective biacetophenone cynandione A was shown to induce microglial $\beta$-endorphin expression, which was blocked by knockdown of p38 $\beta$ (Huang et al., 2017). Microglia-derived $\beta$-endorphin dampens nociceptive stimuli through a mechanism that involves glucagonlike peptide-1 receptors (Gong et al., 2014). These results suggest that $\mathrm{p} 38 \beta$ has a function in modulation of nociceptive sensory systems (Huang et al., 2017).

p38 kinases in microglia may have isoform-specific functions downstream of different receptors. p38 $\beta$ acts downstream of glucagon-like peptide-1 receptors (Gong et al., 2014). p38 $\delta$ was shown to act downstream of the ATP receptors $\mathrm{P} 2 \times 7$ in microglia, enhancing the release of IL-1 $\beta$ and inflammation within the spinal cord (Clark et al., 2010). It will be interesting to explore interaction partners and engagement in distinct signaling pathways for different p38 kinases downstream of microglial surface receptors. Molecular determinants within the primary sequence of the four p38 kinases that would support mechanistic engagement with specific receptor complexes are unknown. An exception is p38 $\gamma$, which carries a C-terminal PDZ interaction motif to recruit p38 $\gamma$ into complexes in neurons and other cells based on interaction with cognate PDZ domain-containing proteins (Sabio et al., 2005; Ittner et al., 2016).

\section{FUNCTIONS OF p38 KINASES IN MYELINATING CELLS}

p38 kinases regulate aspects of myelinating cell function (Figure 3C). Differentiation of oligodendrocytes in vivo is controlled by the p38 $\alpha-\mathrm{MK} 2$ pathway (Fragoso et al., 2007; Haines et al., 2010) through downstream effects on transcription factor cAMP response element binding protein (CREB) (Bhat et al., 2007). However, genetic deletion of $p 38 \alpha$ in oligodendroglia, using the NG2 cre delete strain, resulted in no gross myelination deficits, albeit delayed oligodendrocyte differentiation, alterations in the ultrastructure of myelin, and delayed myelination in the corpus callosum (Chung et al., 2015). Deficiency in oligodendroglial $p 38 \alpha$ has no effect on myelination when inducing demyelination with LPS or oxidative stress (Chung et al., 2015) yet enhances remyelination after cuprizone-induced demyelination (Chung et al., 2015). Consistent with these results genetic heterozygosity in $p 38 \alpha$ improves recovery in an animal model of spinal cord injury (Umezawa et al., 2017). This function of $\mathrm{p} 38 \alpha$ is relevant to the peripheral nervous system as well. Mechanistic studies in Schwann cells with genetic deletion of $p 38 \alpha$ support that $\mathrm{p} 38 \alpha$ limits myelination and showed accelerated myelination by $p 38 \alpha-$ deficient Schwann cells postnatally (Roberts et al., 2017). This function of $\mathrm{p} 38 \alpha$ is partially mediated through transcriptional control of Krox-20 (Hossain et al., 2012), a master transcription factor in Schwann cells.

Functions of p38 kinases other than $\mathrm{p} 38 \alpha$ in myelinating cells are less well characterized. The homolog of the disks large Dlg1, a MAGUK family member that has an inhibitory function in myelination of the peripheral system (Bolis et al., 2009), undergoes post-translational modification downstream of Kif13b, a kinesin-like factor regulating intracellular localization 


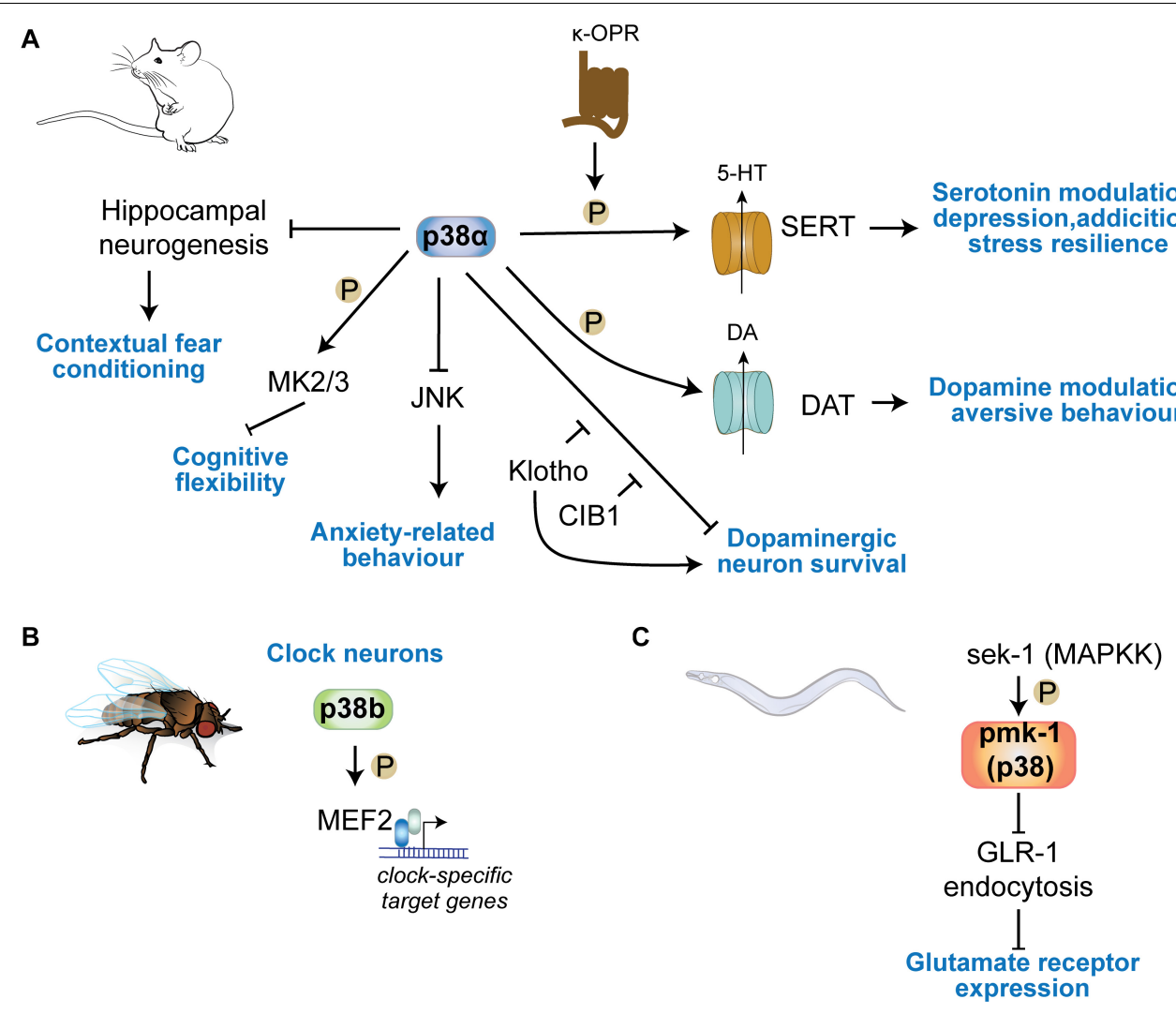

FIGURE 4 | p38 kinases in physiologic central nervous functions. (A) p38 $\alpha$ regulates learning in contextual fear conditioning through regulation of hippocampal neurogenesis. Neuronal $\mathrm{p} 38 \alpha$ inhibits JNK activation in neurons to modulate anxiety-related behavior. p38 $\alpha$ downstream of $\kappa$-opioid channels regulates serotonin reuptake in serotonergic cells by direct phosphorylation of SERT. This mechanism is involved in serotonin-regulated aspects of depression, addiction, social defeat stress. DA re-uptake by phosphorylation of DAT in DA neurons. (B) p38b regulates circadian rhythms in Drosophila by transcriptional regulation of clock neuron gene expression through the transcription factor MEF2C downstream of p38b. (C) The sek1 pmk1(p38) pathway in C. elegans regulates glutamate receptor GLR-1 trafficking at neuronal synapses.

of MAGUKs (Yoshimura et al., 2010). Dlg1 forms a complex with KIF13B and p38 $\gamma$, is then phosphorylated by $\mathrm{p} 38 \gamma$ and subsequently ubiquitinated. These modifications in response to KIF13B activity reduce cellular levels of Dlg1 and result in enhanced myelinating function of Schwann cells (Noseda et al., 2016). Addressing sciatic nerve myelination, this study found reduced myelin sheath thickness in $p 38 \gamma$ knockout nerves, yet normal axonal numbers and fiber diameter (Noseda et al., 2016). Whether the same mechanism regulates myelinating cells of the central nervous system remains to be determined. Nevertheless, the impact of $p 38 \gamma$ on Dlg1 in CNS myelination processes may be limited to specific stimuli and/or non-physiological conditions because global knockout of $p 38 \gamma$ does not result in gross myelination defects in white matter tracks of mice (Ittner et al., 2016; Noseda et al., 2016). The p38 - Dlg1 pathway may potentially have different functions in oligodendrocytes as Dlg1 acts to promote myelinating function of cells through a pathway involving PTEN-dependent inhibition of Akt (v-AKT murine thymoma viral oncogene homolog) activity (Noseda et al., 2016; Hughes and Appel, 2019). Thus, p38 kinase function in myelinating cells of the peripheral and central nervous system differ.

\section{p38 KINASES IN OTHER CNS CELL TYPES}

p38 kinases are involved in functions of additional cell types present in the CNS, including endothelial cells and pericytes, and contribute to neuroinflammation and control of the cerebrovasculature and blood-brain-barrier (BBB). p38 activation promotes experimental $\mathrm{BBB}$ disruption, which is inhibited by TGF- $\beta$-induced expression of MKP1 (Tong and Hamel, 2007). TGF- $\beta 1$ and p38 MAP kinase reciprocally regulate pericyte expression of MMP-9 (Takahashi et al., 2014). This suggests p38 signaling pathway involvement in regulation of neurovascular homeostasis under conditions of stress exposure.

\section{ROLES OF p38 KINASES IN COGNITIVE FUNCTIONS}

p38 is activated by stress stimuli in cells (Raingeaud et al., 1995). Deletion of $p 38$ genes - with the exception of $p 38 \alpha-$ does not result in obvious changes in cognition or behavior of 
mice under resting conditions (Beardmore et al., 2005; del Barco Barrantes et al., 2011; Ittner et al., 2016). Even ablation of $p 38 \alpha$ in neurons, astrocytes or microglia does not result in apparent basal changes (Bruchas et al., 2011; Ittner et al., 2016; Colie et al., 2017; Stefanoska et al., 2018). Several key functions of p38 kinases in cognition became evident with challenge from drugs, cognitive tasks or psychogenic stress.

\section{Anxiety}

$p 38 \alpha$ deletion in neurons results in increased anxiety tested by open field paradigm and elevated plus maze (Figure 4A) (Stefanoska et al., 2018). Grehlin, a gastric peptide with anxiolytic activity in the brain, was shown to require p38 activity based on inhibitor injection into hippocampus (Han et al., 2019). p38 $\alpha$ in serotonergic cells of the Raphe nucleus is necessary for SERT membrane expression and 5HT reuptake induced by chemical/environmental stressors, reducing serotonin-modulated behaviors (Bruchas et al., 2011; Baganz et al., 2015). Activated p38 $\alpha$ in presynaptic VTA neurons phosphorylate GIRK Kir3.1 to decrease somatic excitability and exocytosis of dopamine, allowing for development of place aversion in a behavioral conditioning task (Ehrich et al., 2015). Anxiety-related behavioral phenotypes are not apparent in p38 $\gamma$ knockout mice (Pogozelski et al., 2009; Ittner et al., 2016; Noseda et al., 2016) and have not been addressed for in $\mathrm{p} 38 \beta$ or $\mathrm{p} 38 \delta$ knockout mice (Beardmore et al., 2005; Sumara et al., 2009).

\section{Addiction Behavior}

p38 regulates drug seeking behavior, based on mouse models of addiction (Figure 4A). Cocaine application activated p38 in nucleus accumbens and prefrontal cortex, and results in recruitment of active p38 to norepinephrine transporter (NET) and DA transporter (DAT) (Mannangatti et al., 2015). p38 can phosphorylate NET at Thr-30 and blocking this interaction in mice reduced cocaine-conditioned place preference in mice. Furthermore, morphine-conditioned place preference was not affected by p38 inhibition, suggesting a cocaine-specific engagement of p38 in this behavior (Mannangatti et al., 2015). Interestingly, this study suggests that amphetamine - a drug of addiction that targets the serotonergic system (Kirby et al., 2011; Steinkellner et al., 2015) - selectively induces p38 association with SERT (Mannangatti et al., 2015), confirming previous findings of regulation of SERT and addiction behavior mediated through serotonergic neurons (Bruchas et al., 2007; Bruchas et al., 2011). $\kappa$-opioid receptors regulate drug reinstatement in rat models of cocaine self-administration (Beardsley et al., 2005; Graziane et al., 2013; Ehrich et al., 2015; Heinsbroek et al., 2018). This action of $\kappa$-opioid receptor signaling is dependent on p38 (Heinsbroek et al., 2018). Ablation of $p 38 \alpha$ serotonergic neurons or astrocytes lower reinstatement of cocaine preference (Bruchas et al., 2011), providing genetic evidence for a significant role of p38 - and in particular $\mathrm{p} 38 \alpha$ - in addiction.

\section{Learning and Memory}

Memory tests in neuron-specific $p 38 \alpha$ knockout mice revealed no deficits in memory acquisition or retrieval at 6-8 months of age (Stefanoska et al., 2018) (Figure 4A). Contextual fear condition
DN p38 $\alpha$ knock-in, in which the activation motif is mutated to Ala-Gly-Phe, mice show enhanced performance (Cortez et al., 2017). DN p38 $\alpha$ mice were significantly protected from agedependent reduction in hippocampal adult neurogenesis (Cortez et al., 2017). This suggests that $\mathrm{p} 38 \alpha$ regulates aspects of memory function through inhibiting neurogenic precursor function. Thus, evidence suggest that p38 kinases have limited impact on memory acquisition. However, downstream substrates of $\mathrm{p} 38 \alpha / \beta$, MAPKAP kinases 2 and 3, are important for AMPAR endocytosis during long-term depression and regulate cognitive flexibility in spatial memory tasks (Eales et al., 2014). Other p38 kinases such as p38 $\gamma$ or p $38 \delta$ appear dispensable for physiologic memory function. Knocking out p38 $\gamma$ or increasing activity of neuronal p38 $\gamma$ results in not alteration of memory function in mice (Ittner et al., 2016), even at advanced age (unpublished results).

\section{p38 KINASES IN CNS DISORDERS AND NEURODEGENERATION}

p38 kinases have been linked to several neurological disorders, in particular, when associated with neuroinflammatory responses. This is largely based on their prominent role in cytokine production and release from immune cells including microglia (Lee Y.B. et al., 2000). Despite this role in neuroinflammation, distinct involvement of individual p38 kinases in pathways in different types or even sub-types of cells of the nervous system make contributions to disease processes. This is either through physiologic, protective mechanisms that dampen disease development or by enhancing disease progression through promoting toxic signaling.

\section{Ischemia}

Ischemic conditions are associated with multiple neurological disorders, including stroke, brain injury (Castillo et al., 2004; Shichita et al., 2014) and involves multiple secondary responses such as hypoxic response, neuroinflammation and excitotoxicity (Chamorro et al., 2016). p38 becomes activated by hypoxic conditions in brain tissue (Bu et al., 2007; Lu et al., 2011; Li et al., 2013). Involvement in ischemia-induced neurologic disorder has been largely addressed by inhibitor studies (Barone et al., 2001; Legos et al., 2001; Piao et al., 2003). Inhibition of p38 $\alpha$ and p38 $\beta$ in ischemic conditions lowers neuroinflammation and cytokine release (Barone et al., 2001; Legos et al., 2001; Piao et al., 2003; Sanchez et al., 2012) (Figure 5A). Work in cultured cells showed that $\mathrm{p} 38 \alpha$ and $\mathrm{p} 38 \gamma$ are activated by hypoxia rather than $\mathrm{p} 38 \beta$ or p38 (Conrad et al., 1999) and p38 $\alpha$ is required for hypoxiainduced factor-1 (HIF-1) stabilization (Emerling et al., 2005). Whether $\mathrm{p} 38 \alpha$ and/or $\mathrm{p} 38 \gamma$ are critical for hypoxic response in CNS cells remains to be determined, yet it may suggest that $\mathrm{p} 38 \alpha$ and $\mathrm{p} 38 \gamma$ could be specific targets for treatment of brain ischemia. Understanding the function of these 2 kinases in different brain cell types will be required as hypoxia induces p38 activation in both neurons and microglia (Bu et al., 2007). Phosphatase STEP interacts with and reduces activation of p38, lowering neurotoxicity in ischemia models (Poddar et al., 2010; Deb et al., 2013). Promoting activity of STEP toward p38 is 


\section{A Ischemia/ traumatic brain injury}

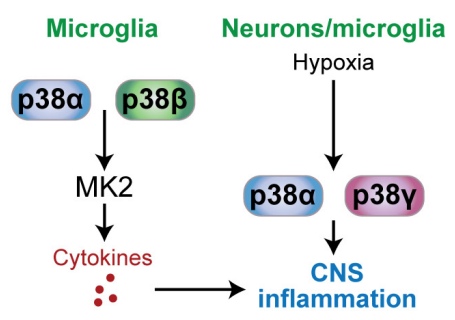

D

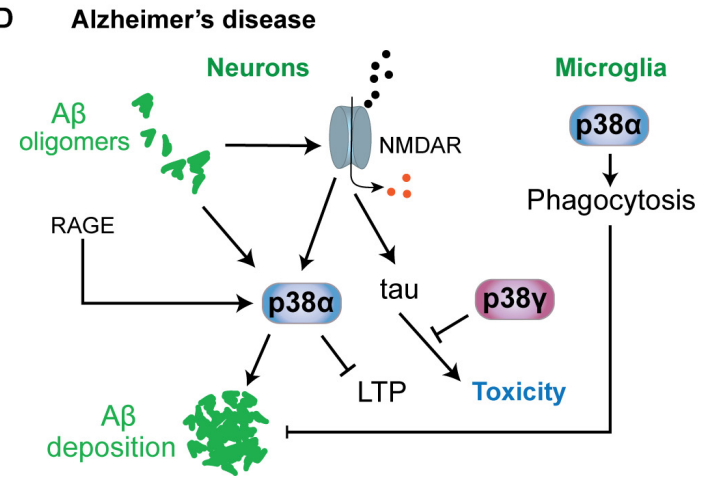

\section{B Pain}

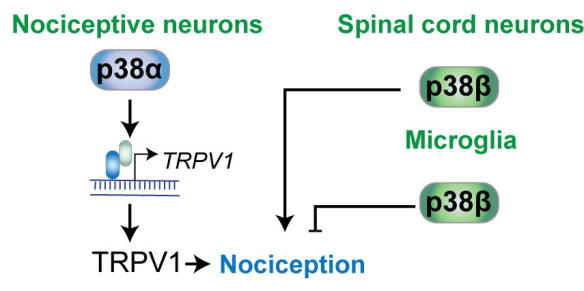

E Parkinson's disease

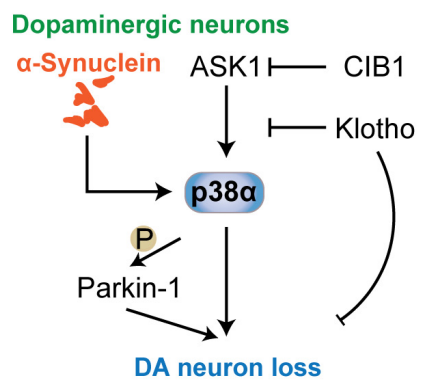

FIGURE 5 | p38 functions in neurological and psychiatric disorders. Mechanisms involving p38 kinases have been described for a variety of neurological and psychiatric disorders. (A) In ischemia or traumatic brain injury, microglial p38 $\alpha$ and p38 $\beta$ contribute to neuroinflammation by targeting MAPKAP kinase-2 (MK2), which promotes the release of proinflammatory cytokines. This mechanism is relevant to other conditions associated with neuroinflammation. Hypoxia is a key stimulus activating p38 $\alpha$ and p38 $\gamma$ in neurons and microglia. (B) In nociception and pain, p38 $\alpha$ in nociceptive neurons promotes the expression of TRPV1 channels that contribute to nociception. $p 38 \beta$ in spinal cord neurons promotes nociception, while microglial p38 $\beta$ has an inhibitory role in nociception. (C) In ALS mouse models based on mutant SOD1, p38 $\alpha$ downstream of ASK1 or MST1 is activated and impairs retrograde transport. (D) In Alzheimer's disease, neuronal p38 $\alpha$ can be activated by a variety of stimuli, including amyloid-beta, RAGE or aberrant glutamate receptor engagement. p38 $\alpha$ activity promotes amyloid aggregation, LTP and neuroinflammation. p38 $\gamma$ inhibits the toxic function of tau in neurons by direct phosphorylation of tau. Interestingly, microglial p38 $\alpha$ reduces amyloid plaque load in models of AD by promoting phagocytic activity. (E) In Parkinson's disease, p38 $\alpha$ in dopaminergic neurons is activated by alpha-synuclein aggregates. p38 $\alpha$ promotes DA neuron loss by direct phosphorylation of Parkin-1. Activity in DA neurons is regulated by ASK1 upstream of p38 $\alpha$. This pathway can be inhibited by survival factors CIB1 and klotho.

neuroprotective and reduces infarct size (Deb et al., 2013). Furthermore, $\mathrm{p} 38 \alpha$ in astrocytes is responsive to hypoxia and astrocyte-specific deletion of p $38 \alpha$ results in lower inflammatory responses, astrocyte recruitment and activation in a model of ischemic stroke (Roy Choudhury et al., 2014).

\section{Traumatic Brain Injury}

p38 $\alpha$ regulates neuroinflammation during traumatic brain injury (Figure 5A). Microglia-specific deletion of $p 38 \alpha$ protects mice in a model of traumatic brain injury or LPS-driven neuroinflammation, lowering activation of microglia, influx of peripheral inflammatory cells, synaptic loss and ameliorates motor impairments (Bachstetter et al., 2013; Morganti et al., 2019). Both the involvement of p38 (foremost p38 $\alpha$ ) in neuroinflammation during TBI is largely based on the function of the p38 $\alpha$-MK2 pathway in cytokine production (Bachstetter et al., 2011, 2013; Morganti et al., 2019). Consistent with the prominent role of $\mathrm{p} 38 \alpha$ in microglia in promoting TBI, inhibition of p38 $\alpha$ and p $38 \beta$ had no effect on injury in a neuronal culture model (Mori et al., 2002). However, this early study did not find an effect of p38 inhibition by p38 $\alpha / \beta$-specific inhibitor SB203580 on the lesion size or motor performance after cerebrocortical injury (Mori et al., 2002). These results indicate cell-type specific contributions of p38 to pathomechanisms in TBI.

\section{Pain}

p38 kinases are involved in nociception (Crown et al., 2008) and neuropathic pain (Svensson et al., 2003; Svensson et al., 2005) (Figure 5B). Antinociceptive action was found in animal models of pain for p38 $\alpha$ inhibitors (Sweitzer et al., 2004; GalanArriero et al., 2015). Mechanism of action of p38 $\alpha$ in nociception are based on regulation of nociceptive channels. Hyperalgesia maintained by p38-mediated TRPV1 levels in sensory neurons (Ji et al., 2002). Other p38 kinases have different functions in nociception than $\mathrm{p} 38 \alpha$. Knockdown of $\mathrm{p} 38 \beta$ within the spinal cord of rats induced hyperalgesia upon spinal cord injury (Svensson et al., 2005). Thus roles of $\mathrm{p} 38 \alpha$ in neurons and for p38 $\beta$ in microglia promote hyperalgesia (Svensson et al., 2005; Fitzsimmons et al., 2010). Other work, however, suggested no involvement of $\mathrm{p} 38 \beta$ in microglial activation (Xing et al., 2013) or even a protective effect of microglial $\mathrm{p} 38 \beta$ from neuropathic pain (Huang et al., 2017). Taken together, mechanisms involving p38 
kinases in nociception are not extensively understood and may depend on the type and time course of pain stimulus. However, overall evidence supports p38 as drug targets in treatment of pain.

\section{Amyotrophic Lateral Sclerosis (ALS)}

Amyotrophic lateral sclerosis, also known as Lou Gehrig's disease, is characterized by specific neurodegeneration within spinal cord, brain stem and cerebrum (Karitzky and Ludolph, 2001; Hammad et al., 2007). Increased activity of stress-activated MAP kinase was detected in cortical neurons of an ALS mouse model (Holasek et al., 2005) while higher p-p38 levels have been detected in human post-mortem ALS brains (Krieger et al., 2003; Sama et al., 2017) and mouse models of ALS (Tortarolo et al., 2003; Holasek et al., 2005; Veglianese et al., 2006; Sama et al., 2017). Activation of p38 in ALS models is associated with activated upstream kinase ASK1 and markers of apoptosis at an early stage (Wengenack et al., 2004) and mammalian sterile-20-like kinase 1 was shown to activate p38 in a SOD1 mouse model (Lee et al., 2013) (Figure 5C). SOD1 mutations are prevalent in ALS (Sau et al., 2007; Farrawell et al., 2015). Inhibition of p38 has protected mutant SOD1 transgenic mice from motor neuron loss (Dewil et al., 2007). Pathogenic SOD1 inhibits axonal transport in motor neurons through activation of $\mathrm{p} 38 \alpha$ downstream of ASK1 (Morfini et al., 2013; Song et al., 2013). Consistently, p38 $\alpha$ inhibition restores retrograde axonal transport in a mouse model of ALS based on expression of mutant SOD1 (Gibbs et al., 2018). Thus, p38 MAP kinase - in particular p38 $\alpha$ - is a promising therapeutic target in SOD1-associated forms of ALS.

Familial ALS can be associated with other mutations than in SOD1 (Farrawell et al., 2015). FUS (fused in osteosarcoma) mutations are linked to familial forms of ALS (Vance et al., 2009). Brain tissue from ALS with FUS mutations displayed increased levels of activated p38 (Sama et al., 2017) and mutant FUS affects axonal transport through p38 activity (Sama et al., 2017). These results suggest that p38 activation and downstream effects are a common mechanism in multiple forms of ALS pathogenesis.

\section{Alzheimer's Disease (AD)}

Alzheimer's disease is the most prevalent form of neurodegenerative dementia and associated with extracellular plaques derived from amyloid- $\beta$ peptide aggregates and intracellular neurofibrillary tangles, which consist mainly of hyperphosphorylated forms of the neuronal tau protein (Ittner and Gotz, 2011; Jin et al., 2011; Bloom, 2014; Ittner and Ittner, 2018). Hence, much research has focussed on amyloid- $\beta$ (A $\beta$ ) and tau as central factors in the diseases (Ittner and Gotz, 2011; Jin et al., 2011; Bloom, 2014).

Increased levels of activated p38 has been found in neurons from AD brains (Sun et al., 2003) and tissue samples from transgenic $\mathrm{AD}$ mouse models based on increased expression of pathogenic amyloid- $\beta$ precursor protein (APP) (Ittner et al., 2014; Criscuolo et al., 2017) (Figure 5D). As such, p38 MAP kinase has been suggested as drug target for $\mathrm{AD}$ treatment (Munoz and Ammit, 2010). A $\beta$ can activate p38 in neurons (Origlia et al., 2008; Li S. et al., 2011), which may be mediated through NMDA receptors because NMDAR blocker MK801 suppressed p38 activation in APP transgenic mice (Ittner et al.,
2014). Furthermore, $\mathrm{p} 38 \alpha$ - was shown to mediate some of the neurotoxic effects of $A \beta$, including suppression of longterm potentiation and neuronal death in culture based both on pharmacological inhibition (Li S. et al., 2011) and neuronspecific deletion of $p 38 \alpha$ (Colie et al., 2017). The latter work also found a reduction in $\mathrm{A} \beta$ deposition in $\mathrm{AD}$ mice crossed with neuron-specific $p 38 \alpha$ knockout mice resulting in lower amyloid plaque burden (Colie et al., 2017). Thus, p38 $\alpha$ appears to regulate both toxic signals downstream of $A \beta$ in neurons as well as $A \beta$ processing and/or deposition. p38 $\alpha$ affects $A \beta$ processing through regulation of protein levels of the APPprocessing protease BACE1 in neurons (Schnoder et al., 2016) and through modulation of autophagy (Alam and Scheper, 2016), both of which increase the amount of extracellular $A \beta$. Results from $\mathrm{p} 38 \alpha$ inhibition in microglia, however, suggest that $\mathrm{p} 38 \alpha$ promotes phagocytosis of amyloid-beta by microglia (Reed-Geaghan et al., 2009). p38 $\alpha$ inhibition also reduces tau pathology, i.e., levels of hyperphosphorylated tau, through increasing autophagy by microglial (Maphis et al., 2016). Thus, p38 $\alpha$ may serve several functions in the context of amyloid and tau pathology. Nevertheless, p38 $\alpha$ has been put forward as key drug target in amyloidosis and associated dementia.

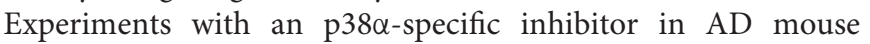
models suggest that this strategy is sufficient to ameliorate A $\beta$-induced cognitive impairment (Alam and Scheper, 2016; Alam et al., 2017).

Receptor for advanced-glycation end products (RAGE) was shown to activate p38, resulting in LTP inihibition (Origlia et al., 2008). Signals through RAGE and p38 may converge on LTP inhibition in AD. Antagonizing RAGE by a dominant negative RAGE receptor in a mouse model of $A D$ prevents $\mathrm{p} 38$ activation in the hippocampus, LTP and memory impairment (Criscuolo et al., 2017).

p38 $\gamma$ MAP kinase has recently been shown to mediate a neuroprotective function in $\mathrm{AD}$ mouse models. $\mathrm{p} 38 \gamma$ differs from other p38 kinases in harboring a C-terminal PDZ interaction motif, which mediates its localization to the post-synapse (Sabio et al., 2005; Ittner et al., 2016). A $\beta$ had previously been shown to mediate its toxic effects through tau (Roberson et al., 2007; Ittner et al., 2010), laying the foundation to the concept of the tau-dependent 'amyloid cascade', which links both key factors in a central toxic signaling pathway (Ittner and Gotz, 2011). Mechanistically, tau, a predominantly axonal protein in neurons (Harada et al., 1994), is partially localizing to dendrites where it interacts with post-synaptic scaffolding factor PSD95 downstream of NMDA receptors (Ittner et al., 2010). This interaction is required to mediate toxic effects of $A \beta$ in neurons and in mice (Ittner and Ittner, 2018). p38 $\gamma$ interacts with PSD-95 and was shown to phosphorylate tau predominantly on Threonine-205 in this complex. This phosphorylation event results in disruption of the PSD-95-tau complex and inhibits toxic signals of $A \beta$ (Ittner et al., 2016). Thus, this mechanism involving post-synaptic p38 $\gamma$ showed a novel neuroprotective function for this p38 kinase and revealed an unprecedented function of tau phosphorylation in inhibiting a pivotal toxicity mechanism of A $\beta$ (Ittner and Ittner, 2018; Ittner et al., 2020). Interestingly, neither $\mathrm{p} 38 \alpha, \mathrm{p} 38 \beta$ nor $\mathrm{p} 38 \delta$ were able to mediate 
the same neuroprotective tau phosphorylation and inhibition of $\mathrm{A} \beta$ toxicity as $\mathrm{p} 38 \gamma$ (Ittner et al., 2016), likely due to the distinct localization of p38 $\gamma$ in neurons at post-synapses (Sabio et al., 2005; Ittner et al., 2016).

\section{Parkinson's Disease (PD)}

Loss of dopaminergic (DA) neurons is a hallmark of $\mathrm{PD}$ (Antony et al., 2013). p38 activity was found in DA neurons in the substantia nigra pars compacta in PD patient samples and PD mouse models (Ferrer et al., 2001; Karunakaran et al., 2008; Ray et al., 2015) (Figure 5E). Activation of p38 induced nuclear localization of p53 in DA neurons in a MPTP model whereas inhibition of p38 protects DA neurons (Karunakaran et al., 2008). In addition, p38 controls DA neuron survival and resistance to oxidative and inflammatory stress (Jeohn et al., 2002; Brobey et al., 2015a,b). p38 activity downstream of ASK1 is inhibited by klotho (Brobey et al., 2015b), a factor that prevents premature aging and striatal DA neuron loss (Kosakai et al., 2011). A transgenic PD mouse model based on mutant $\alpha$-synuclein expression presented with activation of $\mathrm{p} 38$, which phosphorylates Parkin-1 and promotes mitochondrial dysfunction and DA neuron loss (Chen et al., 2018) (Figure 5E).

Though loss of DA neurons is the most prominent feature, neuronal dysfunction and degermation is not strictly limited to DA neurons. Serotonergic loss contributes to symptoms and neuropsychiatric changes in PD (Politis and Niccolini, 2015; Maillet et al., 2016; Schindlbeck and Eidelberg, 2018). This is particularly true for $\mathrm{PD}$ associated with mutations in the $\alpha$-synuclein-encoding SNCA gene (Wilson et al., 2019). Bruchas et al. (2011) indicate that $\mathrm{p} 38 \alpha$ regulates serotonin release and reuptake through serotonin transporter cell surface trafficking (Ehrich et al., 2015). This function of p38 $\alpha$ may be important in serotonergic dysfunction in PD, making $\mathrm{p} 38 \alpha$ a potential drug target for serotonin-associated symptoms of PD.

\section{Huntington's Disease}

Huntingtin (Htt) poly-glutamine expansion is a hallmark of Huntington's disease (Scherzinger et al., 1997). Activated p38 was found in multiple HD models (Gianfriddo et al., 2004; Rangone et al., 2004; Wang et al., 2010). Poly-glutamine Htt activates p38 MAPK kinase (Taylor et al., 2013), yet conflicting evidence suggests mutant $\mathrm{Htt}$ activates ERK MAP kinase rather than JNK or p38 MAP kinases (Apostol et al., 2006). However, MAP kinase phosphatase-1 (MKP-1), which specifically deactivates p38 and JNK has a protective function in striatal neurons of a Huntington's model (Taylor et al., 2013), suggesting that activity of p38 contributes to toxic signals induced by mutant Htt. Consistently, inhibition of $\mathrm{p} 38 \alpha$ and $\mathrm{p} 38 \beta$ protects from neurotoxicity induced by polyglutamic (Tsirigotis et al., 2008).

\section{Spinal Cord Injury (SCl)}

p38 $\alpha$ plays a central role in inflammatory process in SCI through translation and stabilization of inflammatory mRNAs. For example, MAPKAPK2 or MK2, the downstream kinase of $\mathrm{p} 38$, interferes with the interaction between the binding factors and AU-rich elements (AREs) which in turn stabilizes TNF- $\alpha$ mRNA [reviewed in Dean et al. (2004)]. In addition, p38/MK2-induced mRNA stabilization also controls the expression of IL-6 which triggers activation and infiltration of leukocytes in SCI (Zhao et al., 2008). Thus, $\mathrm{p} 38 \alpha$ can initiate major SCI-related proinflammatory cytokines in the post-traumatic inflammation. Extensive research utilizing various $\mathrm{p} 38 \alpha$ inhibitors and genetically modified mice that $\mathrm{p} 38 \alpha$ plays an important role in various stages of inflammatory process [reviewed in Kasuya et al. (2018)]. Increased spatial activation of p38 $\alpha$ was observed in neurons, oligodendrocytes, microglia/macrophages, infiltrated neutrophils, and reactive astrocytes which formed a glial scar following SCI [reviewed in Kasuya et al. (2018)]. Activation of $\mathrm{p} 38 \alpha$ in activated microglia/macrophages in SCI models induces iNOS expression, contributing to loss of neuronal cells (Xu et al., 2006). IL-1 $\beta$ and p38 phosphorylation was detectable prior to neuronal apoptosis, and IL-1 receptor antagonist and p38 inhibition, suppressed p38 phosphorylation and neuronal apoptosis, indicating a critical involvement of IL- $1 \beta / \mathrm{p} 38 \alpha$ signaling axis in neuronal apoptosis post-SCI (Wang et al., 2005).

\section{CONCLUSION AND FUTURE QUESTIONS}

The last two decades of research have seen p38 kinases move from stress-activated kinases to signal transducers in multiple physiologic and pathophysiologic functions. This is particularly true for cells of the central nervous system, where specific functions of p38 kinases were revealed in all major cell types contributing to brain physiology, cognition and behavior as well as disease processes. These discoveries are attributable to the development of more specific genetic and pharmacologic tools that are able to dissect functions of individual kinases. Development of these tools has made answering the following outstanding questions on p38 in the CNS feasible:

- What is the brain region- and cell type-specific expression of individual p38 kinases?

- In tissue with co-expression of p38 isoforms, are the kinases functionally distinct or is there redundancy?

- Does p38a regulate broadly regulate biogenic amine neurotransmission through parallel mechanisms? Can these mechanisms be targeted to treat disorders associated with specific neurotransmitter systems?

- What distinct roles do p38 $\beta$, p38 $\gamma$ and $\mathrm{p} 38 \delta$ have in behavior and cognition?

- What is the therapeutic potential of $\mathrm{p} 38 \alpha$ inhibition for treatment of neurodegeneration, addiction, and anxiety? What are the mechanisms of action? Could drugs target the role of p38 $\alpha$ in neuroinflammation, autophagy, regulating synaptic plasticity, mediating axonal transport?

- What is the therapeutic potential of p38 $\gamma$ for conditions of excitotoxicity and neurodegeneration?

- What is the therapeutic potential of p38 $\beta$ in motor neuron disease/ALS targeting its function in microglia? 
Investigating mechanisms involving p38 kinases provides new molecular insights into brain physiology and opens new therapeutic avenues to understand and target neurological disorders. From the basis of roles in inflammation by initial discoveries of p38, a more diversified picture of p38 kinase functions is still emerging.

\section{AUTHOR CONTRIBUTIONS}

AI, PA, EP, and KS wrote first draft of the manuscript. PA edited sections of cell-type specific functions of $\mathrm{p} 38$ and contributed to preparation of figures. EP edited sections of MAP kinase signaling cascade and prepared figures. KS wrote section of disease-related functions of p38 in CNS. AT and HA edited the manuscript draft and contributed to figure preparation. AI designed concept and outline of the manuscript.

\section{REFERENCES}

Aarts, M., Liu, Y., Liu, L., Besshoh, S., Arundine, M., Gurd, J. W., et al. (2002). Treatment of ischemic brain damage by perturbing NMDA receptor- PSD-95 protein interactions. Science 298, 846-850. doi: 10.1126/science.1072873

Abraham, A. D., Fontaine, H. M., Song, A. J., Andrews, M. M., Baird, M. A., Kieffer, B. L., et al. (2018). kappa-Opioid Receptor Activation in Dopamine Neurons Disrupts Behavioral Inhibition. Neuropsychopharmacology 43, 362-372. doi: 10.1038/npp.2017.133

Ackerley, S., Grierson, A. J., Banner, S., Perkinton, M. S., Brownlees, J., Byers, H. L., et al. (2004). p38alpha stress-activated protein kinase phosphorylates neurofilaments and is associated with neurofilament pathology in amyotrophic lateral sclerosis. Mol. Cell. Neurosci. 26, 354-364. doi: 10.1016/j.mcn.2004. 02.009

Adams, R. H., Porras, A., Alonso, G., Jones, M., Vintersten, K., Panelli, S., et al. (2000). Essential role of p38alpha MAP kinase in placental but not embryonic cardiovascular development. Mol. Cell. 6, 109-116.

Ahn, Y. M., Oh, S. W., Kang, U. G., Park, J., and Kim, Y. S. (2000). An N-methyl-Daspartate antagonist, MK-801, preferentially reduces electroconvulsive shockinduced phosphorylation of p38 mitogen-activated protein kinase in the rat hippocampus. Neurosci. Lett. 296, 101-104. doi: 10.1016/s0304-3940(00) 01632-3

Alam, J., Blackburn, K., and Patrick, D. (2017). Neflamapimod: clinical Phase 2b-Ready Oral Small Molecule Inhibitor of p38alpha to Reverse Synaptic Dysfunction in Early Alzheimer's Disease. J. Prev. Alzheimers Dis. 4, 273-278. doi: 10.14283 /jpad.2017.41

Alam, J., and Scheper, W. (2016). Targeting neuronal MAPK14/p38alpha activity to modulate autophagy in the Alzheimer disease brain. Autophagy 12, 2516-2520. doi: 10.1080/15548627.2016.1238555

Allen, M. P., Linseman, D. A., Udo, H., Xu, M., Schaack, J. B., Varnum, B., et al. (2002). Novel mechanism for gonadotropin-releasing hormone neuronal migration involving Gas6/Ark signaling to p38 mitogen-activated protein kinase. Mol. Cell. Biol. 22, 599-613. doi: 10.1128/mcb.22.2.599-613.2002

Alonso, G., Ambrosino, C., Jones, M., and Nebreda, A. R. (2000). Differential activation of p38 mitogen-activated protein kinase isoforms depending on signal strength. J. Biol. Chem. 275, 40641-40648. doi: 10.1074/jbc.M007835200

Amantini, C., Mosca, M., Nabissi, M., Lucciarini, R., Caprodossi, S., Arcella, A., et al. (2007). Capsaicin-induced apoptosis of glioma cells is mediated by TRPV1 vanilloid receptor and requires p38 MAPK activation. J. Neurochem. 102, 977-990. doi: 10.1111/j.1471-4159.2007.04582.x

Andaloussi, E., Mager, I., Breakefield, X. O., and Wood, M. J. (2013). Extracellular vesicles: biology and emerging therapeutic opportunities. Nat. Rev. Drug Discov. 12, 347-357. doi: 10.1038/nrd3978

Antonescu, C. N., Huang, C., Niu, W., Liu, Z., Eyers, P. A., Heidenreich, K. A., et al. (2005). Reduction of insulin-stimulated glucose uptake in L6 myotubes
All authors contributed to the article and approved the submitted version.

\section{FUNDING}

This work was supported by funding from the National Health and Medical Research Council (grant\# 1143978), the Australian Research Council (grant\# DP200102396) and Macquarie University. AI is a National Health and Medical Research Council Emerging Leadership fellow (grant\# 1176628).

\section{ACKNOWLEDGMENTS}

The authors would like to thank Dr. Yee Lian Chew for critical reading of the manuscript.

by the protein kinase inhibitor SB203580 is independent of p38MAPK activity. Endocrinology 146, 3773-3781. doi: 10.1210/en.2005-0404

Antony, P. M., Diederich, N. J., Kruger, R., and Balling, R. (2013). The hallmarks of Parkinson's disease. FEBS J. 280, 5981-5993. doi: 10.1111/febs.12335

Aouadi, M., Bost, F., Caron, L., Laurent, K., Le Marchand Brustel, Y., and Binetruy, B. (2006). p38 mitogen-activated protein kinase activity commits embryonic stem cells to either neurogenesis or cardiomyogenesis. Stem Cells 24, 13991406. doi: 10.1634/stemcells.2005-0398

Apostol, B. L., Illes, K., Pallos, J., Bodai, L., Wu, J., Strand, A., et al. (2006). Mutant huntingtin alters MAPK signaling pathways in PC12 and striatal cells: ERK1/2 protects against mutant huntingtin-associated toxicity. Hum. Mol. Genet. 15, 273-285. doi: 10.1093/hmg/ddi443

Avitzour, M., Diskin, R., Raboy, B., Askari, N., Engelberg, D., and Livnah, O. (2007). Intrinsically active variants of all human p38 isoforms. FEBS J. 274, 963-975. doi: 10.1111/j.1742-4658.2007.05644.x

Avruch, J. (2007). MAP kinase pathways: the first twenty years. Biochim. Biophys. Acta 1773, 1150-1160. doi: 10.1016/j.bbamcr.2006.11.006

Babiec, W. E., Guglietta, R., Jami, S. A., Morishita, W., Malenka, R. C., and O’Dell, T. J. (2014). Ionotropic NMDA receptor signaling is required for the induction of long-term depression in the mouse hippocampal CA1 region. J. Neurosci. 34, 5285-5290. doi: 10.1523/JNEUROSCI.5419-13.2014

Bachstetter, A. D., Rowe, R. K., Kaneko, M., Goulding, D., Lifshitz, J., and Van Eldik, L. J. (2013). The p38alpha MAPK regulates microglial responsiveness to diffuse traumatic brain injury. J. Neurosci. 33, 6143-6153. doi: 10.1523/ JNEUROSCI.5399-12.2013

Bachstetter, A. D., Xing, B., de Almeida, L., Dimayuga, E. R., Watterson, D. M., and Van Eldik, L. J. (2011). Microglial p38alpha MAPK is a key regulator of proinflammatory cytokine up-regulation induced by toll-like receptor (TLR) ligands or beta-amyloid (Abeta). J. Neuroinflam. 8:79. doi: 10.1186/17422094-8-79

Baganz, N. L., Lindler, K. M., Zhu, C. B., Smith, J. T., Robson, M. J., Iwamoto, H., et al. (2015). A requirement of serotonergic p38alpha mitogen-activated protein kinase for peripheral immune system activation of CNS serotonin uptake and serotonin-linked behaviors. Transl. Psychiatry 5:e671. doi: 10.1038/tp.2015.168

Bailey, C. H., Kandel, E. R., and Harris, K. M. (2015). Structural Components of Synaptic Plasticity and Memory Consolidation. Cold Spring Harb. Perspect. Biol. 7:a021758. doi: 10.1101/cshperspect.a021758

Barone, F. C., Irving, E. A., Ray, A. M., Lee, J. C., Kassis, S., Kumar, S., et al. (2001). SB 239063, a second-generation p38 mitogen-activated protein kinase inhibitor, reduces brain injury and neurological deficits in cerebral focal ischemia. J. Pharmacol. Exp. Ther. 296, 312-321.

Bazuine, M., Carlotti, F., Tafrechi, R. S., Hoeben, R. C., and Maassen, J. A. (2004). Mitogen-activated protein kinase (MAPK) phosphatase- 1 and -4 attenuate p38 MAPK during dexamethasone-induced insulin resistance in 3T3-L1 adipocytes. Mol. Endocrinol. 18, 1697-1707. doi: 10.1210/me.2003-0213 
Beardmore, V. A., Hinton, H. J., Eftychi, C., Apostolaki, M., Armaka, M., Darragh, J., et al. (2005). Generation and characterization of p38beta (MAPK11) genetargeted mice. Mol. Cell. Biol. 25, 10454-10464. doi: 10.1128/MCB.25.23.1045410464.2005

Beardsley, P. M., Howard, J. L., Shelton, K. L., and Carroll, F. I. (2005). Differential effects of the novel kappa opioid receptor antagonist, JDTic, on reinstatement of cocaine-seeking induced by footshock stressors vs cocaine primes and its antidepressant-like effects in rats. Psychopharmacology 183, 118-126. doi: 10. 1007/s00213-005-0167-4

Benson, D. L., and Tanaka, H. (1998). N-cadherin redistribution during synaptogenesis in hippocampal neurons. J. Neurosci. 18, 6892-6904.

Bhat, N. R., Zhang, P., and Mohanty, S. B. (2007). p38 MAP kinase regulation of oligodendrocyte differentiation with CREB as a potential target. Neurochem. Res. 32, 293-302. doi: 10.1007/s11064-006-9274-9

Bianco, F., Perrotta, C., Novellino, L., Francolini, M., Riganti, L., Menna, E., et al. (2009). Acid sphingomyelinase activity triggers microparticle release from glial cells. EMBO J. 28, 1043-1054. doi: 10.1038/emboj.2009.45

Bloom, G. S. (2014). Amyloid-beta and tau: the trigger and bullet in Alzheimer disease pathogenesis. JAMA Neurol. 71, 505-508. doi: 10.1001/jamaneurol. 2013.5847

Bolis, A., Coviello, S., Visigalli, I., Taveggia, C., Bachi, A., Chishti, A. H., et al. (2009). Dlg1, Sec8, and Mtmr2 regulate membrane homeostasis in Schwann cell myelination. J. Neurosci. 29, 8858-8870. doi: 10.1523/JNEUROSCI.142309.2009

Borisova, M. E., Voigt, A., Tollenaere, M. A. X., Sahu, S. K., Juretschke, T., Kreim, N., et al. (2018). p38-MK2 signaling axis regulates RNA metabolism after UVlight-induced DNA damage. Nat. Commun. 9:1017. doi: 10.1038/s41467-01803417-3

Borsch-Haubold, A. G., Pasquet, S., and Watson, S. P. (1998). Direct inhibition of cyclooxygenase- 1 and -2 by the kinase inhibitors SB 203580 and PD 98059. SB 203580 also inhibits thromboxane synthase. J. Biol. Chem. 273, 28766-28772. doi: $10.1074 /$ jbc.273.44.28766

Bosco, F., Valente, P., Milanese, M., Piccini, A., Messa, M., Bonanno, G., et al. (2018). Altered Intracellular Calcium Homeostasis Underlying Enhanced Glutamatergic Transmission in Striatal-Enriched Tyrosine Phosphatase (STEP) Knockout Mice. Mol. Neurobiol. 55, 8084-8102. doi: 10.1007/s12035-0180980-5

Boulton, T. G., Nye, S. H., Robbins, D. J., Ip, N. Y., Radziejewska, E., Morgenbesser, S. D., et al. (1991). ERKs: a family of protein-serine/threonine kinases that are activated and tyrosine phosphorylated in response to insulin and NGF. Cell 65, 663-675.

Brancho, D., Tanaka, N., Jaeschke, A., Ventura, J. J., Kelkar, N., Tanaka, Y., et al. (2003). Mechanism of p38 MAP kinase activation in vivo. Genes Dev. 17, 1969-1978. doi: 10.1101/gad.1107303

Brobey, R. K., Dheghani, M., Foster, P. P., Kuro, O. M., and Rosenblatt, K. P. (2015a). Klotho Regulates 14-3-3zeta Monomerization and Binding to the ASK1 Signaling Complex in Response to Oxidative Stress. PLoS One 10:e0141968. doi: 10.1371/journal.pone.0141968

Brobey, R. K., German, D., Sonsalla, P. K., Gurnani, P., Pastor, J., Hsieh, C. C., et al. (2015b). Klotho Protects Dopaminergic Neuron Oxidant-Induced Degeneration by Modulating ASK1 and p38 MAPK Signaling Pathways. PLoS One 10:e0139914. doi: 10.1371/journal.pone.0139914

Brown, T. C., Tran, I. C., Backos, D. S., and Esteban, J. A. (2005). NMDA receptordependent activation of the small GTPase Rab5 drives the removal of synaptic AMPA receptors during hippocampal LTD. Neuron 45, 81-94. doi: 10.1016/j. neuron.2004.12.023

Bruchas, M. R., Land, B. B., Aita, M., Xu, M., Barot, S. K., Li, S., et al. (2007). Stressinduced p38 mitogen-activated protein kinase activation mediates kappaopioid-dependent dysphoria. J. Neurosci. 27, 11614-11623. doi: 10.1523/ JNEUROSCI.3769-07.2007

Bruchas, M. R., Schindler, A. G., Shankar, H., Messinger, D. I., Miyatake, M., Land, B. B., et al. (2011). Selective p38alpha MAPK deletion in serotonergic neurons produces stress resilience in models of depression and addiction. Neuron 71, 498-511. doi: 10.1016/j.neuron.2011.06.011

Bu, X., Huang, P., Qi, Z., Zhang, N., Han, S., Fang, L., et al. (2007). Cell type-specific activation of 38 MAPK in the brain regions of hypoxic preconditioned mice. Neurochem. Int. 51, 459-466. doi: 10.1016/j.neuint.2007.04.028

Bussi, C., Peralta Ramos, J. M., Arroyo, D. S., Gaviglio, E. A., Gallea, J. I., Wang, J. M., et al. (2017). Autophagy down regulates pro-inflammatory mediators in BV2 microglial cells and rescues both LPS and alpha-synuclein induced neuronal cell death. Sci. Rep. 7:43153. doi: 10.1038/srep43153

Cai, W., Rudolph, J. L., Sengoku, T., and Andres, D. A. (2012). Rit GTPase regulates a p38 MAPK-dependent neuronal survival pathway. Neurosci. Lett. 531, 125-130. doi: 10.1016/j.neulet.2012.10.036

Cao, J., Semenova, M. M., Solovyan, V. T., Han, J., Coffey, E. T., and Courtney, M. J. (2004). Distinct requirements for p38alpha and c-Jun N-terminal kinase stress-activated protein kinases in different forms of apoptotic neuronal death. J. Biol. Chem. 279, 35903-35913. doi: 10.1074/jbc.M402353200

Cao, J., Viholainen, J. I., Dart, C., Warwick, H. K., Leyland, M. L., and Courtney, M. J. (2005). The PSD95-nNOS interface: a target for inhibition of excitotoxic p38 stress-activated protein kinase activation and cell death. J. Cell Biol. 168, 117-126. doi: 10.1083/jcb.200407024

Casar, B., Sanz-Moreno, V., Yazicioglu, M. N., Rodriguez, J., Berciano, M. T., Lafarga, M., et al. (2007). Mxi2 promotes stimulus-independent ERK nuclear translocation. EMBO J. 26, 635-646. doi: 10.1038/sj.emboj.7601523

Castillo, J., Leira, R., Garcia, M. M., Serena, J., Blanco, M., and Davalos, A. (2004). Blood pressure decrease during the acute phase of ischemic stroke is associated with brain injury and poor stroke outcome. Stroke 35, 520-526. doi: 10.1161/ 01.STR.0000109769.22917.B0

Caunt, C. J., and Keyse, S. M. (2013). Dual-specificity MAP kinase phosphatases (MKPs): shaping the outcome of MAP kinase signalling. FEBS J. 280, 489-504. doi: 10.1111/j.1742-4658.2012.08716.x

Cavallini, A., Brewerton, S., Bell, A., Sargent, S., Glover, S., Hardy, C., et al. (2013). An unbiased approach to identifying tau kinases that phosphorylate tau at sites associated with Alzheimer disease. J. Biol. Chem. 288, 23331-23347. doi: 10.1074/jbc.M113.463984

Chamorro, A., Dirnagl, U., Urra, X., and Planas, A. M. (2016). Neuroprotection in acute stroke: targeting excitotoxicity, oxidative and nitrosative stress, and inflammation. Lancet Neurol. 15, 869-881. doi: 10.1016/S1474-4422(16) 00114-9

Che, Y., Piao, C. S., Han, P. L., and Lee, J. K. (2001a). Delayed induction of alpha B-crystallin in activated glia cells of hippocampus in kainic acid-treated mouse brain. J. Neurosci. Res. 65, 425-431. doi: 10.1002/jnr.1170

Che, Y., Yu, Y. M., Han, P. L., and Lee, J. K. (2001b). Delayed induction of p38 MAPKs in reactive astrocytes in the brain of mice after KA-induced seizure. Brain Res. Mol. Brain Res. 94, 157-165. doi: 10.1016/s0169-328x(01) 00233-9

Chen, J., Ren, Y., Gui, C., Zhao, M., Wu, X., Mao, K., et al. (2018). Phosphorylation of Parkin at serine 131 by $\mathrm{p} 38$ MAPK promotes mitochondrial dysfunction and neuronal death in mutant A53T alpha-synuclein model of Parkinson's disease. Cell Death Dis. 9:700. doi: 10.1038/s41419-018-0722-7

Chen, X., Lin, R., Chang, L., Xu, S., Wei, X., Zhang, J., et al. (2013). Enhancement of long-term depression by soluble amyloid beta protein in rat hippocampus is mediated by metabotropic glutamate receptor and involves activation of p38MAPK, STEP and caspase-3. Neuroscience 253, 435-443. doi: 10.1016/j. neuroscience.2013.08.054

Cheung, P. Y., Zhang, Y., Long, J., Lin, S., Zhang, M., Jiang, Y., et al. (2004). p150(Glued), Dynein, and microtubules are specifically required for activation of MKK3/6 and p38 MAPKs. J. Biol. Chem. 279, 45308-45311. doi: 10.1074/jbc. C400333200

Chittajallu, R., Vignes, M., Dev, K. K., Barnes, J. M., Collingridge, G. L., and Henley, J. M. (1996). Regulation of glutamate release by presynaptic kainate receptors in the hippocampus. Nature 379, 78-81. doi: 10.1038/379078a0

Cho, S. S. L., Han, J., James, S. J., Png, C. W., Weerasooriya, M., Alonso, S., et al. (2017). Dual-Specificity Phosphatase 12 Targets p38 MAP Kinase to Regulate Macrophage Response to Intracellular Bacterial Infection. Front. Immunol. 8:1259. doi: 10.3389/fimmu.2017.01259

Chung, S. H., Biswas, S., Selvaraj, V., Liu, X. B., Sohn, J., Jiang, P., et al. (2015). The p38alpha mitogen-activated protein kinase is a key regulator of myelination and remyelination in the CNS. Cell Death Dis. 6:e1748. doi: 10.1038/cddis.2015.119

Chung, S. H., Biswas, S., Sohn, J., Jiang, P., Dehghan, S., Marzban, H., et al. (2018). The p38alpha MAPK Deletion in Oligodendroglia does not Attenuate Myelination Defects in a Mouse Model of Periventricular Leukomalacia. Neuroscience 386, 175-181. doi: 10.1016/j.neuroscience.2018.06.037

Clark, A. K., Staniland, A. A., Marchand, F., Kaan, T. K., McMahon, S. B., and Malcangio, M. (2010). P2X7-dependent release of interleukin-1beta and nociception in the spinal cord following lipopolysaccharide. J. Neurosci. 30, 573-582. doi: 10.1523/JNEUROSCI.3295-09.2010 
Clement, S. L., Scheckel, C., Stoecklin, G., and Lykke-Andersen, J. (2011). Phosphorylation of tristetraprolin by MK2 impairs AU-rich element mRNA decay by preventing deadenylase recruitment. Mol. Cell. Biol. 31, 256-266. doi: 10.1128/MCB.00717-10

Colie, S., Sarroca, S., Palenzuela, R., Garcia, I., Matheu, A., Corpas, R., et al. (2017). Neuronal p38alpha mediates synaptic and cognitive dysfunction in an Alzheimer's mouse model by controlling beta-amyloid production. Sci. Rep. 7:45306. doi: 10.1038/srep45306

Conrad, P. W., Rust, R. T., Han, J., Millhorn, D. E., and Beitner-Johnson, D. (1999). Selective activation of p38alpha and p38gamma by hypoxia. Role in regulation of cyclin D1 by hypoxia in PC12 cells. J. Biol. Chem. 274, 23570-23576. doi: $10.1074 /$ jbc. 274.33 .23570

Consortium, G. T. (2015). Human genomics. The Genotype-Tissue Expression (GTEx) pilot analysis: multitissue gene regulation in humans. Science 348, 648-660. doi: 10.1126/science.1262110

Coogan, A. N., O'Neill, L. A., and O'Connor, J. J. (1999). The P38 mitogenactivated protein kinase inhibitor SB203580 antagonizes the inhibitory effects of interleukin-1beta on long-term potentiation in the rat dentate gyrus in vitro. Neuroscience 93, 57-69. doi: 10.1016/s0306-4522(99)00100- 1

Cortez, I., Bulavin, D. V., Wu, P., McGrath, E. L., Cunningham, K. A., Wakamiya, M., et al. (2017). Aged dominant negative p38alpha MAPK mice are resistant to age-dependent decline in adult-neurogenesis and context discrimination fear conditioning. Behav. Brain Res. 322(Pt B), 212-222. doi: 10.1016/j.bbr.2016. 10.023

Cremer, C. M., Palomero-Gallagher, N., Bidmon, H. J., Schleicher, A., Speckmann, E. J., and Zilles, K. (2009). Pentylenetetrazole-induced seizures affect binding site densities for GABA, glutamate and adenosine receptors in the rat brain. Neuroscience 163, 490-499. doi: 10.1016/j.neuroscience.2009.03.068

Criscuolo, C., Fontebasso, V., Middei, S., Stazi, M., Ammassari-Teule, M., Yan, S. S., et al. (2017). Entorhinal Cortex dysfunction can be rescued by inhibition of microglial RAGE in an Alzheimer's disease mouse model. Sci. Rep. 7:42370. doi: $10.1038 /$ srep42370

Crown, E. D., Gwak, Y. S., Ye, Z., Johnson, K. M., and Hulsebosch, C. E. (2008). Activation of p 38 MAP kinase is involved in central neuropathic pain following spinal cord injury. Exp. Neurol. 213, 257-267. doi: 10.1016/j.expneurol.2008. 05.025

Cuadrado, A., and Nebreda, A. R. (2010). Mechanisms and functions of p38 MAPK signalling. Biochem. J. 429, 403-417. doi: 10.1042/BJ20100323

Cuenda, A., Rouse, J., Doza, Y. N., Meier, R., Cohen, P., Gallagher, T. F., et al. (1995). SB 203580 is a specific inhibitor of a MAP kinase homologue which is stimulated by cellular stresses and interleukin-1. FEBS Lett. 364, 229-233. doi: 10.1016/0014-5793(95)00357-f

Cuenda, A., and Rousseau, S. (2007). p38 MAP-kinases pathway regulation, function and role in human diseases. Biochim. Biophys. Acta 1773, 1358-1375. doi: 10.1016/j.bbamcr.2007.03.010

Culbert, A. A., Skaper, S. D., Howlett, D. R., Evans, N. A., Facci, L., Soden, P. E., et al. (2006). MAPK-activated protein kinase 2 deficiency in microglia inhibits pro-inflammatory mediator release and resultant neurotoxicity. Relevance to neuroinflammation in a transgenic mouse model of Alzheimer disease. J. Biol. Chem. 281, 23658-23667. doi: 10.1074/jbc.M513646200

Da Silva, J., Pierrat, B., Mary, J. L., and Lesslauer, W. (1997). Blockade of p38 mitogen-activated protein kinase pathway inhibits inducible nitric-oxide synthase expression in mouse astrocytes. J. Biol. Chem. 272, 28373-28380. doi: $10.1074 / j b c .272 .45 .28373$

Dai, H. L., Hu, W. Y., Jiang, L. H., Li, L., Gaung, X. F., and Xiao, Z. C. (2016). p38 MAPK Inhibition Improves Synaptic Plasticity and Memory in Angiotensin II-dependent Hypertensive Mice. Sci. Rep. 6:27600. doi: 10.1038/srep27600

Damjanov, N., Kauffman, R. S., and Spencer-Green, G. T. (2009). Efficacy, pharmacodynamics, and safety of VX-702, a novel p38 MAPK inhibitor, in rheumatoid arthritis: results of two randomized, double-blind, placebocontrolled clinical studies. Arthritis Rheum. 60, 1232-1241. doi: 10.1002/art. 24485

Dapper, J. D., Crish, S. D., Pang, I. H., and Calkins, D. J. (2013). Proximal inhibition of p38 MAPK stress signaling prevents distal axonopathy. Neurobiol. Dis. 59, 26-37. doi: 10.1016/j.nbd.2013.07.001

De Vos, K., Severin, F., Van Herreweghe, F., Vancompernolle, K., Goossens, V., Hyman, A., et al. (2000). Tumor necrosis factor induces hyperphosphorylation of kinesin light chain and inhibits kinesin-mediated transport of mitochondria. J. Cell Biol. 149, 1207-1214. doi: 10.1083/jcb.149.6.1207
Dean, J. L., Sully, G., Clark, A. R., and Saklatvala, J. (2004). The involvement of AU-rich element-binding proteins in p38 mitogen-activated protein kinase pathway-mediated mRNA stabilisation. Cell. Signal. 16, 1113-1121. doi: 10. 1016/j.cellsig.2004.04.006

Deb, I., Manhas, N., Poddar, R., Rajagopal, S., Allan, A. M., Lombroso, P. J., et al. (2013). Neuroprotective role of a brain-enriched tyrosine phosphatase, STEP, in focal cerebral ischemia. J. Neurosci. 33, 17814-17826. doi: 10.1523/ JNEUROSCI.2346-12.2013

del Barco Barrantes, I., Coya, J. M., Maina, F., Arthur, J. S., and Nebreda, A. R. (2011). Genetic analysis of specific and redundant roles for p38alpha and p38beta MAPKs during mouse development. Proc. Natl. Acad. Sci. U.S.A. 108, 12764-12769. doi: 10.1073/pnas.1015013108

Dewachter, I., Reverse, D., Caluwaerts, N., Ris, L., Kuiperi, C., Van den Haute, C., et al. (2002). Neuronal deficiency of presenilin 1 inhibits amyloid plaque formation and corrects hippocampal long-term potentiation but not a cognitive defect of amyloid precursor protein [V717I] transgenic mice. J. Neurosci. 22, 3445-3453.

Dewil, M., dela Cruz, V. F., Van Den Bosch, L., and Robberecht, W. (2007). Inhibition of $\mathrm{p} 38$ mitogen activated protein kinase activation and mutant SOD1(G93A)-induced motor neuron death. Neurobiol. Dis. 26, 332-341. doi: 10.1016/j.nbd.2006.12.023

Diskin, R., Askari, N., Capone, R., Engelberg, D., and Livnah, O. (2004). Active mutants of the human p38alpha mitogen-activated protein kinase. J. Biol. Chem. 279, 47040-47049. doi: 10.1074/jbc.M404595200

Dusik, V., Senthilan, P. R., Mentzel, B., Hartlieb, H., Wulbeck, C., Yoshii, T., et al. (2014). The MAP kinase p38 is part of Drosophila melanogaster's circadian clock. PLoS Genet. 10:e1004565. doi: 10.1371/journal.pgen.1004565

Eales, K. L., Palygin, O., O’Loughlin, T., Rasooli-Nejad, S., Gaestel, M., Muller, J., et al. (2014). The MK2/3 cascade regulates AMPAR trafficking and cognitive flexibility. Nat. Commun. 5:4701. doi: 10.1038/ncomms5701

Ehrich, J. M., Messinger, D. I., Knakal, C. R., Kuhar, J. R., Schattauer, S. S., Bruchas, M. R., et al. (2015). Kappa Opioid Receptor-Induced Aversion Requires p38 MAPK Activation in VTA Dopamine Neurons. J. Neurosci. 35, 12917-12931. doi: 10.1523/JNEUROSCI.2444-15.2015

Emami, H., Vucic, E., Subramanian, S., Abdelbaky, A., Fayad, Z. A., Du, S., et al. (2015). The effect of BMS-582949, a P38 mitogen-activated protein kinase (P38 MAPK) inhibitor on arterial inflammation: a multicenter FDG-PET trial. Atherosclerosis 240, 490-496. doi: 10.1016/j.atherosclerosis.2015.03.039

Emerling, B. M., Platanias, L. C., Black, E., Nebreda, A. R., Davis, R. J., and Chandel, N. S. (2005). Mitochondrial reactive oxygen species activation of p38 mitogenactivated protein kinase is required for hypoxia signaling. Mol. Cell. Biol. 25, 4853-4862. doi: 10.1128/MCB.25.12.4853-4862.2005

Enslen, H., Raingeaud, J., and Davis, R. J. (1998). Selective activation of p38 mitogen-activated protein (MAP) kinase isoforms by the MAP kinase kinases MKK3 and MKK6. J. Biol. Chem. 273, 1741-1748. doi: 10.1074/jbc.273.3. 1741

Fabian, M. A., Biggs, W. H. III, Treiber, D. K., Atteridge, C. E., Azimioara, M. D., Benedetti, M. G., et al. (2005). A small molecule-kinase interaction map for clinical kinase inhibitors. Nat. Biotechnol. 23, 329-336. doi: 10.1038/nbt1068

Fang, C., Wu, B., Le, N. T. T., Imberdis, T., Mercer, R. C. C., and Harris, D. A. (2018). Prions activate a p38 MAPK synaptotoxic signaling pathway. PLoS Pathog. 14:e1007283. doi: 10.1371/journal.ppat.1007283

Farooq, F., Balabanian, S., Liu, X., Holcik, M., and MacKenzie, A. (2009). p38 Mitogen-activated protein kinase stabilizes SMN mRNA through RNA binding protein HuR. Hum. Mol. Genet. 18, 4035-4045. doi: 10.1093/hmg/ddp352

Farrawell, N. E., Lambert-Smith, I. A., Warraich, S. T., Blair, I. P., Saunders, D. N., Hatters, D. M., et al. (2015). Distinct partitioning of ALS associated TDP-43, FUS and SOD1 mutants into cellular inclusions. Sci. Rep. 5:13416. doi: $10.1038 /$ srep 13416

Feijoo, C., Campbell, D. G., Jakes, R., Goedert, M., and Cuenda, A. (2005). Evidence that phosphorylation of the microtubule-associated protein Tau by SAPK4/p38delta at Thr50 promotes microtubule assembly. J. Cell Sci. 118(Pt 2), 397-408. doi: 10.1242/jcs.01655

Ferrer, I., Blanco, R., Carmona, M., Puig, B., Barrachina, M., Gomez, C., et al. (2001). Active, phosphorylation-dependent mitogen-activated protein kinase (MAPK/ERK), stress-activated protein kinase/c-Jun N-terminal kinase (SAPK/JNK), and p38 kinase expression in Parkinson's disease and Dementia with Lewy bodies. J. Neural Transm. 108, 1383-1396. doi: 10.1007/s00702 0100015 
Fitzsimmons, B. L., Zattoni, M., Svensson, C. I., Steinauer, J., Hua, X. Y., and Yaksh, T. L. (2010). Role of spinal p38alpha and beta MAPK in inflammatory hyperalgesia and spinal COX-2 expression. Neuroreport 21, 313-317. doi: 10. 1097/WNR.0b013e32833774bf

Foster, J. D., Cervinski, M. A., Gorentla, B. K., and Vaughan, R. A. (2006). Regulation of the dopamine transporter by phosphorylation. Handb. Exp. Pharmacol. 175, 197-214. doi: 10.1007/3-540-29784-7_10

Fragoso, G., Haines, J. D., Roberston, J., Pedraza, L., Mushynski, W. E., and Almazan, G. (2007). p38 mitogen-activated protein kinase is required for central nervous system myelination. Glia 55, 1531-1541. doi: 10.1002/glia. 20567

Freshney, N. W., Rawlinson, L., Guesdon, F., Jones, E., Cowley, S., Hsuan, J., et al. (1994). Interleukin-1 activates a novel protein kinase cascade that results in the phosphorylation of Hsp27. Cell 78, 1039-1049.

Galan-Arriero, I., Avila-Martin, G., Ferrer-Donato, A., Gomez-Soriano, J., Piazza, S., and Taylor, J. (2015). Early treatment with UR13870, a novel inhibitor of p38alpha mitogenous activated protein kinase, prevents hyperreflexia and anxiety behaviors, in the spared nerve injury model of neuropathic pain. Neurosci. Lett. 604, 69-74. doi: 10.1016/j.neulet.2015.07.044

Ge, B., Gram, H., Di Padova, F., Huang, B., New, L., Ulevitch, R. J., et al. (2002). MAPKK-independent activation of p38alpha mediated by TAB1-dependent autophosphorylation of p38alpha. Science 295, 1291-1294. doi: 10.1126/science. 1067289

Ghasemlou, N., Lopez-Vales, R., Lachance, C., Thuraisingam, T., Gaestel, M., Radzioch, D., et al. (2010). Mitogen-activated protein kinase-activated protein kinase 2 (MK2) contributes to secondary damage after spinal cord injury. J. Neurosci. 30, 13750-13759. doi: 10.1523/JNEUROSCI.2998-10.2010

Gianfriddo, M., Melani, A., Turchi, D., Giovannini, M. G., and Pedata, F. (2004). Adenosine and glutamate extracellular concentrations and mitogen-activated protein kinases in the striatum of Huntington transgenic mice. Selective antagonism of adenosine A2A receptors reduces transmitter outflow. Neurobiol. Dis. 17, 77-88. doi: 10.1016/j.nbd.2004.05.008

Gibbs, K. L., Kalmar, B., Rhymes, E. R., Fellows, A. D., Ahmed, M., Whiting, P., et al. (2018). Inhibiting p38 MAPK alpha rescues axonal retrograde transport defects in a mouse model of ALS. Cell Death Dis. 9:596. doi: 10.1038/s41419018-0624-8

Gibson, H. E., Edwards, J. G., Page, R. S., Van Hook, M. J., and Kauer, J. A. (2008). TRPV1 channels mediate long-term depression at synapses on hippocampal interneurons. Neuron 57, 746-759. doi: 10.1016/j.neuron.2007.12.027

Gills, J. J., Castillo, S. S., Zhang, C., Petukhov, P. A., Memmott, R. M., Hollingshead, M., et al. (2007). Phosphatidylinositol ether lipid analogues that inhibit AKT also independently activate the stress kinase, p38alpha, through MKK3/6independent and -dependent mechanisms. J. Biol. Chem. 282, 27020-27029. doi: $10.1074 /$ jbc.M701108200

Goebel-Goody, S. M., Wilson-Wallis, E. D., Royston, S., Tagliatela, S. M., Naegele, J. R., and Lombroso, P. J. (2012). Genetic manipulation of STEP reverses behavioral abnormalities in a fragile X syndrome mouse model. Genes Brain Behav. 11, 586-600. doi: 10.1111/j.1601-183X.2012.00781.x

Goedert, M., Hasegawa, M., Jakes, R., Lawler, S., Cuenda, A., and Cohen, P. (1997). Phosphorylation of microtubule-associated protein tau by stressactivated protein kinases. FEBS Lett. 409, 57-62. doi: 10.1016/s0014-5793(97) 00483-3

Goginashvili, A., Zhang, Z., Erbs, E., Spiegelhalter, C., Kessler, P., Mihlan, M., et al. (2015). Insulin granules. Insulin secretory granules control autophagy in pancreatic beta cells. Science 347, 878-882. doi: 10.1126/science.aaa2628

Goldin, A. L. (1999). Diversity of mammalian voltage-gated sodium channels. Ann. N. Y. Acad. Sci. 868, 38-50. doi: 10.1111/j.1749-6632.1999.tb11272.x

Gong, N., Xiao, Q., Zhu, B., Zhang, C. Y., Wang, Y. C., Fan, H., et al. (2014). Activation of spinal glucagon-like peptide-1 receptors specifically suppresses pain hypersensitivity. J. Neurosci. 34, 5322-5334. doi: 10.1523/JNEUROSCI. 4703-13.2014

Gong, X., Ming, X., Deng, P., and Jiang, Y. (2010). Mechanisms regulating the nuclear translocation of p38 MAP kinase. J. Cell. Biochem. 110, 1420-1429. doi: $10.1002 /$ jcb. 22675

Gonzalez-Teran, B., Matesanz, N., Nikolic, I., Verdugo, M. A., Sreeramkumar, V., Hernandez-Cosido, L., et al. (2016). p38gamma and p38delta reprogram liver metabolism by modulating neutrophil infiltration. EMBO J. 35, 536-552. doi: $10.15252 / \mathrm{embj} .201591857$
Graziane, N. M., Polter, A. M., Briand, L. A., Pierce, R. C., and Kauer, J. A. (2013). Kappa opioid receptors regulate stress-induced cocaine seeking and synaptic plasticity. Neuron 77, 942-954. doi: 10.1016/j.neuron.2012.12.034

Guan, Z., Kim, J. H., Lomvardas, S., Holick, K., Xu, S., Kandel, E. R., et al. (2003). p38 MAP kinase mediates both short-term and long-term synaptic depression in aplysia. J. Neurosci. 23, 7317-7325.

Guldal, C. G., Ahmad, A., Korshunov, A., Squatrito, M., Awan, A., Mainwaring, L. A., et al. (2012). An essential role for p38 MAPK in cerebellar granule neuron precursor proliferation. Acta Neuropathol. 123, 573-586. doi: 10.1007/s00401012-0946-Z

Guo, G., and Bhat, N. R. (2007). p38alpha MAP kinase mediates hypoxia-induced motor neuron cell death: a potential target of minocycline's neuroprotective action. Neurochem. Res. 32, 2160-2166. doi: 10.1007/s11064-007-9408-8

Guo, Y. L., Ye, J., and Huang, F. (2007). p38alpha MAP kinase-deficient mouse embryonic stem cells can differentiate to endothelial cells, smooth muscle cells, and neurons. Dev. Dyn. 236, 3383-3392. doi: 10.1002/dvdy.21374

Gupta, J., and Nebreda, A. R. (2015). Roles of p38alpha mitogen-activated protein kinase in mouse models of inflammatory diseases and cancer. FEBS J. 282, 1841-1857. doi: 10.1111/febs.13250

Haines, J. D., Fang, J., Mushynski, W. E., and Almazan, G. (2010). Mitogenactivated protein kinase activated protein kinase 2 (MK2) participates in p38 MAPK regulated control of oligodendrocyte differentiation. Glia 58, 13841393. doi: 10.1002/glia.21014

Haines, J. D., Fulton, D. L., Richard, S., and Almazan, G. (2015). p38 MitogenActivated Protein Kinase Pathway Regulates Genes during Proliferation and Differentiation in Oligodendrocytes. PLoS One 10:e0145843. doi: 10.1371/ journal.pone. 0145843

Halassa, M. M., Fellin, T., and Haydon, P. G. (2007). The tripartite synapse: roles for gliotransmission in health and disease. Trends Mol. Med. 13, 54-63. doi: 10.1016/j.molmed.2006.12.005

Hammad, M., Silva, A., Glass, J., Sladky, J. T., and Benatar, M. (2007). Clinical, electrophysiologic, and pathologic evidence for sensory abnormalities in ALS. Neurology 69, 2236-2242. doi: 10.1212/01.wnl.0000286948.99150.16

Han, J., Lee, J. D., Bibbs, L., and Ulevitch, R. J. (1994). A MAP kinase targeted by endotoxin and hyperosmolarity in mammalian cells. Science $265,808-811$. doi: $10.1126 /$ science.7914033

Han, Q. Q., Huang, H. J., Wang, Y. L., Yang, L., Pilot, A., Zhu, X. C., et al. (2019). Ghrelin exhibited antidepressant and anxiolytic effect via the p38MAPK signaling pathway in hippocampus. Prog. Neuropsychopharmacol. Biol. Psychiatry 93, 11-20. doi: 10.1016/j.pnpbp.2019.02.013

Harada, A., Oguchi, K., Okabe, S., Kuno, J., Terada, S., Ohshima, T., et al. (1994). Altered microtubule organization in small-calibre axons of mice lacking tau protein. Nature 369, 488-491. doi: 10.1038/369488a0

Hardingham, G. E., and Bading, H. (2003). The Yin and Yang of NMDA receptor signalling. Trends Neurosci. 26, 81-89. doi: 10.1016/S0166-2236(02)00040-1

Hayashi, Y., Sanada, K., Hirota, T., Shimizu, F., and Fukada, Y. (2003). p38 mitogen-activated protein kinase regulates oscillation of chick pineal circadian clock. J. Biol. Chem. 278, 25166-25171. doi: 10.1074/jbc.M212726200

He, Y., She, H., Zhang, T., Xu, H., Cheng, L., Yepes, M., et al. (2018). p38 MAPK inhibits autophagy and promotes microglial inflammatory responses by phosphorylating ULK1. J. Cell Biol. 217, 315-328. doi: 10.1083/jcb.201701049

Heinrichsdorff, J., Luedde, T., Perdiguero, E., Nebreda, A. R., and Pasparakis, M. (2008). p38 alpha MAPK inhibits JNK activation and collaborates with IkappaB kinase 2 to prevent endotoxin-induced liver failure. EMBO Rep. 9, 1048-1054. doi: 10.1038/embor.2008.149

Heinsbroek, J. A., Furbish, A. B., and Peters, J. (2018). A single, extinction-based treatment with a kappa opioid receptor agonist elicits a long-term reduction in cocaine relapse. Neuropsychopharmacology 43, 1492-1497. doi: 10.1038/ s41386-017-0006-4

Henley, J. M., and Wilkinson, K. A. (2016). Synaptic AMPA receptor composition in development, plasticity and disease. Nat. Rev. Neurosci. 17, 337-350. doi: 10.1038/nrn.2016.37

Herlaar, E., and Brown, Z. (1999). p38 MAPK signalling cascades in inflammatory disease. Mol. Med. Today 5, 439-447.

Hideshima, T., Podar, K., Chauhan, D., Ishitsuka, K., Mitsiades, C., Tai, Y. T., et al. (2004). p38 MAPK inhibition enhances PS-341 (bortezomib)-induced cytotoxicity against multiple myeloma cells. Oncogene 23, 8766-8776. doi: 10. 1038/sj.onc. 1208118 
Hirai, S., Cui, D. F., Miyata, T., Ogawa, M., Kiyonari, H., Suda, Y., et al. (2006). The c-Jun N-terminal kinase activator dual leucine zipper kinase regulates axon growth and neuronal migration in the developing cerebral cortex. J. Neurosci. 26, 11992-12002. doi: 10.1523/JNEUROSCI.2272-06.2006

Holasek, S. S., Wengenack, T. M., Kandimalla, K. K., Montano, C., Gregor, D. M., Curran, G. L., et al. (2005). Activation of the stress-activated MAP kinase, p38, but not JNK in cortical motor neurons during early presymptomatic stages of amyotrophic lateral sclerosis in transgenic mice. Brain Res. 1045, 185-198. doi: 10.1016/j.brainres.2005.03.037

Hossain, S., de la Cruz-Morcillo, M. A., Sanchez-Prieto, R., and Almazan, G. (2012). Mitogen-activated protein kinase p38 regulates Krox-20 to direct Schwann cell differentiation and peripheral myelination. Glia 60, 1130-1144. doi: 10.1002/glia.22340

Hsieh, C. C., Kuro-o, M., Rosenblatt, K. P., Brobey, R., and Papaconstantinou, J. (2010). The ASK1-Signalosome regulates p38 MAPK activity in response to levels of endogenous oxidative stress in the Klotho mouse models of aging. Aging 2, 597-611. doi: 10.18632/aging.100194

Hsieh, H., Boehm, J., Sato, C., Iwatsubo, T., Tomita, T., Sisodia, S., et al. (2006). AMPAR removal underlies Abeta-induced synaptic depression and dendritic spine loss. Neuron 52, 831-843. doi: 10.1016/j.neuron.2006.10.035

Huang, C. C., You, J. L., Wu, M. Y., and Hsu, K. S. (2004). Rap1induced p38 mitogen-activated protein kinase activation facilitates AMPA receptor trafficking via the GDI.Rab5 complex. Potential role in (S)-3,5dihydroxyphenylglycene-induced long term depression. J. Biol. Chem. 279, 12286-12292. doi: 10.1074/jbc.M312868200

Huang, Q., Mao, X. F., Wu, H. Y., Liu, H., Sun, M. L., Wang, X., et al. (2017). Cynandione A attenuates neuropathic pain through p38beta MAPK-mediated spinal microglial expression of beta-endorphin. Brain Behav. Immun. 62, 64-77. doi: 10.1016/j.bbi.2017.02.005

Hudmon, A., Choi, J. S., Tyrrell, L., Black, J. A., Rush, A. M., Waxman, S. G., et al. (2008). Phosphorylation of sodium channel $\mathrm{Na}(\mathrm{v}) 1.8$ by p38 mitogenactivated protein kinase increases current density in dorsal root ganglion neurons. J. Neurosci. 28, 3190-3201. doi: 10.1523/JNEUROSCI.4403-07.2008

Huganir, R. L., and Nicoll, R. A. (2013). AMPARs and synaptic plasticity: the last 25 years. Neuron 80, 704-717. doi: 10.1016/j.neuron.2013.10.025

Hughes, A. N., and Appel, B. (2019). Oligodendrocytes express synaptic proteins that modulate myelin sheath formation. Nat. Commun. 10:4125. doi: 10.1038/ s41467-019-12059-y

Hui, L., Bakiri, L., Mairhorfer, A., Schweifer, N., Haslinger, C., Kenner, L., et al. (2007). p38alpha suppresses normal and cancer cell proliferation by antagonizing the JNK-c-Jun pathway. Nat. Genet. 39, 741-749. doi: 10.1038/ ng2033

Hynes, N. E., Ingham, P. W., Lim, W. A., Marshall, C. J., Massague, J., and Pawson, T. (2013). Signalling change: signal transduction through the decades. Nat. Rev. Mol. Cell Biol. 14, 393-398. doi: 10.1038/nrm3581

Ittner, A., Asih, P. R., Tan, A. R. P., Prikas, E., Bertz, J., Stefanoska, K., et al. (2020). Reduction of advanced tau-mediated memory deficits by the MAP kinase p38gamma. Acta Neuropathol. 140, 279-294. doi: 10.1007/s00401-020-02191-1

Ittner, A., Block, H., Reichel, C. A., Varjosalo, M., Gehart, H., Sumara, G., et al. (2012). Regulation of PTEN activity by p38delta-PKD1 signaling in neutrophils confers inflammatory responses in the lung. J. Exp. Med. 209, 2229-2246. doi: 10.1084/jem.20120677

Ittner, A., Chua, S. W., Bertz, J., Volkerling, A., van der Hoven, J., Gladbach, A., et al. (2016). Site-specific phosphorylation of tau inhibits amyloid-beta toxicity in Alzheimer's mice. Science 354, 904-908. doi: 10.1126/science.aah6205

Ittner, A., and Ittner, L. M. (2018). Dendritic Tau in Alzheimer's Disease. Neuron 99, 13-27. doi: 10.1016/j.neuron.2018.06.003

Ittner, A. A., Gladbach, A., Bertz, J., Suh, L. S., and Ittner, L. M. (2014). p38 MAP kinase-mediated NMDA receptor-dependent suppression of hippocampal hypersynchronicity in a mouse model of Alzheimer's disease. Acta Neuropathol. Commun. 2:149. doi: 10.1186/s40478-014-0149-z

Ittner, L. M., and Gotz, J. (2011). Amyloid-beta and tau-a toxic pas de deux in Alzheimer's disease. Nat. Rev. Neurosci. 12, 65-72. doi: 10.1038/nrn2967

Ittner, L. M., Ke, Y. D., Delerue, F., Bi, M., Gladbach, A., van Eersel, J., et al. (2010). Dendritic function of tau mediates amyloid-beta toxicity in Alzheimer's disease mouse models. Cell 142, 387-397. doi: 10.1016/j.cell.2010.06.036

Jackson, J. R., Bolognese, B., Hillegass, L., Kassis, S., Adams, J., Griswold, D. E., et al. (1998). Pharmacological effects of SB 220025, a selective inhibitor of P38 mitogen-activated protein kinase, in angiogenesis and chronic inflammatory disease models. J. Pharmacol. Exp. Ther. 284, 687-692.

Jan, A. T., Malik, M. A., Rahman, S., Yeo, H. R., Lee, E. J., Abdullah, T. S., et al. (2017). Perspective insights of exosomes in neurodegenerative diseases: a critical appraisal. Front. Aging Neurosci. 9:317. doi: 10.3389/fnagi.2017. 00317

Jeffrey, K. L., Camps, M., Rommel, C., and Mackay, C. R. (2007). Targeting dualspecificity phosphatases: manipulating MAP kinase signalling and immune responses. Nat. Rev. Drug Discov. 6, 391-403. doi: 10.1038/nrd2289

Jeohn, G. H., Cooper, C. L., Wilson, B., Chang, R. C., Jang, K. J., Kim, H. C., et al. (2002). p38 MAP kinase is involved in lipopolysaccharide-induced dopaminergic neuronal cell death in rat mesencephalic neuron-glia cultures. Ann. N. Y. Acad. Sci. 962, 332-346. doi: 10.1111/j.1749-6632.2002.tb04078.x

Ji, R. R., Samad, T. A., Jin, S. X., Schmoll, R., and Woolf, C. J. (2002). p38 MAPK activation by NGF in primary sensory neurons after inflammation increases TRPV1 levels and maintains heat hyperalgesia. Neuron 36, 57-68. doi: 10.1016/ s0896-6273(02)00908-x

Jiang, Y., Gram, H., Zhao, M., New, L., Gu, J., Feng, L., et al. (1997). Characterization of the structure and function of the fourth member of p38 group mitogen-activated protein kinases, p38delta. J. Biol. Chem. 272, 3012230128. doi: 10.1074/jbc.272.48.30122

Jin, M., Shepardson, N., Yang, T., Chen, G., Walsh, D., and Selkoe, D. J. (2011). Soluble amyloid beta-protein dimers isolated from Alzheimer cortex directly induce Tau hyperphosphorylation and neuritic degeneration. Proc. Natl. Acad. Sci. U.S.A. 108, 5819-5824. doi: 10.1073/pnas. 1017033108

Karitzky, J., and Ludolph, A. C. (2001). Imaging and neurochemical markers for diagnosis and disease progression in ALS. J. Neurol. Sci. 191, 35-41. doi: 10. 1016/s0022-510x(01)00628-1

Karunakaran, S., Saeed, U., Mishra, M., Valli, R. K., Joshi, S. D., Meka, D. P., et al. (2008). Selective activation of p38 mitogen-activated protein kinase in dopaminergic neurons of substantia nigra leads to nuclear translocation of p53 in 1-methyl-4-phenyl-1,2,3,6-tetrahydropyridine-treated mice. J. Neurosci. 28, 12500-12509. doi: 10.1523/JNEUROSCI.4511-08.2008

Kase, Y., Otsu, K., Shimazaki, T., and Okano, H. (2019). Involvement of p38 in Age-Related Decline in Adult Neurogenesis via Modulation of Wnt Signaling. Stem Cell Rep. 12, 1313-1328. doi: 10.1016/j.stemcr.2019.04.010

Kasuya, Y., Umezawa, H., and Hatano, M. (2018). Stress-Activated Protein Kinases in Spinal Cord Injury: Focus on Roles of p38. Int. J. Mol. Sci. 19:867. doi: 10.3390/ijms19030867

Kato, Y., Chao, T. H., Hayashi, M., Tapping, R. I., and Lee, J. D. (2000). Role of BMK1 in regulation of growth factor-induced cellular responses. Immunol. Res. 21, 233-237. doi: 10.1385/IR:21:2-3:233

Kawasaki, H., Morooka, T., Shimohama, S., Kimura, J., Hirano, T., Gotoh, Y., et al. (1997). Activation and involvement of p38 mitogen-activated protein kinase in glutamate-induced apoptosis in rat cerebellar granule cells. J. Biol. Chem. 272, 18518-18521. doi: 10.1074/jbc.272.30.18518

Kelkar, N., Standen, C. L., and Davis, R. J. (2005). Role of the JIP4 scaffold protein in the regulation of mitogen-activated protein kinase signaling pathways. Mol. Cell. Biol. 25, 2733-2743. doi: 10.1128/MCB.25.7.2733-2743.2005

Kim, C., Sano, Y., Todorova, K., Carlson, B. A., Arpa, L., Celada, A., et al. (2008). The kinase p38 alpha serves cell type-specific inflammatory functions in skin injury and coordinates pro- and anti-inflammatory gene expression. Nat. Immunol. 9, 1019-1027. doi: 10.1038/ni.1640

Kimura, Y., Tsutsumi, K., Konno, A., Ikegami, K., Hameed, S., Kaneko, T., et al. (2018). Environmental responsiveness of tubulin glutamylation in sensory cilia is regulated by the p38 MAPK pathway. Sci. Rep. 8:8392. doi: 10.1038/s41598018-26694-w

Kirby, L. G., Zeeb, F. D., and Winstanley, C. A. (2011). Contributions of serotonin in addiction vulnerability. Neuropharmacology 61, 421-432. doi: 10.1016/j. neuropharm.2011.03.022

Klinedinst, S., Wang, X., Xiong, X., Haenfler, J. M., and Collins, C. A. (2013). Independent pathways downstream of the Wnd/DLK MAPKKK regulate synaptic structure, axonal transport, and injury signaling. J. Neurosci. 33, 12764-12778. doi: 10.1523/JNEUROSCI.5160-12.2013

Kosakai, A., Ito, D., Nihei, Y., Yamashita, S., Okada, Y., Takahashi, K., et al. (2011). Degeneration of mesencephalic dopaminergic neurons in klotho mouse related to vitamin D exposure. Brain Res. 1382, 109-117. doi: 10.1016/j.brainres.2011. 01.056 
Kotlyarov, A., Yannoni, Y., Fritz, S., Laass, K., Telliez, J. B., Pitman, D., et al. (2002). Distinct cellular functions of MK2. Mol. Cell. Biol. 22, 4827-4835. doi: $10.1128 / \mathrm{mcb} .22 .13 .4827-4835.2002$

Krapivinsky, G., Medina, I., Krapivinsky, L., Gapon, S., and Clapham, D. E. (2004). SynGAP-MUPP1-CaMKII synaptic complexes regulate p38 MAP kinase activity and NMDA receptor-dependent synaptic AMPA receptor potentiation. Neuron 43, 563-574. doi: 10.1016/j.neuron.2004.08.003

Krieger, C., Hu, J. H., and Pelech, S. (2003). Aberrant protein kinases and phosphoproteins in amyotrophic lateral sclerosis. Trends Pharmacol. Sci. 24, 535-541. doi: 10.1016/j.tips.2003.08.003

Kuma, Y., Campbell, D. G., and Cuenda, A. (2004). Identification of glycogen synthase as a new substrate for stress-activated protein kinase $2 \mathrm{~b} / \mathrm{p} 38$ beta. Biochem. J. 379(Pt 1), 133-139. doi: 10.1042/BJ20031559

Kyriakis, J. M., and Avruch, J. (2001). Mammalian mitogen-activated protein kinase signal transduction pathways activated by stress and inflammation. Physiol. Rev. 81, 807-869. doi: 10.1152/physrev.2001.81.2.807

Lawson, S. K., Dobrikova, E. Y., Shveygert, M., and Gromeier, M. (2013). p38alpha mitogen-activated protein kinase depletion and repression of signal transduction to translation machinery by miR-124 and -128 in neurons. Mol. Cell. Biol. 33, 127-135. doi: 10.1128/MCB.00695-12

Lee, J., Shin, J. S., Park, J. Y., Kwon, D., Choi, S. J., Kim, S. J., et al. (2003). p38 mitogen-activated protein kinase modulates expression of tumor necrosis factor-related apoptosis-inducing ligand induced by interferon-gamma in fetal brain astrocytes. J. Neurosci. Res. 74, 884-890. doi: 10.1002/jnr.10815

Lee, J. C., Laydon, J. T., McDonnell, P. C., Gallagher, T. F., Kumar, S., Green, D., et al. (1994). A protein kinase involved in the regulation of inflammatory cytokine biosynthesis. Nature 372, 739-746. doi: 10.1038/372739a0

Lee, J. K., and Kim, N. J. (2017). Recent Advances in the Inhibition of p38 MAPK as a Potential Strategy for the Treatment of Alzheimer's Disease. Molecules 22:1287. doi: $10.3390 /$ molecules 22081287

Lee, J. K., Shin, J. H., Hwang, S. G., Gwag, B. J., McKee, A. C., Lee, J., et al. (2013). MST1 functions as a key modulator of neurodegeneration in a mouse model of ALS. Proc. Natl. Acad. Sci. U.S.A. 110, 12066-12071. doi: 10.1073/pnas. 1300894110

Lee, S. H., Park, J., Che, Y., Han, P. L., and Lee, J. K. (2000). Constitutive activity and differential localization of p38alpha and p38beta MAPKs in adult mouse brain. J. Neurosci. Res. 60, 623-631. doi: 10.1002/(SICI)1097-4547(20000601) 60:5<623:AID-JNR7<3.0.CO;2-4

Lee, Y. B., Schrader, J. W., and Kim, S. U. (2000). p38 map kinase regulates TNFalpha production in human astrocytes and microglia by multiple mechanisms. Cytokine 12, 874-880. doi: 10.1006/cyto.2000.0688

Legos, J. J., Erhardt, J. A., White, R. F., Lenhard, S. C., Chandra, S., Parsons, A. A., et al. (2001). SB 239063, a novel p38 inhibitor, attenuates early neuronal injury following ischemia. Brain Res. 892, 70-77. doi: 10.1016/s0006-8993(00)03228-5

Lemos, J. C., Roth, C. A., Messinger, D. I., Gill, H. K., Phillips, P. E., and Chavkin, C. (2012). Repeated stress dysregulates kappa-opioid receptor signaling in the dorsal raphe through a p38alpha MAPK-dependent mechanism. J. Neurosci. 32, 12325-12336. doi: 10.1523/JNEUROSCI.2053-12.2012

Li, L. L., Ginet, V., Liu, X., Vergun, O., Tuittila, M., Mathieu, M., et al. (2013). The nNOS-p38MAPK pathway is mediated by NOS1AP during neuronal death. J. Neurosci. 33, 8185-8201. doi: 10.1523/JNEUROSCI.4578-12.2013

Li, M., Liu, J., and Zhang, C. (2011). Evolutionary history of the vertebrate mitogen activated protein kinases family. PLoS One 6:e26999. doi: 10.1371/journal.pone. 0026999

Li, S., Jin, M., Koeglsperger, T., Shepardson, N. E., Shankar, G. M., and Selkoe, D. J. (2011). Soluble Abeta oligomers inhibit long-term potentiation through a mechanism involving excessive activation of extrasynaptic NR2B-containing NMDA receptors. J. Neurosci. 31, 6627-6638. doi: 10.1523/JNEUROSCI.020311.2011

Li, S., Tian, X., Hartley, D. M., and Feig, L. A. (2006). Distinct roles for Ras-guanine nucleotide-releasing factor 1 (Ras-GRF1) and Ras-GRF2 in the induction of long-term potentiation and long-term depression. J. Neurosci. 26, 1721-1729. doi: 10.1523/JNEUROSCI.3990-05.2006

Lo, U., Selvaraj, V., Plane, J. M., Chechneva, O. V., Otsu, K., and Deng, W. (2014). p38alpha (MAPK14) critically regulates the immunological response and the production of specific cytokines and chemokines in astrocytes. Sci. Rep. 4:7405. doi: 10.1038/srep07405

Loy, B., Apostolova, G., Dorn, R., McGuire, V. A., Arthur, J. S., and Dechant, G. (2011). p38alpha and p38beta mitogen-activated protein kinases determine cholinergic transdifferentiation of sympathetic neurons. J. Neurosci. 31, 1205912067. doi: 10.1523/JNEUROSCI.0448-11.2011

Lu, Q., Rau, T. F., Harris, V., Johnson, M., Poulsen, D. J., and Black, S. M. (2011). Increased p38 mitogen-activated protein kinase signaling is involved in the oxidative stress associated with oxygen and glucose deprivation in neonatal hippocampal slice cultures. Eur. J. Neurosci. 34, 1093-1101. doi: 10.1111/j.14609568.2011.07786.x

Maillet, A., Krack, P., Lhommee, E., Metereau, E., Klinger, H., Favre, E., et al. (2016). The prominent role of serotonergic degeneration in apathy, anxiety and depression in de novo Parkinson's disease. Brain 139(Pt 9), 2486-2502. doi: 10.1093/brain/aww162

Mannangatti, P., NarasimhaNaidu, K., Damaj, M. I., Ramamoorthy, S., and Jayanthi, L. D. (2015). A Role for p38 Mitogen-activated Protein Kinasemediated Threonine 30-dependent Norepinephrine Transporter Regulation in Cocaine Sensitization and Conditioned Place Preference. J. Biol. Chem. 290, 10814-10827. doi: 10.1074/jbc.M114.612192

Maphis, N., Jiang, S., Xu, G., Kokiko-Cochran, O. N., Roy, S. M., Van Eldik, L. J., et al. (2016). Selective suppression of the alpha isoform of p38 MAPK rescues late-stage tau pathology. Alzheimers Res. Ther. 8:54. doi: 10.1186/s13195-0160221-y

Menon, M. B., Dhamija, S., Kotlyarov, A., and Gaestel, M. (2015). The problem of pyridinyl imidazole class inhibitors of MAPK14/p38alpha and MAPK11/p38beta in autophagy research. Autophagy 11, 1425-1427. doi: 10. 1080/15548627.2015.1059562

Mittelstadt, P. R., Salvador, J. M., Fornace, A. J. Jr., and Ashwell, J. D. (2005). Activating p38 MAPK: new tricks for an old kinase. Cell Cycle 4, 1189-1192. doi: $10.4161 /$ cc.4.9.2043

Mizumura, K., Takeda, K., Hashimoto, S., Horie, T., and Ichijo, H. (2006). Identification of Op18/stathmin as a potential target of ASK1-p38 MAP kinase cascade. J. Cell. Physiol. 206, 363-370. doi: 10.1002/jcp.20465

Morfini, G. A., Bosco, D. A., Brown, H., Gatto, R., Kaminska, A., Song, Y., et al. (2013). Inhibition of fast axonal transport by pathogenic SOD1 involves activation of p38 MAP kinase. PLoS One 8:e65235. doi: 10.1371/journal.pone. 0065235

Morganti, J. M., Goulding, D. S., and Van Eldik, L. J. (2019). Deletion of p38alpha MAPK in microglia blunts trauma-induced inflammatory responses in mice. J. Neuroinflam. 16:98. doi: 10.1186/s12974-019-1493-5

Mori, T., Wang, X., Jung, J. C., Sumii, T., Singhal, A. B., Fini, M. E., et al. (2002). Mitogen-activated protein kinase inhibition in traumatic brain injury: in vitro and in vivo effects. J. Cereb. Blood Flow Metab. 22, 444-452. doi: 10.1097/ 00004647-200204000-00008

Morrison, D. K. (2012). MAP kinase pathways. Cold Spring Harb. Perspect. Biol. 4:a011254. doi: 10.1101/cshperspect.a011254

Moult, P. R., Correa, S. A., Collingridge, G. L., Fitzjohn, S. M., and Bashir, Z. I. (2008). Co-activation of p38 mitogen-activated protein kinase and protein tyrosine phosphatase underlies metabotropic glutamate receptor-dependent long-term depression. J. Physiol. 586, 2499-2510. doi: 10.1113/jphysiol.2008. 153122

Mucke, L., and Selkoe, D. J. (2012). Neurotoxicity of amyloid beta-protein: synaptic and network dysfunction. Cold Spring Harb. Perspect. Med. 2:a006338. doi: 10.1101/cshperspect.a006338

Muda, M., Theodosiou, A., Rodrigues, N., Boschert, U., Camps, M., Gillieron, C., et al. (1996). The dual specificity phosphatases M3/6 and MKP-3 are highly selective for inactivation of distinct mitogen-activated protein kinases. J. Biol. Chem. 271, 27205-27208. doi: 10.1074/jbc.271.44.27205

Munoz, J. J., Tarrega, C., Blanco-Aparicio, C., and Pulido, R. (2003). Differential interaction of the tyrosine phosphatases PTP-SL, STEP and HePTP with the mitogen-activated protein kinases ERK1/2 and p38alpha is determined by a kinase specificity sequence and influenced by reducing agents. Biochem. J. 372(Pt 1), 193-201. doi: 10.1042/BJ20021941

Munoz, L., and Ammit, A. J. (2010). Targeting p38 MAPK pathway for the treatment of Alzheimer's disease. Neuropharmacology 58, 561-568. doi: 10 1016/j.neuropharm.2009.11.010

Murray, H. J., and O'Connor, J. J. (2003). A role for COX-2 and p38 mitogen activated protein kinase in long-term depression in the rat dentate gyrus in vitro. Neuropharmacology 44, 374-380. doi: 10.1016/s0028-3908(02) 00375-1

Nabavi, S., Fox, R., Alfonso, S., Aow, J., and Malinow, R. (2014). GluA1 trafficking and metabotropic NMDA: addressing results from other laboratories 
inconsistent with ours. Philos. Trans. R. Soc. Lond. B Biol. Sci. 369, 20130145. doi: 10.1098/rstb.2013.0145

Nabavi, S., Kessels, H. W., Alfonso, S., Aow, J., Fox, R., and Malinow, R. (2013). Metabotropic NMDA receptor function is required for NMDA receptordependent long-term depression. Proc. Natl. Acad. Sci. U.S.A. 110, 4027-4032. doi: 10.1073/pnas.1219454110

Nahirnyj, A., Livne-Bar, I., Guo, X., and Sivak, J. M. (2013). ROS detoxification and proinflammatory cytokines are linked by p38 MAPK signaling in a model of mature astrocyte activation. PLoS One 8:e83049. doi: 10.1371/journal.pone. 0083049

Nakata, K., Abrams, B., Grill, B., Goncharov, A., Huang, X., Chisholm, A. D., et al. (2005). Regulation of a DLK-1 and p38 MAP kinase pathway by the ubiquitin ligase RPM-1 is required for presynaptic development. Cell 120, 407-420. doi: 10.1016/j.cell.2004.12.017

Namiki, K., Nakamura, A., Furuya, M., Mizuhashi, S., Matsuo, Y., Tokuhara, N., et al. (2007). Involvement of p38alpha in kainate-induced seizure and neuronal cell damage. J. Recept. Signal Transduct. Res. 27, 99-111. doi: 10.1080/ 10799890701357855

Nemoto, S., Xiang, J., Huang, S., and Lin, A. (1998). Induction of apoptosis by SB202190 through inhibition of p38beta mitogen-activated protein kinase. J. Biol. Chem. 273, 16415-16420. doi: 10.1074/jbc.273.26.16415

Nito, C., Kamada, H., Endo, H., Niizuma, K., Myer, D. J., and Chan, P. H. (2008). Role of the p38 mitogen-activated protein kinase/cytosolic phospholipase A2 signaling pathway in blood-brain barrier disruption after focal cerebral ischemia and reperfusion. J. Cereb. Blood Flow Metab. 28, 1686-1696. doi: $10.1038 / \mathrm{jcbfm} .2008 .60$

Nix, P., Hisamoto, N., Matsumoto, K., and Bastiani, M. (2011). Axon regeneration requires coordinate activation of $\mathrm{p} 38$ and JNK MAPK pathways. Proc. Natl. Acad. Sci. U.S.A. 108, 10738-10743. doi: 10.1073/pnas.1104830108

Noseda, R., Guerrero-Valero, M., Alberizzi, V., Previtali, S. C., Sherman, D. L., Palmisano, M., et al. (2016). Kif13b Regulates PNS and CNS Myelination through the Dlg1 Scaffold. PLoS Biol. 14:e1002440. doi: 10.1371/journal.pbio. 1002440

Okamoto, S., Krainc, D., Sherman, K., and Lipton, S. A. (2000). Antiapoptotic role of the p38 mitogen-activated protein kinase-myocyte enhancer factor 2 transcription factor pathway during neuronal differentiation. Proc. Natl. Acad. Sci. U.S.A. 97, 7561-7566. doi: 10.1073/pnas.130502697

Origlia, N., Righi, M., Capsoni, S., Cattaneo, A., Fang, F., Stern, D. M., et al. (2008). Receptor for advanced glycation end product-dependent activation of $\mathrm{p} 38$ mitogen-activated protein kinase contributes to amyloid-beta-mediated cortical synaptic dysfunction. J. Neurosci. 28, 3521-3530. doi: 10.1523/JNEUROSCI. 0204-08.2008

Park, E. C., and Rongo, C. (2016). The p38 MAP kinase pathway modulates the hypoxia response and glutamate receptor trafficking in aging neurons. eLife 5:e12010. doi: 10.7554/eLife.12010

Parker, C. G., Hunt, J., Diener, K., McGinley, M., Soriano, B., Keesler, G. A., et al. (1998). Identification of stathmin as a novel substrate for $\mathrm{p} 38$ delta. Biochem. Biophys. Res. Commun. 249, 791-796. doi: 10.1006/bbrc.1998.9250

Patterson, K. I., Brummer, T., O'Brien, P. M., and Daly, R. J. (2009). Dual-specificity phosphatases: critical regulators with diverse cellular targets. Biochem. J. 418 , 475-489. doi: 10.1042/bj20082234

Piao, C. S., Che, Y., Han, P. L., and Lee, J. K. (2002). Delayed and differential induction of p38 MAPK isoforms in microglia and astrocytes in the brain after transient global ischemia. Brain Res. Mol. Brain Res. 107, 137-144. doi: 10.1016/s0169-328x(02)00456-4

Piao, C. S., Kim, J. B., Han, P. L., and Lee, J. K. (2003). Administration of the p38 MAPK inhibitor SB203580 affords brain protection with a wide therapeutic window against focal ischemic insult. J. Neurosci. Res. 73, 537-544. doi: 10.1002/ jnr.10671

Poddar, R., Deb, I., Mukherjee, S., and Paul, S. (2010). NR2B-NMDA receptor mediated modulation of the tyrosine phosphatase STEP regulates glutamate induced neuronal cell death. J. Neurochem. 115, 1350-1362. doi: 10.1111/j. 1471-4159.2010.07035.x

Pogozelski, A. R., Geng, T., Li, P., Yin, X., Lira, V. A., Zhang, M., et al. (2009). p38gamma mitogen-activated protein kinase is a key regulator in skeletal muscle metabolic adaptation in mice. PLoS One 4:e7934. doi: 10.1371/journal. pone. 0007934

Politis, M., and Niccolini, F. (2015). Serotonin in Parkinson's disease. Behav. Brain Res. 277, 136-145. doi: 10.1016/j.bbr.2014.07.037
Potolicchio, I., Carven, G. J., Xu, X., Stipp, C., Riese, R. J., Stern, L. J., et al. (2005). Proteomic analysis of microglia-derived exosomes: metabolic role of the aminopeptidase CD13 in neuropeptide catabolism. J. Immunol. 175, 22372243. doi: 10.4049/jimmunol.175.4.2237

Pozniak, C. D., Sengupta Ghosh, A., Gogineni, A., Hanson, J. E., Lee, S. H., Larson, J. L., et al. (2013). Dual leucine zipper kinase is required for excitotoxicityinduced neuronal degeneration. J. Exp. Med. 210, 2553-2567. doi: 10.1084/jem. 20122832

Prikas, E., Poljak, A., and Ittner, A. (2020). Mapping p38alpha mitogen-activated protein kinase signaling by proximity-dependent labeling. Protein Sci. 29, 1196-1210. doi: 10.1002/pro.3854

Pulido, R., Zuniga, A., and Ullrich, A. (1998). PTP-SL and STEP protein tyrosine phosphatases regulate the activation of the extracellular signal-regulated kinases ERK1 and ERK2 by association through a kinase interaction motif. EMBO J. 17, 7337-7350. doi: 10.1093/emboj/17.24.7337

Raingeaud, J., Gupta, S., Rogers, J. S., Dickens, M., Han, J., Ulevitch, R. J., et al. (1995). Pro-inflammatory cytokines and environmental stress cause p38 mitogen-activated protein kinase activation by dual phosphorylation on tyrosine and threonine. J. Biol. Chem. 270, 7420-7426. doi: 10.1074/jbc.270.13. 7420

Rangone, H., Poizat, G., Troncoso, J., Ross, C. A., MacDonald, M. E., Saudou, F., et al. (2004). The serum- and glucocorticoid-induced kinase SGK inhibits mutant huntingtin-induced toxicity by phosphorylating serine 421 of huntingtin. Eur. J. Neurosci. 19, 273-279. doi: 10.1111/j.0953-816x.2003. 03131.x

Ray, A., Sehgal, N., Karunakaran, S., Rangarajan, G., and Ravindranath, V. (2015). MPTP activates ASK1-p38 MAPK signaling pathway through TNF-dependent Trx1 oxidation in parkinsonism mouse model. Free Radic. Biol. Med. 87, 312-325. doi: 10.1016/j.freeradbiomed.2015.06.041

Reed-Geaghan, E. G., Savage, J. C., Hise, A. G., and Landreth, G. E. (2009). CD14 and toll-like receptors 2 and 4 are required for fibrillar A $\{$ beta $\}$-stimulated microglial activation. J. Neurosci. 29, 11982-11992. doi: 10.1523/JNEUROSCI. 3158-09.2009

Regan, J., Capolino, A., Cirillo, P. F., Gilmore, T., Graham, A. G., Hickey, E., et al. (2003). Structure-activity relationships of the p38alpha MAP kinase inhibitor 1-(5-tert-butyl-2-p-tolyl-2H-pyrazol-3-yl)-3-[4-(2-morpholin4-yl-ethoxy)naph- thalen-1-yl]urea (BIRB 796). J. Med. Chem. 46, 4676-4686. doi: $10.1021 / \mathrm{jm} 030121 \mathrm{k}$

Ren, J., Zhang, S., Kovacs, A., Wang, Y., and Muslin, A. J. (2005). Role of p38alpha MAPK in cardiac apoptosis and remodeling after myocardial infarction. J. Mol. Cell Cardiol. 38, 617-623. doi: 10.1016/j.yjmcc.2005.01.012

Risco, A., del Fresno, C., Mambol, A., Alsina-Beauchamp, D., MacKenzie, K. F., Yang, H. T., et al. (2012). p38gamma and p38delta kinases regulate the Toll-like receptor 4 (TLR4)-induced cytokine production by controlling ERK1/2 protein kinase pathway activation. Proc. Natl. Acad. Sci. U.S.A. 109, 11200-11205. doi: 10.1073/pnas. 1207290109

Roberson, E. D., Scearce-Levie, K., Palop, J. J., Yan, F., Cheng, I. H., Wu, T., et al. (2007). Reducing endogenous tau ameliorates amyloid beta-induced deficits in an Alzheimer's disease mouse model. Science 316, 750-754. doi: 10.1126/ science. 1141736

Roberts, S. L., Dun, X. P., Dee, G., Gray, B., Mindos, T., and Parkinson, D. B. (2017). The role of p38alpha in Schwann cells in regulating peripheral nerve myelination and repair. J. Neurochem. 141, 37-47. doi: 10.1111/jnc. 13929

Robson, M. J., Quinlan, M. A., Margolis, K. G., Gajewski-Kurdziel, P. A., VeenstraVanderWeele, J., Gershon, M. D., et al. (2018). p38alpha MAPK signaling drives pharmacologically reversible brain and gastrointestinal phenotypes in the SERT Ala56 mouse. Proc. Natl. Acad. Sci. U.S.A. 115, E10245-E10254. doi: $10.1073 /$ pnas. 1809137115

Roccaro, A. M., Ghobrial, I. M., Blotta, S., Treon, S. P., Malagola, M., Anderson, K. C., et al. (2008). Advances in the treatment of monoclonal gammopaties: the emerging role of targeted therapy in plasma cell dyscrasias. Biologics 2, 419-431. doi: $10.2147 / \mathrm{btt} .33088$

Rohm, S., Berger, B. T., Schroder, M., Chaikuad, A., Winkel, R., Hekking, K. F. W., et al. (2019). Fast Iterative Synthetic Approach toward Identification of Novel Highly Selective p38 MAP Kinase Inhibitors. J. Med. Chem. 62, 10757-10782. doi: 10.1021/acs.jmedchem.9b01227

Rouse, J., Cohen, P., Trigon, S., Morange, M., Alonso-Llamazares, A., Zamanillo, D., et al. (1994). A novel kinase cascade triggered by stress and heat shock 
that stimulates MAPKAP kinase-2 and phosphorylation of the small heat shock proteins. Cell 78, 1027-1037.

Roy Choudhury, G., Ryou, M. G., Poteet, E., Wen, Y., He, R., Sun, F., et al. (2014). Involvement of p38 MAPK in reactive astrogliosis induced by ischemic stroke. Brain Res. 1551, 45-58. doi: 10.1016/j.brainres.2014.01.013

Rumbaugh, G., Adams, J. P., Kim, J. H., and Huganir, R. L. (2006). SynGAP regulates synaptic strength and mitogen-activated protein kinases in cultured neurons. Proc. Natl. Acad. Sci. U.S.A. 103, 4344-4351. doi: 10.1073/pnas. 0600084103

Rush, A. M., Wu, J., Rowan, M. J., and Anwyl, R. (2002). Group I metabotropic glutamate receptor (mGluR)-dependent long-term depression mediated via p38 mitogen-activated protein kinase is inhibited by previous high-frequency stimulation and activation of mGluRs and protein kinase $\mathrm{C}$ in the rat dentate gyrus in vitro. J. Neurosci. 22, 6121-6128.

Sabio, G., Arthur, J. S., Kuma, Y., Peggie, M., Carr, J., Murray-Tait, V., et al. (2005). p38gamma regulates the localisation of SAP97 in the cytoskeleton by modulating its interaction with GKAP. EMBO J. 24, 1134-1145. doi: 10.1038/sj. emboj.7600578

Salvador, J. M., Mittelstadt, P. R., Guszczynski, T., Copeland, T. D., Yamaguchi, H., Appella, E., et al. (2005). Alternative p38 activation pathway mediated by T cell receptor-proximal tyrosine kinases. Nat. Immunol. 6, 390-395. doi: $10.1038 /$ ni1177

Sama, R. R., Fallini, C., Gatto, R., McKeon, J. E., Song, Y., Rotunno, M. S., et al. (2017). ALS-linked FUS exerts a gain of toxic function involving aberrant p38 MAPK activation. Sci. Rep. 7:115. doi: 10.1038/s41598-017-00091-1

Sanchez, A., Tripathy, D., Yin, X., Desobry, K., Martinez, J., Riley, J., et al. (2012). p38 MAPK: a mediator of hypoxia-induced cerebrovascular inflammation. J. Alzheimers. Dis. 32, 587-597. doi: 10.3233/JAD-2012-120829

Santello, M., Cali, C., and Bezzi, P. (2012). Gliotransmission and the tripartite synapse. Adv. Exp. Med. Biol. 970, 307-331. doi: 10.1007/978-3-70910932-8_14

Sau, D., De Biasi, S., Vitellaro-Zuccarello, L., Riso, P., Guarnieri, S., Porrini, M., et al. (2007). Mutation of SOD1 in ALS: a gain of a loss of function. Hum. Mol. Genet. 16, 1604-1618. doi: 10.1093/hmg/ddm110

Scherzinger, E., Lurz, R., Turmaine, M., Mangiarini, L., Hollenbach, B., Hasenbank, R., et al. (1997). Huntingtin-encoded polyglutamine expansions form amyloidlike protein aggregates in vitro and in vivo. Cell 90, 549-558. doi: 10.1016/ s0092-8674(00)80514-0

Schindlbeck, K. A., and Eidelberg, D. (2018). Network imaging biomarkers: insights and clinical applications in Parkinson's disease. Lancet Neurol. 17, 629-640. doi: 10.1016/S1474-4422(18)30169-8

Schindler, A. G., Messinger, D. I., Smith, J. S., Shankar, H., Gustin, R. M., Schattauer, S. S., et al. (2012). Stress produces aversion and potentiates cocaine reward by releasing endogenous dynorphins in the ventral striatum to locally stimulate serotonin reuptake. J. Neurosci. 32, 17582-17596. doi: 10.1523/JNEUROSCI. 3220-12.2012

Schnoder, L., Hao, W., Qin, Y., Liu, S., Tomic, I., Liu, X., et al. (2016). Deficiency of Neuronal p38alpha MAPK Attenuates Amyloid Pathology in Alzheimer Disease Mouse and Cell Models through Facilitating Lysosomal Degradation of BACE1. J. Biol. Chem. 291, 2067-2079. doi: 10.1074/jbc.M115.695916

Schreiber, S., Feagan, B., D’Haens, G., Colombel, J. F., Geboes, K., Yurcov, M., et al. (2006). Oral p38 mitogen-activated protein kinase inhibition with BIRB 796 for active Crohn's disease: a randomized, double-blind, placebo-controlled trial. Clin. Gastroenterol. Hepatol. 4, 325-334. doi: 10.1016/j.cgh.2005.11.013

Scior, T., Domeyer, D. M., Cuanalo-Contreras, K., and Laufer, S. A. (2011). Pharmacophore design of p38alpha MAP kinase inhibitors with either 2,4,5-trisubstituted or 1,2,4,5-tetrasubstituted imidazole scaffold. Curr. Med. Chem. 18, 1526-1539. doi: 10.2174/09298671179 5328409

Segarra, J., Balenci, L., Drenth, T., Maina, F., and Lamballe, F. (2006). Combined signaling through ERK, PI3K/AKT, and RAC1/p38 is required for met-triggered cortical neuron migration. J. Biol. Chem. 281, 4771-4778. doi: 10.1074/jbc. M508298200

Semenova, M. M., Maki-Hokkonen, A. M., Cao, J., Komarovski, V., Forsberg, K. M., Koistinaho, M., et al. (2007). Rho mediates calcium-dependent activation of p38alpha and subsequent excitotoxic cell death. Nat. Neurosci. 10, 436-443. doi: $10.1038 / \mathrm{nn} 1869$

Shanware, N. P., Williams, L. M., Bowler, M. J., and Tibbetts, R. S. (2009). Nonspecific in vivo inhibition of CK1 by the pyridinyl imidazole p38 inhibitors SB
203580 and SB 202190. BMB Rep. 42, 142-147. doi: 10.5483/bmbrep.2009.42. 3.142

Shi, G. X., Han, J., and Andres, D. A. (2005). Rin GTPase couples nerve growth factor signaling to $\mathrm{p} 38$ and b-Raf/ERK pathways to promote neuronal differentiation. J. Biol. Chem. 280, 37599-37609. doi: 10.1074/jbc.M507364200

Shichita, T., Ito, M., and Yoshimura, A. (2014). Post-ischemic inflammation regulates neural damage and protection. Front. Cell Neurosci. 8:319. doi: 10. 3389/fncel.2014.00319

Shin, J. H., Jeong, J. Y., Jin, Y., Kim, I. D., and Lee, J. K. (2011). p38beta MAPK affords cytoprotection against oxidative stress-induced astrocyte apoptosis via induction of alphaB-crystallin and its anti-apoptotic function. Neurosci. Lett. 501, 132-137. doi: 10.1016/j.neulet.2011.06.061

Sirabella, R., Secondo, A., Pannaccione, A., Molinaro, P., Formisano, L., Guida, N., et al. (2012). ERK1/2, p38, and JNK regulate the expression and the activity of the three isoforms of the $\mathrm{Na}+/ \mathrm{Ca} 2+$ exchanger, NCX1, NCX2, and NCX3, in neuronal PC12 cells. J. Neurochem. 122, 911-922. doi: 10.1111/j.1471-4159. 2012.07838.x

Song, Y., Nagy, M., Ni, W., Tyagi, N. K., Fenton, W. A., Lopez-Giraldez, F., et al. (2013). Molecular chaperone Hsp110 rescues a vesicle transport defect produced by an ALS-associated mutant SOD1 protein in squid axoplasm. Proc. Natl. Acad. Sci. U.S.A. 110, 5428-5433. doi: 10.1073/pnas.1303279110

Soriano, F. X., Martel, M. A., Papadia, S., Vaslin, A., Baxter, P., Rickman, C., et al. (2008). Specific targeting of pro-death NMDA receptor signals with differing reliance on the NR2B PDZ ligand. J. Neurosci. 28, 10696-10710. doi: 10.1523/ JNEUROSCI.1207-08.2008

Stamboulian, S., Choi, J. S., Ahn, H. S., Chang, Y. W., Tyrrell, L., Black, J. A., et al. (2010). ERK1/2 mitogen-activated protein kinase phosphorylates sodium channel $\mathrm{Na}(\mathrm{v}) 1.7$ and alters its gating properties. J. Neurosci. 30, 1637-1647. doi: 10.1523/JNEUROSCI.4872-09.2010

Stefanoska, K., Bertz, J., Volkerling, A. M., van der Hoven, J., Ittner, L. M., and Ittner, A. (2018). Neuronal MAP kinase p38alpha inhibits c-Jun N-terminal kinase to modulate anxiety-related behaviour. Sci. Rep. 8:14296. doi: 10.1038/ s41598-018-32592-y

Stein, I. S., Gray, J. A., and Zito, K. (2015). Non-Ionotropic NMDA Receptor Signaling Drives Activity-Induced Dendritic Spine Shrinkage. J. Neurosci. 35, 12303-12308. doi: 10.1523/JNEUROSCI.4289-14.2015

Stein, I. S., Park, D. K., Flores, J. C., Jahncke, J. N., and Zito, K. (2020). Molecular Mechanisms of Non-ionotropic NMDA Receptor Signaling in Dendritic Spine Shrinkage. J Neurosci. 40:JN-RM-0046-20. doi: 10.1523/JNEUROSCI.0046-20. 2020

Steinkellner, T., Montgomery, T. R., Hofmaier, T., Kudlacek, O., Yang, J. W., Rickhag, M., et al. (2015). Amphetamine action at the cocaine- and antidepressant-sensitive serotonin transporter is modulated by alphaCaMKII. J. Neurosci. 35, 8258-8271. doi: 10.1523/JNEUROSCI.4034-14.2015

Su, P., Zhang, J., Wang, D., Zhao, F., Cao, Z., Aschner, M., et al. (2016). The role of autophagy in modulation of neuroinflammation in microglia. Neuroscience 319, 155-167. doi: 10.1016/j.neuroscience.2016.01.035

Sumara, G., Formentini, I., Collins, S., Sumara, I., Windak, R., Bodenmiller, B., et al. (2009). Regulation of PKD by the MAPK p38delta in insulin secretion and glucose homeostasis. Cell 136, 235-248. doi: 10.1016/j.cell.2008.11.018

Sun, A., Liu, M., Nguyen, X. V., and Bing, G. (2003). P38 MAP kinase is activated at early stages in Alzheimer's disease brain. Exp. Neurol. 183, 394-405. doi: 10.1016/s0014-4886(03)00180-8

Svensson, C. I., Fitzsimmons, B., Azizi, S., Powell, H. C., Hua, X. Y., and Yaksh, T. L. (2005). Spinal p38beta isoform mediates tissue injury-induced hyperalgesia and spinal sensitization. J. Neurochem. 92, 1508-1520. doi: 10.1111/j.1471-4159. 2004.02996.x

Svensson, C. I., Marsala, M., Westerlund, A., Calcutt, N. A., Campana, W. M., Freshwater, J. D., et al. (2003). Activation of p38 mitogen-activated protein kinase in spinal microglia is a critical link in inflammation-induced spinal pain processing. J. Neurochem. 86, 1534-1544. doi: 10.1046/j.1471-4159.2003. 01969.x

Swaroop, S., Sengupta, N., Suryawanshi, A. R., Adlakha, Y. K., and Basu, A. (2016). HSP60 plays a regulatory role in IL-1beta-induced microglial inflammation via TLR4-p38 MAPK axis. J. Neuroinflam. 13:27. doi: 10.1186/s12974-016-0486-x

Sweitzer, S. M., Wong, S. M., Tjolsen, A., Allen, C. P., Mochly-Rosen, D., and Kendig, J. J. (2004). Exaggerated nociceptive responses on morphine withdrawal: roles of protein kinase C epsilon and gamma. Pain 110, 281-289. doi: 10.1016/j.pain.2004.04.004 
Tai, C. Y., Mysore, S. P., Chiu, C., and Schuman, E. M. (2007). Activity-regulated N-cadherin endocytosis. Neuron 54, 771-785. doi: 10.1016/j.neuron.2007. 05.013

Takahashi, Y., Maki, T., Liang, A. C., Itoh, K., Lok, J., Osumi, N., et al. (2014). p38 MAP kinase mediates transforming-growth factor-betal-induced upregulation of matrix metalloproteinase- 9 but not -2 in human brain pericytes. Brain Res. 1593, 1-8. doi: 10.1016/j.brainres.2014.10.029

Tannenbaum, C. S., Koerner, T. J., Jansen, M. M., and Hamilton, T. A. (1988). Characterization of lipopolysaccharide-induced macrophage gene expression. J. Immunol. 140, 3640-3645.

Taylor, D. M., Moser, R., Regulier, E., Breuillaud, L., Dixon, M., Beesen, A. A., et al. (2013). MAP kinase phosphatase 1 (MKP-1/DUSP1) is neuroprotective in Huntington's disease via additive effects of JNK and p38 inhibition. J. Neurosci. 33, 2313-2325. doi: 10.1523/JNEUROSCI.4965-11.2013

Theodosiou, A., and Ashworth, A. (2002). Differential effects of stress stimuli on a JNK-inactivating phosphatase. Oncogene 21, 2387-2397. doi: 10.1038/sj.onc. 1205309

Tian, J., Popal, M. S., Zhao, Y., Liu, Y., Chen, K., and Liu, Y. (2019). Interplay between exosomes and autophagy in cardiovascular diseases: novel promising target for diagnostic and therapeutic application. Aging Dis. 10, 1302-1310. doi: 10.14336/AD.2018.1020

Tong, L., Prieto, G. A., Kramar, E. A., Smith, E. D., Cribbs, D. H., Lynch, G., et al. (2012). Brain-derived neurotrophic factor-dependent synaptic plasticity is suppressed by interleukin-1beta via p38 mitogen-activated protein kinase. J. Neurosci. 32, 17714-17724. doi: 10.1523/JNEUROSCI.1253-12.2012

Tong, X. K., and Hamel, E. (2007). Transforming growth factor-beta 1 impairs endothelin-1-mediated contraction of brain vessels by inducing mitogenactivated protein (MAP) kinase phosphatase-1 and inhibiting p38 MAP kinase. Mol. Pharmacol. 72, 1476-1483. doi: 10.1124/mol.107.039602

Tortarolo, M., Veglianese, P., Calvaresi, N., Botturi, A., Rossi, C., Giorgini, A., et al. (2003). Persistent activation of p38 mitogen-activated protein kinase in a mouse model of familial amyotrophic lateral sclerosis correlates with disease progression. Mol. Cell. Neurosci. 23, 180-192. doi: 10.1016/s1044-7431(03) 00022-8

Trouillas, M., Saucourt, C., Duval, D., Gauthereau, X., Thibault, C., Dembele, D., et al. (2008). Bcl2, a transcriptional target of p38alpha, is critical for neuronal commitment of mouse embryonic stem cells. Cell Death. Differ. 15, 1450-1459. doi: $10.1038 / \mathrm{cdd} .2008 .63$

Tsirigotis, M., Baldwin, R. M., Tang, M. Y., Lorimer, I. A., and Gray, D. A. (2008). Activation of p38MAPK contributes to expanded polyglutamineinduced cytotoxicity. PLoS One 3:e2130. doi: 10.1371/journal.pone.0002130

Uhlen, M., Fagerberg, L., Hallstrom, B. M., Lindskog, C., Oksvold, P., Mardinoglu, A., et al. (2015). Proteomics. Tissue-based map of the human proteome. Science 347:1260419. doi: 10.1126/science.1260419

Umezawa, H., Naito, Y., Tanaka, K., Yoshioka, K., Suzuki, K., Sudo, T., et al. (2017). Genetic and pharmacological inhibition of p38alpha improves locomotor recovery after spinal cord injury. Front. Pharmacol. 8:72. doi: 10.3389/fphar. 2017.00072

Underwood, D. C., Osborn, R. R., Kotzer, C. J., Adams, J. L., Lee, J. C., Webb, E. F., et al. (2000). SB 239063, a potent p38 MAP kinase inhibitor, reduces inflammatory cytokine production, airways eosinophil infiltration, and persistence. J. Pharmacol. Exp. Ther. 293, 281-288.

van der Vaart, A., Rademakers, S., and Jansen, G. (2015). DLK-1/p38 MAP Kinase Signaling Controls Cilium Length by Regulating RAB-5 Mediated Endocytosis in Caenorhabditis elegans. PLoS Genet. 11:e1005733. doi: 10.1371/journal.pgen. 1005733

van Stegen, B., Dagar, S., and Gottmann, K. (2017). Release activity-dependent control of vesicle endocytosis by the synaptic adhesion molecule $\mathrm{N}$-cadherin. Sci. Rep. 7:40865. doi: 10.1038/srep40865

Vance, C., Rogelj, B., Hortobagyi, T., De Vos, K. J., Nishimura, A. L., Sreedharan, J., et al. (2009). Mutations in FUS, an RNA processing protein, cause familial amyotrophic lateral sclerosis type 6. Science 323, 1208-1211. doi: 10.1126/ science. 1165942

Veglianese, P., Lo Coco, D., Bao Cutrona, M., Magnoni, R., Pennacchini, D., Pozzi, B., et al. (2006). Activation of the p38MAPK cascade is associated with upregulation of TNF alpha receptors in the spinal motor neurons of mouse models of familial ALS. Mol. Cell. Neurosci. 31, 218-231. doi: 10.1016/j.mcn. 2005.09.009
Ventura, J. J., Tenbaum, S., Perdiguero, E., Huth, M., Guerra, C., Barbacid, M., et al. (2007). p38alpha MAP kinase is essential in lung stem and progenitor cell proliferation and differentiation. Nat. Genet. 39, 750-758. doi: 10.1038/ng2037

Vrailas-Mortimer, A. D., Ryan, S. M., Avey, M. J., Mortimer, N. T., Dowse, H., and Sanyal, S. (2014). p38 MAP kinase regulates circadian rhythms in Drosophila. J. Biol. Rhythms 29, 411-426. doi: 10.1177/074873041455 5183

Wada, T., and Penninger, J. M. (2004). Mitogen-activated protein kinases in apoptosis regulation. Oncogene 23, 2838-2849. doi: 10.1038/sj.onc.1207556

Wang, L., Ankati, H., Akubathini, S. K., Balderamos, M., Storey, C. A., Patel, A. V., et al. (2010). Identification of novel 1,4-benzoxazine compounds that are protective in tissue culture and in vivo models of neurodegeneration. J. Neurosci. Res. 88, 1970-1984. doi: 10.1002/jnr.22352

Wang, X. J., Kong, K. M., Qi, W. L., Ye, W. L., and Song, P. S. (2005). Interleukin-1 beta induction of neuron apoptosis depends on p38 mitogen-activated protein kinase activity after spinal cord injury. Acta Pharmacol. Sin. 26, 934-942. doi: 10.1111/j.1745-7254.2005.00152.x

Watanabe, T., Sekine, S., Naguro, I., Sekine, Y., and Ichijo, H. (2015). Apoptosis Signal-regulating Kinase 1 (ASK1)-p38 Pathway-dependent Cytoplasmic Translocation of the Orphan Nuclear Receptor NR4A2 Is Required for Oxidative Stress-induced Necrosis. J. Biol. Chem. 290, 10791-10803. doi: 10. 1074/jbc.M114.623280

Watterson, D. M., Grum-Tokars, V. L., Roy, S. M., Schavocky, J. P., Bradaric, B. D., Bachstetter, A. D., et al. (2013). Development of Novel In Vivo Chemical Probes to Address CNS Protein Kinase Involvement in Synaptic Dysfunction. PLoS One 8:e66226. doi: 10.1371/journal.pone.0066226

Wengenack, T. M., Holasek, S. S., Montano, C. M., Gregor, D., Curran, G. L., and Poduslo, J. F. (2004). Activation of programmed cell death markers in ventral horn motor neurons during early presymptomatic stages of amyotrophic lateral sclerosis in a transgenic mouse model. Brain Res. 1027, 73-86. doi: 10.1016/j. brainres.2004.08.054

Widmann, C., Gibson, S., Jarpe, M. B., and Johnson, G. L. (1999). Mitogenactivated protein kinase: conservation of a three-kinase module from yeast to human. Physiol. Rev. 79, 143-180. doi: 10.1152/physrev.1999.79.1.143

Wilson, H., Dervenoulas, G., Pagano, G., Koros, C., Yousaf, T., Picillo, M., et al. (2019). Serotonergic pathology and disease burden in the premotor and motor phase of A53T alpha-synuclein parkinsonism: a crosssectional study. Lancet Neurol. 18, 748-759. doi: 10.1016/S1474-4422(19) 30140-1

Wittmack, E. K., Rush, A. M., Hudmon, A., Waxman, S. G., and Dib-Hajj, S. D. (2005). Voltage-gated sodium channel Nav1.6 is modulated by p38 mitogenactivated protein kinase. J. Neurosci. 25, 6621-6630. doi: 10.1523/JNEUROSCI. 0541-05.2005

Wu, J., Kubota, J., Hirayama, J., Nagai, Y., Nishina, S., Yokoi, T., et al. (2010). p38 Mitogen-activated protein kinase controls a switch between cardiomyocyte and neuronal commitment of murine embryonic stem cells by activating myocyte enhancer factor 2C-dependent bone morphogenetic protein 2 transcription. Stem Cells Dev. 19, 1723-1734. doi: 10.1089/scd.2010.0066

Wu, R., Chen, H., Ma, J., He, Q., Huang, Q., Liu, Q., et al. (2016). cAbl-p38alpha signaling plays an important role in MPTP-induced neuronal death. Cell Death. Differ. 23, 542-552. doi: 10.1038/cdd.20 15.135

Xing, B., Bachstetter, A. D., and Van Eldik, L. J. (2013). Deficiency in p38beta MAPK fails to inhibit cytokine production or protect neurons against inflammatory insult in in vitro and in vivo mouse models. PLoS One 8:e56852. doi: 10.1371/journal.pone.0056852

Xing, B., Bachstetter, A. D., and Van Eldik, L. J. (2015). Inhibition of neuronal p38alpha, but not p38beta MAPK, provides neuroprotection against three different neurotoxic insults. J. Mol. Neurosci. 55, 509-518. doi: 10.1007/s12031014-0372-X

Xu, H., Stamova, B., Jickling, G., Tian, Y., Zhan, X., Ander, B. P., et al. (2010). Distinctive RNA expression profiles in blood associated with white matter hyperintensities in brain. Stroke 41, 2744-2749. doi: 10.1161/STROKEAHA. 110.591875

Xu, J., Chatterjee, M., Baguley, T. D., Brouillette, J., Kurup, P., Ghosh, D., et al. (2014). Inhibitor of the tyrosine phosphatase STEP reverses cognitive deficits in a mouse model of Alzheimer's disease. PLoS Biol. 12:e1001923. doi: 10.1371/ journal.pbio. 1001923 
Xu, J., Kurup, P., Foscue, E., and Lombroso, P. J. (2015). Striatal-enriched protein tyrosine phosphatase regulates the PTPalpha/Fyn signaling pathway. J. Neurochem. 134, 629-641. doi: 10.1111/jnc.13160

Xu, J., Kurup, P., Zhang, Y., Goebel-Goody, S. M., Wu, P. H., Hawasli, A. H., et al. (2009). Extrasynaptic NMDA receptors couple preferentially to excitotoxicity via calpain-mediated cleavage of STEP. J. Neurosci. 29, 9330-9343. doi: 10.1523/ JNEUROSCI.2212-09.2009

Xu, Z., Wang, B. R., Wang, X., Kuang, F., Duan, X. L., Jiao, X. Y., et al. (2006). ERK1/2 and p38 mitogen-activated protein kinase mediate iNOS-induced spinal neuron degeneration after acute traumatic spinal cord injury. Life Sci. 79, 1895-1905. doi: 10.1016/j.lfs.2006.06.023

Yagasaki, Y., Sudo, T., and Osada, H. (2004). Exip, a splicing variant of p38alpha, participates in interleukin-1 receptor proximal complex and downregulates NF-kappaB pathway. FEBS Lett. 575, 136-140. doi: 10.1016/j.febslet.2004. 08.050

Yan, D., Wu, Z., Chisholm, A. D., and Jin, Y. (2009). The DLK-1 kinase promotes mRNA stability and local translation in C. elegans synapses and axon regeneration. Cell 138, 1005-1018. doi: 10.1016/j.cell.2009.06.023

Yang, K., Liu, Y., Liu, Z., Liu, J., Liu, X., Chen, X., et al. (2013). p38gamma overexpression in gliomas and its role in proliferation and apoptosis. Sci. Rep. 3:2089. doi: 10.1038/srep02089

Yasuda, S., Tanaka, H., Sugiura, H., Okamura, K., Sakaguchi, T., Tran, U., et al. (2007). Activity-induced protocadherin arcadlin regulates dendritic spine number by triggering $\mathrm{N}$-cadherin endocytosis via TAO2beta and p38 MAP kinases. Neuron 56, 456-471. doi: 10.1016/j.neuron.2007.08.020

Yoon, K. W., Yang, H. S., Kim, Y. M., Kim, Y., Kang, S., Sun, W., et al. (2017). CIB1 protects against MPTP-induced neurotoxicity through inhibiting ASK1. Sci. Rep. 7:12178. doi: 10.1038/s41598-017-12379-3

Yoshimura, Y., Terabayashi, T., and Miki, H. (2010). Par1b/MARK2 phosphorylates kinesin-like motor protein GAKIN/KIF13B to regulate axon formation. Mol. Cell. Biol. 30, 2206-2219. doi: 10.1128/MCB.01 181-09

Yoshioka, K., Namiki, K., Sudo, T., and Kasuya, Y. (2015). p38alpha controls self-renewal and fate decision of neurosphere-forming cells in adult hippocampus. FEBS Open Bio 5, 437-444. doi: 10.1016/j.fob.2015. 05.001

Zarubin, T., and Han, J. (2005). Activation and signaling of the p38 MAP kinase pathway. Cell Res. 15, 11-18. doi: 10.1038/sj.cr.7290257

Zeldich, E., Chen, C. D., Avila, R., Medicetty, S., and Abraham, C. R. (2015). The Anti-Aging Protein Klotho Enhances Remyelination Following CuprizoneInduced Demyelination. J. Mol. Neurosci. 57, 185-196. doi: 10.1007/s12031015-0598-2

Zhao, M., New, L., Kravchenko, V. V., Kato, Y., Gram, H., di Padova, F., et al. (1999). Regulation of the MEF2 family of transcription factors by p38. Mol. Cell. Biol. 19, 21-30. doi: 10.1128/mcb.19.1.21

Zhao, W., Liu, M., and Kirkwood, K. L. (2008). p38alpha stabilizes interleukin6 mRNA via multiple AU-rich elements. J. Biol. Chem. 283, 1778-1785. doi: 10.1074/jbc.M707573200

Conflict of Interest: The authors declare that the research was conducted in the absence of any commercial or financial relationships that could be construed as a potential conflict of interest.

Copyright (c) 2020 Asih, Prikas, Stefanoska, Tan, Ahel and Ittner. This is an openaccess article distributed under the terms of the Creative Commons Attribution License (CC BY). The use, distribution or reproduction in other forums is permitted, provided the original author(s) and the copyright owner(s) are credited and that the original publication in this journal is cited, in accordance with accepted academic practice. No use, distribution or reproduction is permitted which does not comply with these terms. 